\title{
Northern Eurasia Future Initiative (NEFI): facing the challenges and pathways of global change in the twenty-first century
}

Pavel Groisman ${ }^{1,9,30^{*}}$ (D), Herman Shugart ${ }^{2}$, David Kicklighter ${ }^{3}$, Geoffrey Henebry ${ }^{4}$, Nadezhda Tchebakova ${ }^{5}$, Shamil Maksyutov ${ }^{6}$, Erwan Monier ${ }^{7}$, Garik Gutman ${ }^{8}$, Sergey Gulev ${ }^{9}$, Jiaguo Qi ${ }^{10,19}$, Alexander Prishchepov ${ }^{11,31}$, Elena Kukavskaya ${ }^{5}$, Boris Porfiriev ${ }^{12}$, Alexander Shiklomanov ${ }^{13}$, Tatiana Loboda ${ }^{14}$, Nikolay Shiklomanov ${ }^{15}$, Son Nghiem ${ }^{16}$, Kathleen Bergen ${ }^{17}$, Jana Albrechtová ${ }^{18}$, Jiquan Chen ${ }^{10,19}$, Maria Shahgedanova ${ }^{20}$, Anatoly Shvidenko ${ }^{21}$, Nina Speranskaya ${ }^{22}$, Amber Soja ${ }^{23}$, Kirsten de Beurs ${ }^{24}$, Olga Bulygina ${ }^{25}$, Jessica McCarty ${ }^{26,27}$, Qianlai Zhuang ${ }^{28}$ and Olga Zolina ${ }^{29}$

\begin{abstract}
During the past several decades, the Earth system has changed significantly, especially across Northern Eurasia. Changes in the socio-economic conditions of the larger countries in the region have also resulted in a variety of regional environmental changes that can have global consequences. The Northern Eurasia Future Initiative (NEFI) has been designed as an essential continuation of the Northern Eurasia Earth Science Partnership Initiative (NEESPI), which was launched in 2004. NEESPI sought to elucidate all aspects of ongoing environmental change, to inform societies and, thus, to better prepare societies for future developments. A key principle of NEFI is that these developments must now be secured through science-based strategies codesigned with regional decision-makers to lead their societies to prosperity in the face of environmental and institutional challenges. NEESPI scientific research, data, and models have created a solid knowledge base to support the NEFI program. This paper presents the NEFI research vision consensus based on that knowledge. It provides the reader with samples of recent accomplishments in regional studies and formulates new NEFI science questions. To address these questions, nine research foci are identified and their selections are briefly justified. These foci include warming of the Arctic; changing frequency, pattern, and intensity of extreme and inclement environmental conditions; retreat of the cryosphere; changes in terrestrial water cycles; changes in the biosphere; pressures on land use; changes in infrastructure; societal actions in response to environmental change; and quantification of Northern Eurasia's role in the global Earth system. Powerful feedbacks between the Earth and human systems in Northern Eurasia (e.g., mega-fires, droughts, depletion of the cryosphere essential for water supply, retreat of sea ice) result from past and current human activities (e.g., large-scale water withdrawals, land use, and governance change) and potentially restrict or provide new opportunities for future human activities. Therefore, we propose that integrated assessment models are needed as the final stage of global change assessment. The overarching goal of this NEFI modeling effort will enable evaluation (Continued on next page)
\end{abstract}

\footnotetext{
* Correspondence: Pasha.Groisman@noaa.gov

${ }^{1}$ NEESPI Project Scientist, NC State University Research Scholar, at at NOAA

National Centers for Environment Information, Federal Building, 151 Patton

Avenue, Asheville, NC 28801, USA

${ }^{9}$ P.P. Shirshov Institute of Oceanology, RAS, 36 Nakhimovsky Ave, 117218

Moscow, Russia

Full list of author information is available at the end of the article
} 


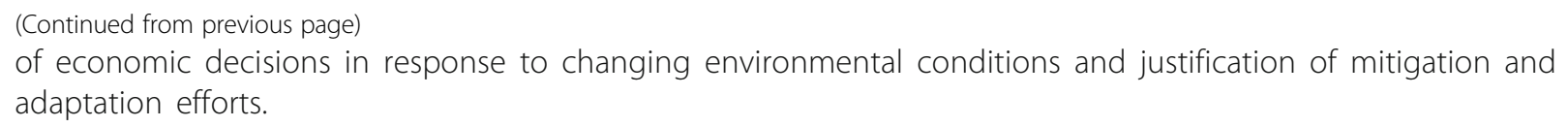

Keywords: Environmental changes, Northern Eurasia, Ecosystems dynamics, Terrestrial water cycle, Cryosphere retreat, Extreme and inclement environmental conditions, Sustainable development, Land cover and land use change, Integrated assessment models for decision-makers

\section{Introduction}

Northern Eurasia Future Initiative (NEFI) was conceived at the Workshop "Ten years of Northern Eurasia Earth Science Partnership Initiative (NEESPI): Synthesis and Future Plans" hosted by Charles University in Prague, Czech Republic (April 9-12, 2015). That event was attended by more than 70 participants from Japan, China, Russia, Ukraine, Kyrgyzstan, Kazakhstan, the European Union, and the USA. The workshop included an overview, synthesis presentations, and scientific visions for NEESPI in its transition to NEFI. These results (http://neespi.org/web-content/PragueWorkshop SynthesisBriefing.pdf) were delivered at a dedicated open public Splinter Meeting at the European Geophysical Union Assembly in Vienna, Austria (16 April 2015). On 20 May 2016, a NEFI White Paper was released for public consideration on the NEESPI website and 4 months later, after accounting for numerous comments and recommendations, it was finalized and posted at http://nefi-neespi.org/. The current paper presents the consensus of the future NEFI vision to address the challenges facing the region and to develop pathways to mitigate future problematic changes.

During the past 12 years, NEESPI has been quite successful at conducting and advancing research within its large geographical domain of Northern Eurasia (Fig. 1; Groisman and Bartalev 2007). The NEFI research domain is the same. The NEESPI program accommodated 172 projects focused on different environmental issues in Northern Eurasia. More than 1500 peer-reviewed journal papers and 40 books were published during the past decade (http://nefi-neespi.org/science/publicati ons.html; Groisman et al. 2009, 2014; Groisman and Soja 2009). Several overview books further synthesized findings (Gutman and Reissell 2011; Groisman and Lyalko 2012; Groisman and Gutman 2013; Chen et al. 2013; Gutman and Radeloff 2016). While the initial duration of the NEESPI research program was estimated to be 10-12 years, its momentum has exceeded original expectations. In addition to accumulating knowledge and publishing scientific journal papers and books, NEESPI scientists developed new observations, datasets, data networks, tools, and models. As a result, a new research realm emerged for studies in Northern Eurasia, and we are now poised to apply these results to directly support decision-making for various coupled environmentalsocietal needs.

The past accomplishments are not the only driver for the proposed NEFI initiative. Just as, or perhaps even more importantly, NEFI will address two significant and intertwined changes that have emerged. These are (1) continued and exacerbated change in the global Earth and climate system, and (2) societal change and stress with a heightened need for mitigation and adaptation approaches. With respect to the first, the global Earth system has significantly changed, with the changes in Northern Eurasia being substantially larger than the global average (cf., Figs. 2 and 3). Subsequently, one NEFI endeavor is to analyze this new state with its unexpected novel features and distributions. These novel characteristics include shifts of the seasonal cycle for various climatic functions to changes in intensity, frequency, and spatial patterns and temporal trends of extreme events. These changes have already occurred, but their impacts on (and feedbacks to) atmospheric, biospheric, cryospheric, hydrologic, oceanic, and macro-socioeconomic processes are ongoing.

The second significant change that NEFI will need to address concerns the socio-economic dynamics in the major nations of Northern Eurasia. These dynamics have also dramatically changed, including the ability of societies to withstand and adapt to the adverse manifestations of the above-described environmental changes. Fundamental to addressing this is the sound scientific understanding and quantification of the amount of Earth system change that societies are currently experiencing and may experience by the end of the twenty-first century. However, in addition to understanding the scientific basis, communities (and even nations) have increasingly begun to inquire about what mitigation and/or adaptation strategies are possible for the upcoming decades. These types of questions need to be addressed differently, because societal decision-making impacts the environment, which feeds back to influence future societal decision-making. The major anthropogenic causes of global change remain ongoing. Thus, the Earth science community and society in general will need to be informed and prepared to assure a sustainable future.

The results of scientific research, data, and models accumulated during the past decade will allow us to build upon 


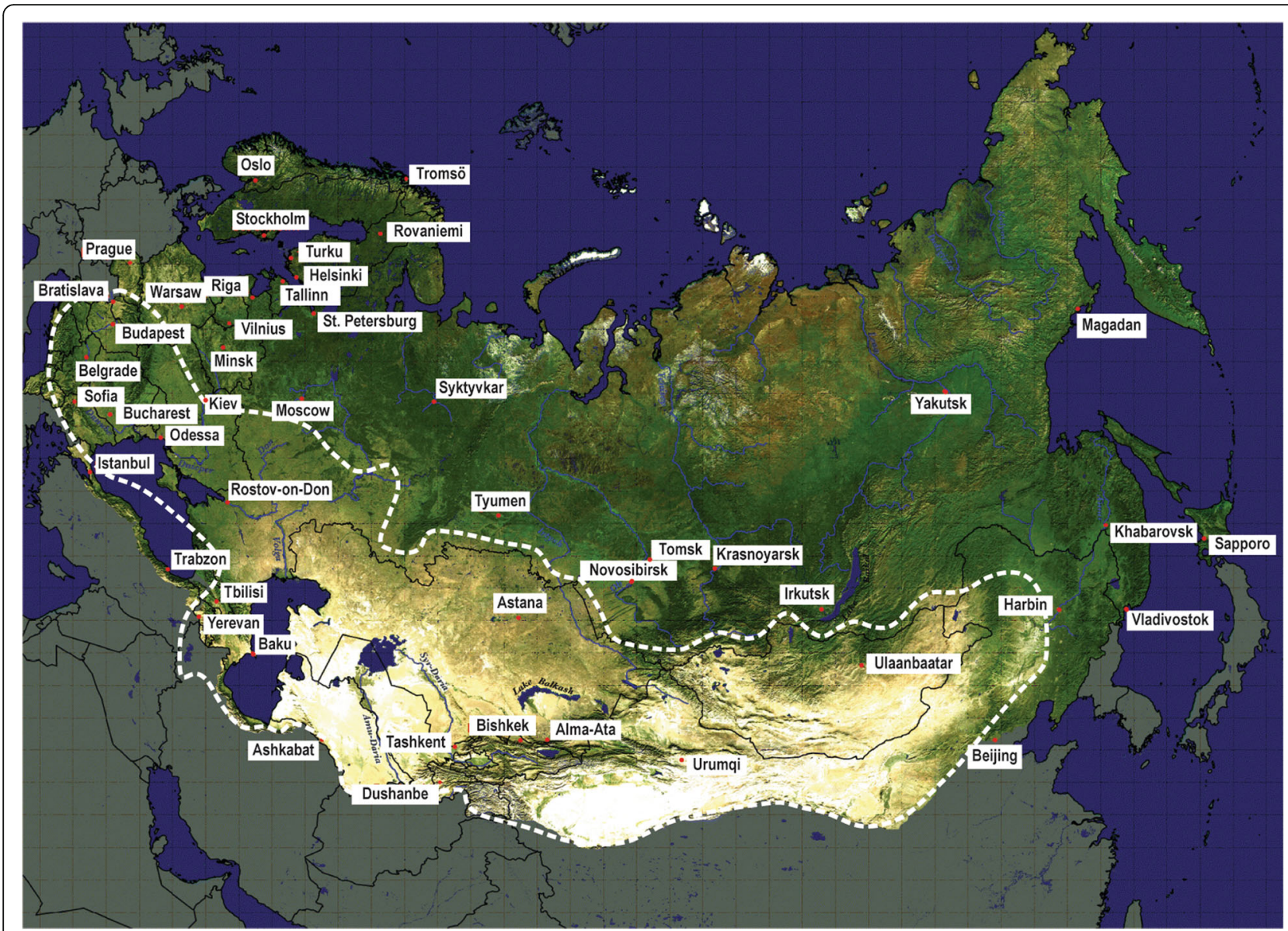

Fig. 1 The NEESPI study area is loosely defined as the region between $15^{\circ} \mathrm{E}$ in the west, the Pacific Coast in the east, $40^{\circ} \mathrm{N}$ in the south, and the Arctic Ocean coastal zone in the north. On this map, green corresponds to vegetated lands. Light brown and yellow indicate sparse vegetation and arid areas, respectively (Groisman et al. 2009). Major cities within the NEESPI domain and their names are shown by red dots and text in white inserts, respectively. During the NEESPI studies, we expand the study domain occasionally to address the ecosystem in its entirety beyond the strict lat/long boundaries (e.g., taiga and tundra zones in Fennoscandia or barren and semi-desert areas in China. The Dry Land Belt of Northern Eurasia is sketched on the map by a dashed white line

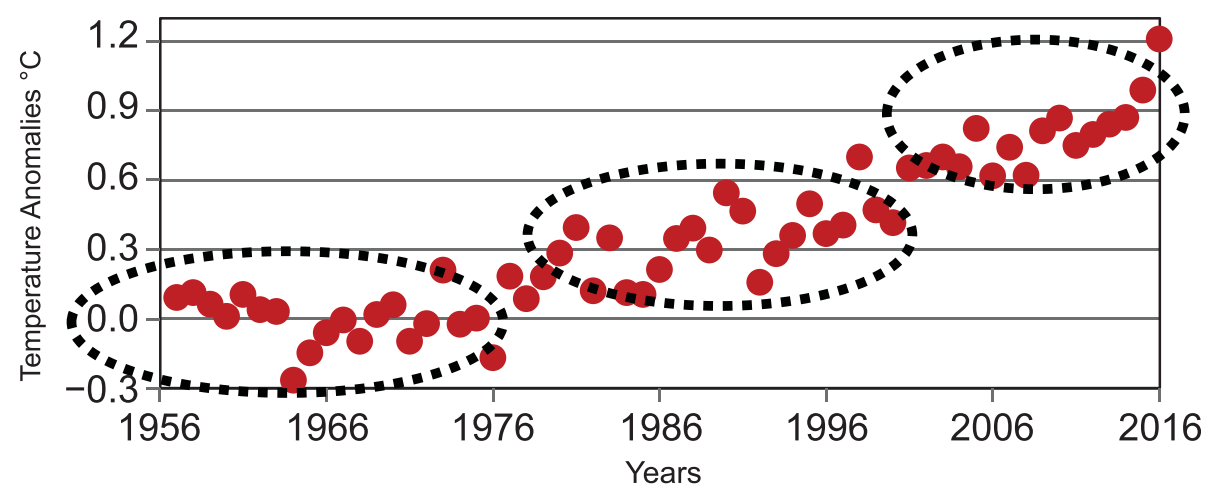

Fig. 2 Global annual surface air temperature anomalies ( ${ }^{\circ} \mathrm{C}$ ) derived from the meteorological station data for the 1957-2016 period (Lugina et al. 2006, updated). This time series is based upon the land-based surface air temperature station data with a processing algorithm developed 25 years ago by Vinnikov et al. (1990). The reference period used for calculations of anomalies is 1951-1975. Dotted ovals in the figure show this reference period, the new state of the global Earth system $\left(+0.3^{\circ}\right.$ to $0.4{ }^{\circ} \mathrm{C}$ of the global temperature) with shift during the late 1970 s and early 1980 s, that manifested itself in biospheric, oceanic, cryospheric, and atmospheric variables around the world (Reid et al. 2016), and the last period (since circa 2001), when impacts on the Earth system (e.g., retreat of the cryosphere, Arctic warming, increasing dryness of interior of the continents) still need to be completely documented 


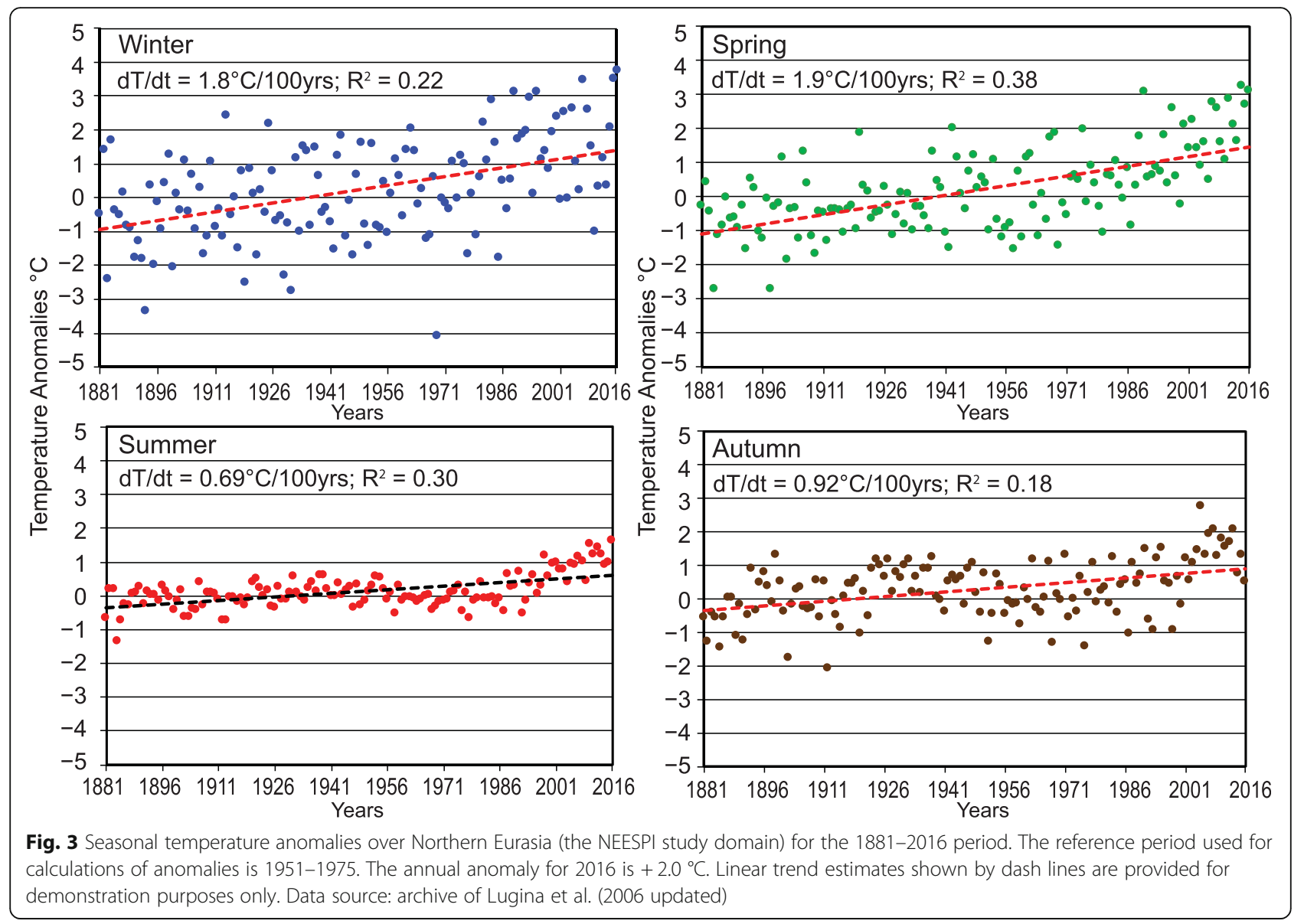

this knowledge to directly support decision-making activities that address societal needs in Northern Eurasia. During the last decade, substantial climatic and environmental changes have already been quantified. While natural processes (except the high amplitude of their variations) are mainly the same as in other parts of the World, human factors and changes in land cover and land use in the NEFI domain during the past decades were dramatic and unique. Changes in the socio-economics of major nations in the region have ultimately transformed human-environment interactions. This in turn has transformed regional land cover and water resources towards conditions that endanger or even overcome the resilience of natural ecosystems (e.g., disappearing lakes and runoff diversions, deforestation, degradation and abandonment of agriculture fields and pasture; air, soil, and water pollution). These and projected changes will require expeditious direct responses on behalf of human well-being and societal health in order to move towards a sustainable future.

Therefore, the core motivation of NEFI is to best use science to serve the decision-making process to maintain Earth system health and to sustain society. In the next two sections, we:
- Formulate three major science questions of global concern associated with unique features of Northern Eurasia,

- Formulate the major research foci for the next decade that, as the NEFI Science Plan authors believe, are of crucial importance to be addressed expediently, and

- Examine and justify the issues related to these research foci in more detail.

An approach to regional studies in Northern Eurasia based on integrated assessment modeling is described and justified in the last section of the paper. Because this paper is an overview of a large amount of relevant findings from the past decade, we also provide a comprehensive list of references to those works.

\section{Review}

Three unique features of Northern Eurasia of global concern and their related major science questions

To develop effective mitigation and adaptation strategies, future NEFI activities will need to consider three unique features of Northern Eurasia: (1) the sensitivity 
of land surface characteristics to global change that feedback to influence the global energy budget; (2) potential changes in the Dry Land Belt of Northern Eurasia (DLB) that will have a large influence on the availability of water for food, energy, industry, and transportation; and (3) evolving social institutions and economies. Below, we look at these features in more detail and suggest that three major science questions emerge from this examination.

\section{Sensitivity of land surface characteristics to global change}

The Arctic, Arctic Ocean shelf, and the boreal Zone of Eurasia are areas of substantial terrestrial carbon storage in wetlands, soil, boreal forest, terrestrial, and sea shelf permafrost. From these emerge powerful carboncryosphere interactions and variability that intertwine with strong climatic and environmental changes (Fig. 4). These interactions also can generate positive feedback to Earth system changes via both biogeochemical (atmospheric composition, water quality, plant, and microbial metabolism) and biogeophysical impacts (surface albedo, fresh water budget, and thermohaline circulation of the World Ocean). These intertwined linkages and feedbacks may increase the rate of global (or near-global) change and/or increase uncertainties about that change. In turn, this places the wellbeing of societies at risk if planned mitigation and adaptation measures are not implemented in a sound and timely fashion.

Thus, in future studies within Northern Eurasia, special attention should be paid to the changes on the volatile boundaries of the Arctic, boreal, and dry zones. The highly variable components of the cryosphere (seasonal snow cover) which are vitally controlled by components that have been systematically changing (e.g., glaciers and permafrost) should be recognized. The rates of change due to catastrophic forest fires (Conard et al. 2002; Goldammer 2013), dust storms (Goudie and Middleton 1992; Sokolik 2013), and controversial future methane release from frozen ground in high latitudinal land and shelf areas (Kirschke et al. 2013; Shakhova et al. 2013, 2015; Zhu et al. 2013; Ruppel and Kessler 2017) must be accounted for or ameliorated.

Based on the above, the first Major Science Question is "How can we quantify and project ecosystem dynamics in Northern Eurasia that influence the global energy budget when these dynamics are internally unstable (e.g., operate within narrow temperature ranges), are interrelated and have the potential to impact the global Earth system with unprecedented rates of change?"

Water availability and the dry land belt of Northern Eurasia The interior of the Earth's largest continent is mostly cut off from water vapor transport from the tropics by mountain ridges and plateaus spread across the central regions of Asia, thus creating the Dry Land Belt of Northern Eurasia (DLB; Fig. 1). The DLB is the largest dry area in the extratropics and may be expanding northward (Shuman et al. 2015; Fig. 4) as it has done in past millennia (Chen et al. 2008, 2010; Kozharinov and Borisov 2013). Parts of the DLB are quite densely populated (e.g., Northern China, Central Asia) and have fertile land. For example, the Pannonian Lowland and the black soils in Ukraine and European Russia provide substantial grain export to the global market.

However, the DLB has strong physical limitations in the production of crops. It has a very limited fresh water supply, which is highly dependent upon irregular extratropical cyclones (mostly from the North Atlantic) and a shrinking regional cryosphere. Increases in evapotranspiration arising from increases in warm season temperatures and expansions of the growing season in the DLB are generally not compensated by precipitation increase. Further, changes in the spatio-temporal shifts in precipitation pattern increase the probability of various unusual or extreme events affecting the livelihoods of regional societies and their interactions with the global economy (e.g., Henebry et al. 2013; Chen et al. 2015). This region is a source of dust storms that can adversely impact the environment, climate, and human well-being (Darmenova et al. 2009).

Arising from these considerations, the second Major Science Question is "What are the major drivers of the ongoing and future changes in the water cycles within the regions of Northern Eurasia with insufficient water resources (i.e., DLB and its vicinity)?" In addressing this question, future studies should examine how changes in the water cycle will affect regional ecosystems and societies, and how these changes will feedback to the Earth system and the global economy.

\section{Evolving social institutions and economies}

Institutional changes in Northern Eurasia that have taken place over the past few decades have led to large changes in the socio-economic fabric of the societies in the region, affecting land use and the natural environment (cf., Lerman et al. 2004). One overarching challenge has been the transition from command-driven to "transitional" and more market-driven economics in the countries of Northern Eurasia. This phenomenon has occurred at different rates, with differing levels of success, and often with societal costs. This has created unexpected economic and environmental problems but also opportunities (Bergen et al. 2013; Gutman and Radeloff 2016). Environmental changes and their related problems include massive agricultural land abandonment (Alcantara et al. 2013; Griffiths et al. 2013; Wright et al. 2012), inefficient and illegal forest logging (Kuemmerle et al. 2009; Knorn et al. 2012; Newell and 


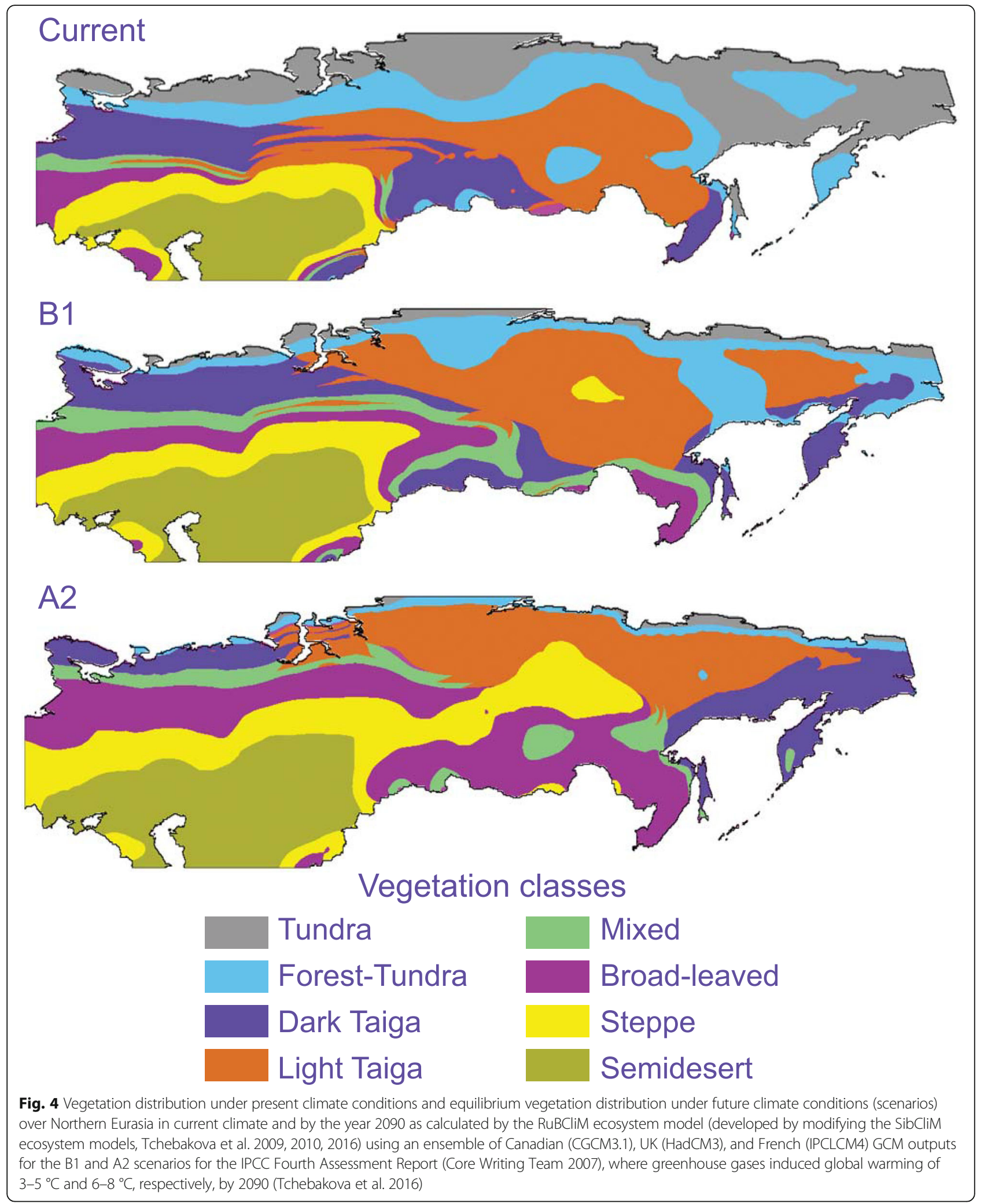

Simeone 2014), degradation of cultivated and pasture lands (Ioffe et al. 2012; Chen et al. 2015, 2015), growing water deficits and drought (especially in the DLB and new independent states), and the spread of humaninduced fires (Soja et al. 2007; McCarty et al. 2017). Many of these outcomes have become important 
concerns with policy implications at the national and intergovernmental levels. Opportunities emerge mostly with advances of warmer climate conditions northward (agriculture benefits at high latitudes, better transportation conditions in the Arctic Seas; Tchebakova et al. 2011). Other opportunities are institutional, such as cooperation between nations and non-profit organizations in attempting to implement forestry certification.

Furthermore, the countries of Northern Eurasia with these "transitional" economies are playing an increasingly important role in the world economic system. Thus, they face further challenges in highly competitive economic conditions under the additional stresses of climatic, environmental, and internal societal change. For countries and/or regions with resource-rich lands and low population (e.g., Russia, Kazakhstan, Mongolia, and Turkmenistan), their development continues to depend on natural resources inclusive especially of timber, oil/gas, mining, fisheries, agriculture, and hydropower (Bergen et al. 2013). Other countries (e.g., China and Japan) with very large populations and strained or limited resources (such as available domestic timber in China or Japan) may be strong consumers of natural resources from elsewhere in Northern Eurasia (Newell and Simeone 2014).

Considering the triad "climate - environmental socio-economic impacts," past NEESPI investigations sufficiently embraced regional climate diagnostics and, to a somewhat lesser extent, diagnostics of environmental and ecosystem characteristics. However, the socioeconomic impacts of variability and/or systematic changes in climate and environmental variables are still poorly defined. This makes it difficult to effectively plan for the future or to accurately interpret prospective actions based on existing model experiments. These model-based projections of climate and environmental changes still have to be attributed to and associated with the mid-term and long-term strategies for the development of different sectors of the economy including agriculture and grazing, forestry, fisheries, mining, energy, and on-shore and off-shore infrastructure development. This will be an important NEFI endeavor.

The third Major Science Question is "How can the sustainable development of societies of Northern Eurasia be secured in the near future (the next few decades)? In addressing this question, future studies should examine how societies can overcome the "transitional" nature of their economic, environmental, and climatic change challenges, and resolve counterproductive institutional legacies.

\section{Major research foci: why do they matter?}

During the preparation and review of the NEFI Science Plan, the directions of future research over Northern
Eurasia have been analyzed in light of the new information gained from past NEESPI activities, the apparent need to advance further in these directions addressing the latest dynamics of environmental and socioeconomic changes, and the unique features of Northern Eurasia that are of global concern. Nine major research foci have been identified as NEFI priorities (listed in no specific order):

1. Influence of global change, with a focus on warming in the Arctic;

2. Increasing frequency and intensity of extremes (e.g., intense rains, floods, droughts, wildfires) and changes in the spatial and temporal distributions of inclement weather conditions (e.g., heavy wet snowfalls, freezing rains, untimely thaws, and peak streamflow);

3. Retreat of the cryosphere (snow cover, sea ice, glaciers, and permafrost);

4. Changes in the terrestrial water cycle (quantity and quality of water supply available for societal needs);

5. Changes in the biosphere (e.g., ecosystem shifts, changes in the carbon cycle, phenology, land-cover degradation and dust storms);

6. Pressures on agriculture and pastoral production (growing supply and demand, changes in land use, water available for irrigation, and food-energy-water security);

7. Changes in infrastructure (roads, new routes, construction codes, pipelines, risks with permafrost thawing, air, water, and soil pollution);

8. Societal adaptations and actions to mitigate the negative consequences of environmental changes and benefit from the positive consequences; and

9. Quantification of the role of Northern Eurasia in the global Earth and socioeconomic systems to advance research tools with an emphasis on observations and models.

Socio-economic research challenges are the top priority for several of these foci. These challenges have not been overlooked in the past but have not been addressed satisfactorily in the NEESPI domain, nor indeed globally. The introduction of the Future Earth research objectives is a response to this gap (http://www.futureearth.org/). There is an urgent need to incorporate socio-economic studies into regional programs by linking the findings of diagnostic and model-based climate and environmental analyses with the requirements for the regional infrastructure, which arise from the detailed treatment of socio-economic conditions.

We are establishing this strategy as the foundation for the Northern Eurasia Future Initiative (NEFI) and expect that it will bridge climate and environmental studies 
with the economic consequences of the observed changes. This will spur advances in physical sciences to better quantify observed and projected climate and environmental changes and improve economic analyses of impacts. This new strategy will directly benefit many stakeholders and end-users. It will provide them with recommendations and assessments going far beyond those based exclusively on the analysis of climate and environmental variables. It will also provide them with a new suite of modeling tools and new data sets to enable much better and smarter decision-making. Furthermore, this strategy will provide a strong feedback on further planning of climate and environmental studies, pointing to the parameters, phenomena, and mechanisms which, so far, have not been studied and quantified to a full extent. This will make it possible to revisit and comprehensively review the 12-year NEESPI legacy in order to transform conventional climate and environmental metrics to those relevant for building more effective economic strategies and risk assessments.

Below, we examine and justify the issues related to the above nine major research foci in more detail, and in the final section propose an integrated assessment modeling approach that would allow NEFI to eventually address them as best as current technology and knowledge will support.

\section{Research focus 1: global change and the Arctic}

Global changes are ongoing and until the causes of these changes are eliminated or mitigated, there are no expectations that they will slow down (Intergovernmental Panel on Climate Change (IPCC) 2014; Barros et al. 2014; Karl et al. 2015; see also Fig. 2). Regionally, the temperature changes in Northern Eurasia have been among the largest (Blunden and Arndt 2015, 2016). Additionally, there are special reasons to list the changes in the Arctic among major concerns for future environmental well-being in the extratropics. This small sliver of the globe (the zone north of $60^{\circ} \mathrm{N}$ occupies only $7 \%$ of the globe surface) plays an important role in the global climate. Its air temperature changes during the past decade were unprecedented for the period of instrumental observations (Fig. 5, left) and well above the $2{ }^{\circ} \mathrm{C}$ warming threshold set by the recent United Nations Climate Change Conference (30 November-12 December 2015, Paris, France).

There are two major consequences of Arctic warming: (a) changes in the Arctic sea ice and (b) changes in the meridional gradient of air temperature. The Arctic has become increasingly closely interlinked with the polar atmosphere with the ongoing retreat and thinning of the sea ice (Fig. 5, right; Renner et al. 2014). The depletion of sea ice increases the heat and water vapor exchange with the atmosphere, especially during the cold season (i.e., from mid-September through early June), affecting weather, climate, and the water cycle across the extratropics and, possibly, over the entire hemisphere (Drozdov 1966; Newson 1973; Groisman et al. 2003, 2013; Arctic Climate Impact Assessment 2005; AMAP 2011; Bulygina et al. 2013). There are direct practical implications for transportation, regional infrastructure development and maintenance, and fisheries (AMAP 2011; Farré et al. 2014; Strategic Assessment of Development of the Arctic 2014; Streletskiy et al. 2015).

The Arctic is closely interlinked with the North Atlantic Ocean. Together they control the World Ocean thermohaline circulation, which provide most of the cold water influx into the deep ocean. They define the climate of the northern extratropics (especially the regions adjacent to the North Atlantic) due to intense meridional heat and mass exchange of the atmosphere with the ocean in the Atlantic Sector of the Arctic and the subsequent transport of air masses inside the continents. This exchange is modulated by variations of the Arctic Oscillation, a large-scale mode of climate variability, also referred to as the Northern Hemisphere annular mode (Thompson and Wallace 1998). All together, they create strong deviations from the zonal temperature distribution (for example, compare the climate of Edinburgh, Scotland, UK with Churchill, Canada, and Yakutsk, Russia) and are highly volatile.
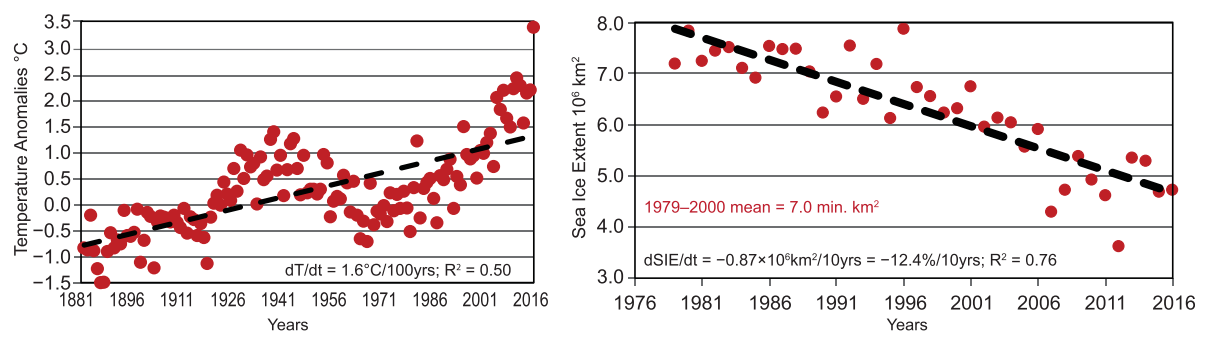

Fig. 5 Left: annual surface air temperature anomalies $\left({ }^{\circ} \mathrm{C}\right.$ ) area-averaged over the $60^{\circ} \mathrm{N}-90^{\circ} \mathrm{N}$ latitudinal zone (Lugina et al. 2006, updated). Right: September Arctic sea ice extent, SIE, $10^{6} \mathrm{~km}^{2}$ (US National Snow and Ice Data Center, Boulder, CO, USA website, http://nsidc.org/data; date of retrieval; 30 December 2015). For possible change in 2016, see Gannon (2016). Linear trend estimates shown by dash lines are provided for demonstration purposes only 
Relatively small deviations of the oceanic salinity and sea ice distribution in the northernmost Atlantic may affect the deep water formation process with adverse global consequences for oceanic circulation (Gulfstream) and climate of the extratropics (LeGrande et al. 2006). The ongoing decrease of the meridional temperature gradient in the cold season (Groisman and Soja 2009) may weaken westerlies, causing cold winter outbreaks in the interior of the continent, larger meandering of the cyclone trajectories over the extratropics (Francis and Vavrus 2012), and increasing probability of blocking events (Lupo et al. 1997; Semenov 2012; Mokhov et al. 2013; Schubert et al. 2014) that can devastate regional agriculture through the combination of harsh winters and summer heatwaves (Wright et al. 2014).

\section{Research focus 2: frequency and intensity of extremes}

There is already evidence of climate-induced change across Northern Eurasia during the past few decades (Soja et al. 2007; Groisman and Gutman 2013; Rimkus et al. 2013; Shvidenko and Schepaschenko 2013; Valendik et al. 2014) with southern regions being particularly vulnerable to climate change and fires (Malevsky-Malevich et al. 2008). First, there has been an increase in rainfall intensity and prolonged no-rain periods (summarized in Groisman et al. 2013; see also Zhai et al. 2004 and Chen and Zhai 2014), which at times may occur in the same region. Second, an increase in extraordinary temperature anomalies has been accompanied by summer droughts (Barriopedro et al. 2011; Lei 2011; Lupo et al. 2012; Bastos et al. 2014; Horion et al. 2016). Third, cold outbreaks and/or thaws have increased during winter (Arctic Climate Impact Assessment 2005; Groisman et al. 2016). Fourth, an increase in the frequency of large and severe wildfires has occurred (Conard et al. 2002; Soja et al. 2007; Kukavskaya et al. 2013; Shvidenko and Schepaschenko 2013). Finally, intense dust storms have occurred (Xi and Sokolik 2015a). Official Russian statistics on "dangerous meteorological phenomena" (DMP), which are events that caused significant damage to the national economy and vital activities of the population, report that seven years of the last decade (2006-2015) had the largest numbers of DMP (from 385 to 467). The impacts of these events often extend far beyond Northern Eurasia, sending aftershocks into global markets and raising concerns about global food security (Loboda et al. 2016).

There are also changes in the spatial and temporal distribution of inclement weather conditions (e.g., heavy wet snowfalls, freezing rains, rain on snow, untimely thaws and peak streamflow) that, while not being extremes per se, substantially affect societal well-being and health (e.g., freezing events, Bulygina et al. 2015;
Groisman et al. 2016) or indirectly impact the regional water budget (e.g., the influence of winter thaws and/or early snowmelt on the water deficit of the following growing season, Bulygina et al. 2009, 2011; Groisman and Soja 2009). Societal consequences of changes in the frequency and intensity of these extreme and inclement events have become an urgent task to address for the entire Earth Science research community (Forbes et al. 2016). In this regard, it is not enough to report and/or to project changes in characteristics of these events but also to develop a suite of strategies for resilient responses to new climate conditions that are forthcoming and/or have an increased higher probability than was previously expected.

Extreme events that affect the biosphere and their temporal and spatial changes represent a special focus for NEFI studies. Wildland fire is the dominant disturbance agent in the boreal forests, which are in turn the largest global reservoir of terrestrial carbon (Pan et al. 2011; Parham et al. 2014; Gauthier et al. 2015). While fire plays a critical role in maintaining the overall forest well-being through regulating ecosystem functioning, productivity, and health, extreme fire events and changing fire regimes intensify the impacts of climate change and variability on ecosystem states and deliver a suite of powerful feedbacks to the climate system. These events heighten the interactions among the biosphere, atmosphere, and climate systems by affecting carbon balances, hydrologic regimes, permafrost structure, modifying patterns of clouds and precipitation, and radiative forcing by changing surface and planetary albedo (Rogers et al. 2015). Wildfires, in general and particularly during extreme events, also have a direct adverse impact on human health, pose a considerable threat to life and property, and impose a substantial economic burden.

A typical feature of the current fire regime is increasing frequency and severity of mega-fires, defined as fires that involve high suppression costs, property losses, natural resource damages, and loss of life (Williams 2013). These fires may cause the irreversible transformation of the forest environment for a period that exceeds the life cycle of major forest-forming species (Sukhinin 2010; Shvidenko et al. 2011; Fig. 6). Mega-fires of the last decade have led up to a two-fold increase in the share of crown and peat fires. Post-fire dieback in the area of mega-fires as a rule exceeds $50 \%$. A substantial part of post-fire areas may become unsuitable for forest growth for hundreds of years. For instance, such areas in the Russian Far East (RFE) are estimated to cover tens of million hectares (Shvidenko et al. 2013). The increasing aridity of the climate provokes outbreaks of harmful insects that could envelope large areas, for example, the outbreak of Siberian silk moth (Dendrolimus superans sibiricus) which enveloped an area of about $10 \times 10^{6}$ ha in 2010. Human- and climate- 


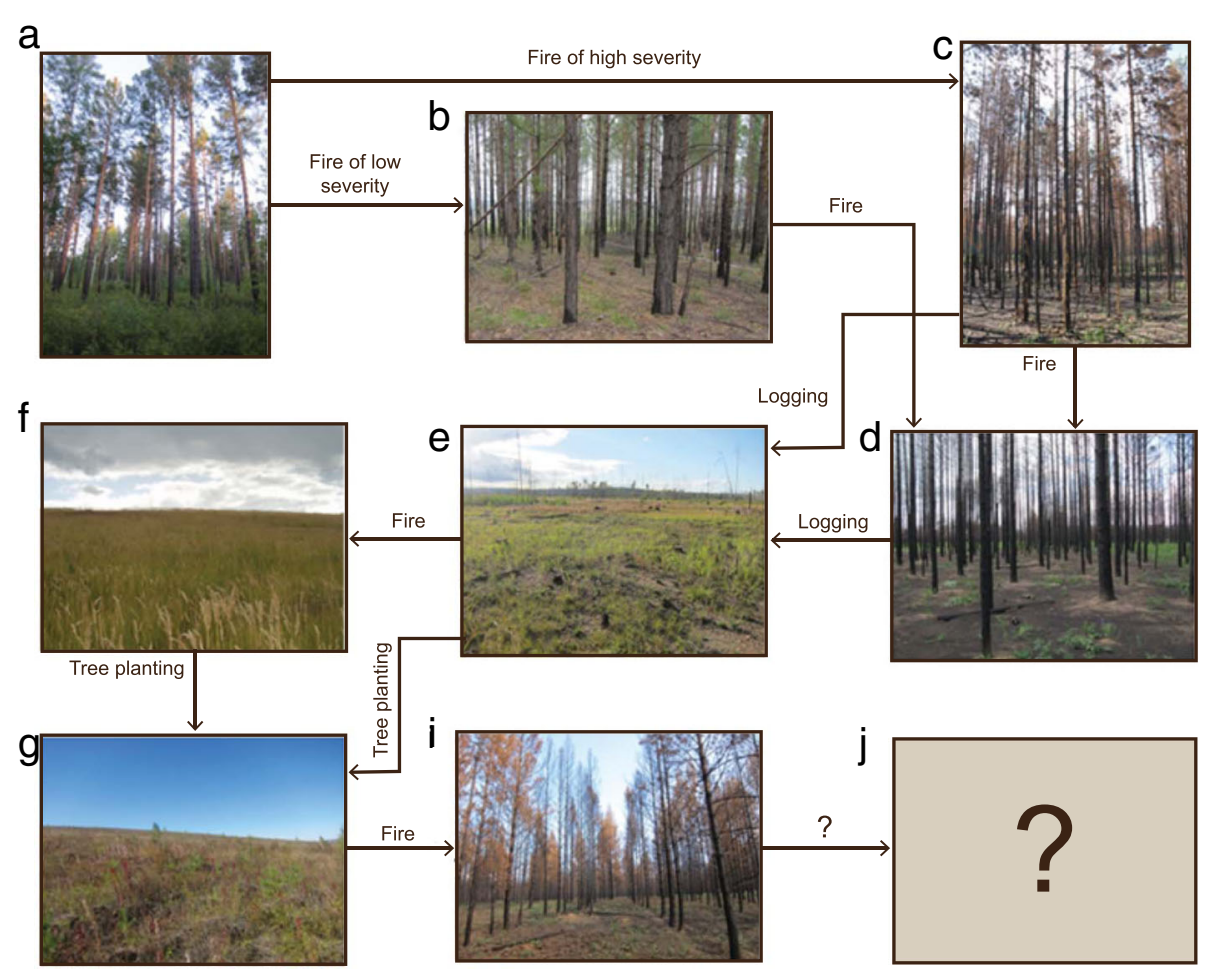

Fig. 6 Examples of fire-induced forest transformations in the light-coniferous (Scots pine and larch) forests of southern Siberia when logging and plantation are done. a Unburned forest. b Forest burned by low-severity fire with high trees survival. c Forest burned by high-severity fire with high tree mortality. d Repeatedly burned forest with all trees killed and almost all organic layer consumed. e Logging after post-fire tree mortality. f Repeatedly burned and logged forest site, with little to no tree regeneration, dominated by tall grasses. $\mathbf{g}$ Plantation of Scots pine on a repeatedly disturbed site with no natural regeneration. $\mathbf{i}$ Burned plantation. $\mathbf{j}$ The "question" mark indicates sites where management activities may alter these disturbance trajectories in unknown ways (Kukavskaya et al. 2016)

induced change in disturbance regimes is currently acting in concert to force ecosystems to move more quickly towards a new equilibrium with the climate (van den Werf et al. 2010; Soja et al. 2007).

Severe fires, driven by anomalous weather conditions, are increasingly becoming the new norm across Russia. In the past 15 years, extreme fires have been reported across nearly all large geographic regions, including very remote zones (e.g., Yakutia in 2002) and densely populated regions (European Russia in 2010). Fire weather (temperature, precipitation, relative humidity and wind speed) in recent decades (2003-2012) is much more dangerous than in an earlier decade (1984-1993). In Fig. 6, at the stages from b to $\mathrm{i}$, forests might have the possibility to recover with (1) the absence of repeated disturbances; and (2) implementation of forest management mitigation efforts with increased resources for the most severe cases. However, if the recent tendencies of fire weather continue, the survival of the forest biome in its present boundaries is not possible (Tchebakova et al. 2009).

In 2008, smoke and related emissions from early season fires associated with agricultural/clearing in the country of Kazakhstan, in the Transbaikal region, and the Russian Amur Oblast (oblast is a large administrative division in Russia) were observed in the Arctic. On reaching the Arctic, this early season ash deposition could result in more rapid snow and ice melting, further altering albedo impacts on the ice sheet (Warneke et al. 2009). In 2010, the Moscow region experienced a record drought and the hottest summer in Russian recorded history $\left(42{ }^{\circ} \mathrm{C}\right)$, which resulted in extreme fires that burned in previously drained peatlands. This lethal combination of natural and human forcings resulted in monetary losses of $3.6 \times 10^{9}$ \$US (by other estimates up to $10 \times 10^{9}$ \$US) and the death of nearly 56,000 people (Guha-Sapir 2010). In the spring of 2015, anomalous weather caused extensive and severe fires in Siberia that destroyed 1200 houses in 42 settlements and resulted in 36 deaths and hundreds of injuries in the Republic of Khakassia (Valendik et al. 2015). Similarly, fires in the Transbaikal region resulted in the loss of more than 240 houses in 18 settlements, the death of 11 people, and more than 30 people injured (Kukavskaya et al. 2016).

Wildfires are uncommon in Eastern Europe and European Russia (Krylov et al. 2014), but anthropogenic fires in agricultural areas, including croplands and 
pastures, are widespread (Soja et al. 2004; Dubinin et al. 2011; McCarty et al. 2017; Derevyagin 1987). Romanenkov et al. (2014) noted that a peak of satellite fire detections occurs in cropland areas in Russia, Baltic countries, Belarus, Ukraine, and Kazakhstan directly after the snow melt in the spring (indicating field preparation) and after agricultural harvests in the fall. Agricultural burning is a source of short-lived climate pollutants like black carbon (McCarty et al. 2012) and methane (McCarty et al. 2017). However, prescribed fire in forests, grasslands, or croplands is either illegal or not reported by national agencies in Lithuania, Belarus, or Russia (Narayan et al. 2007). Efforts to organize reliable monitoring of such fires from space are warranted.

\section{Research focus 3: retreat of the cryosphere}

The cryosphere in the montane regions of Northern Eurasia is represented by three components: (i) seasonal and perennial snow pack; (ii) glaciers; and (iii) permafrost. The cryosphere retreat has a continent-wide spatial scale with temporal scales that vary from the century to millennia for glaciers and permafrost, to seasonal for snow cover extent (Shahgedanova et al. 2010, 2012, 2014; Aizen et al. 2007; Bulygina et al. 2011; Gutman and Reissell 2011; Sorg et al. 2012; Chen et al. 2013; Groisman and Gutman 2013; Nosenko et al. 2013; Khromova et al. 2014; Blunden and Arndt 2015; Farinotti et al. 2015; Syromyatina et al. 2014, 2015; Fausto et al. 2016).

This retreat affects (a) continental energy balance changes due to decreases in surface albedo, increases in heat flux into the upper surface layers, and earlier spring onsets and longer growing seasons; (b) the depletion of the continental water storage accumulated during the past millennia in ground ice with the subsequent desiccation of lands that rely upon water supply from glacial melt and permafrost thaw; and (c) large-scale biosphere changes (Fig. 4) especially prominent in regions where the cryosphere is intrinsically linked with the survival/ dominance of major species within biomes (e.g., larch forest over the permafrost areas in northern Asia).
The most prominent snow cover changes are observed in the late spring (Fig. 7a) while the total duration of seasonal snow on the ground is decreasing, there are days/periods, when snow maximum water equivalent and maximum snow depth have been increased over most of Russia (Bulygina et al. 2009, 2011, updated). Note that the strong systematic increase in spring temperatures in Northern Eurasia (Fig. 3) was apparently enhanced by positive snow cover feedback.

Changes in the extent and mass balance of glaciers are important primarily because of their impact on water resources. Yet, while there is extensive information about glacier area change, less is known about changes in glacier volume and mass, either observed or projected. Within the domain of Northern Eurasia, assessments of changes of glacier mass on a regional scale are available for the Tien-Shan mountain system using Landsat and Corona satellite imagery which provided data on volume change (e.g., Pieczonka and Bolch 2015) and Gravity Recovery Satellite Experiment (GRACE) data (e.g., Farinotti et al. 2015). The latter provides data on changes in ice mass and is therefore directly relevant to the assessment of water resources. Yet for regions other than the Tien-Shan, the uncertainty of measurements using GRACE remains very high and often exceed the measured signal (Jacob et al. 2012). In other regions, changes in the mass and volume of ice are characterized using traditional glaciological surveyors' pole measurements of mass balance at the benchmark glaciers (World Glacier Monitoring Service 2015). Geodetic mass balance for smaller areas is based on using in situ geodetic measurements, aerial photography and high-resolution satellite imagery (e.g., Shahgedanova et al. 2012), and groundpenetrating radar (GPR) measurements performed both in situ and from the air (e.g., Kutuzov et al. 2015). This last method appears to be promising, particularly in combination with ice thickness modeling, e.g., the recently developed glacier base topography model, 2nd version (GLABTOP2; Linsbauer et al. 2012).

Within Northern Eurasia, the contemporary glaciation reaches its maximum extent in the mountains of Central
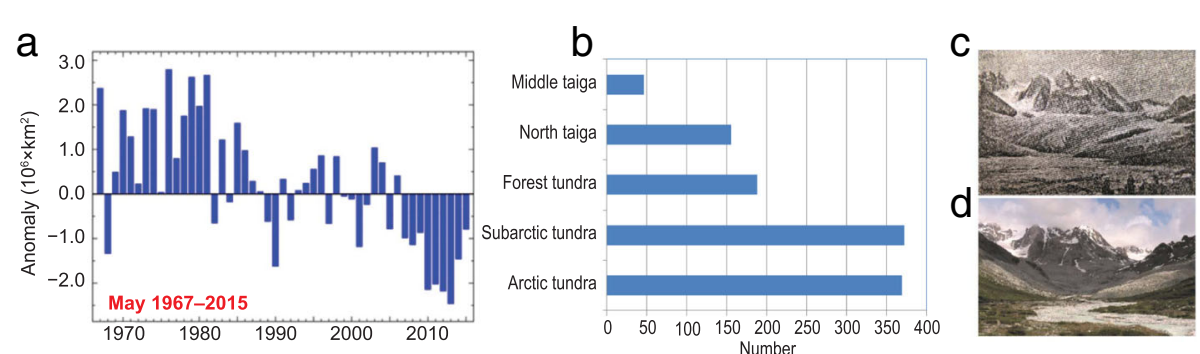

Fig. 7 Manifestations of the cryosphere retreat. a Spring snow cover extent anomalies over Eurasia (Blunden and Arndt 2016). b Number of newly emerging thermokarst lakes in West Siberia during the 1973-2013 period (Polishchuk et al. 2015). c-d Altai Mountains on the boundary of Russia, China, and Mongolia; Kozlov glacier in 1906 and 2013, respectively (Syromyatina et al. 2015) 
Asia. In the Tien-Shan alone, according to different estimates, glaciers occupy between 15,400 and $16,400 \mathrm{~km}^{2}$ (Sorg et al. 2012). The Altai Sayan Mountains and the Caucasus Mountains are other important centers of contemporary montane glaciation with a combined glacier area of approximately $1550 \mathrm{~km}^{2}$ (Aizen 2011) and $1350 \mathrm{~km}^{2}$ (Shahgedanova et al. 2014), respectively. Smaller centers of contemporary glaciation occur in the Polar Urals, mountains of eastern Siberia (e.g., Kodar, Chersky, and Suntar-Kayata), and Kamchatka (Khromova et al. 2014). Across all these regions, with the exception of the coastal glaciers of Kamchatka (Khromova et al. 2014), glaciers are retreating although regional variations in retreat rates are observed both between and within the mountainous systems (Kutuzov and Shahgedanova 2009; Narama et al. 2010; Sorg et al. 2012; Shahgedanova et al. 2010). When observations allow, the retreat of glaciers can be documented at the century scale (cf., Fig. 7c, d). In the first decade of the twenty-first century, the retreat rates increased to $1 \%$ year $^{-1}$, e.g., across most of Tien-Shan and Djungarskiy Alatau (Severskiy et al. 2016; Sorg et al. 2012; Farinotti et al. 2015; Pieczonka and Bolch 2015). In addition to glaciers, the ongoing climate warming has already affected the ground ice of these mountain ecosystems (Jin et al. 2000, 2007; Marchenko et al. 2007; Wu et al. 2013).

Across the Caucasus, the glaciered area has been shrinking at a slower rate of $0.4-0.5 \%$ year $^{-1}$ (Shahgedanova et al. 2014). Changes in the extent of glaciers of northeastern Siberia and the Urals are often more difficult to quantify because of the small size and cloudy summer weather which make it difficult to obtain suitable satellite imagery. However, analysis of glacier change in the Kodar Mountains shows both a strong loss of glacier area, as high as $0.9 \%$ year $^{-1}$ between the $1960 \mathrm{~s}$ and 2010 (Stokes et al. 2013), and a strong loss of glacier volume and negative mass balance (Shahgedanova et al. 2011). Glaciers of the Polar Urals have lost nearly half of their area since the 1950s and exhibited negative mass balance (Shahgedanova et al. 2012).

It is difficult to believe that the temperature increases over montane areas of Central Asia and Caucasus will not affect the extent of the regional cryosphere unless there is a concurrent two-digit percentage increase in regional precipitation. Analyses of cyclonic activity over Central Asia do not show sizeable changes in the total cyclone numbers, and there are some increases in their variability. Furthermore, the number of deep cyclones, which are already rare here, has decreased in the last decade (Fig. 8). Thus, the countries comprising this region should be prepared to confront potential problems with water availability for montane agricultural fields and pastures.

Permafrost and associated periglacial landforms can store large quantities of fresh water in the form of ice (30-70\% by volume, Bolch and Marchenko 2009) to buffer the loss of glacial mass. The impact of a declining cryosphere on water resources varies among the regions. While the impact is predicted to be moderate in the northern Caucasus, which receives ample precipitation (Lambrecht et al. 2011), it is likely to be stronger in arid regions such as southern Caucasus and Central Asia. In particular, the mountains and plateaus of Central Asia have been in the spotlight of cryosphere research because they are a major regional source of fresh water for surface runoff, groundwater recharge, hydropower plants, community water supply, agriculture, urban industry, and wildlife habitat. Central Asia is categorized as a water-stressed area where projected climate change could further decrease streamflow and groundwater recharge (Core Writing Team 2007).

It is anticipated that under the current climate warming trend, the recession of glaciers in Central Asia will accelerate, leading to a temporary increase of runoff during the dry season. The studies of the observed and projected changes in discharge suggest that the peak flow

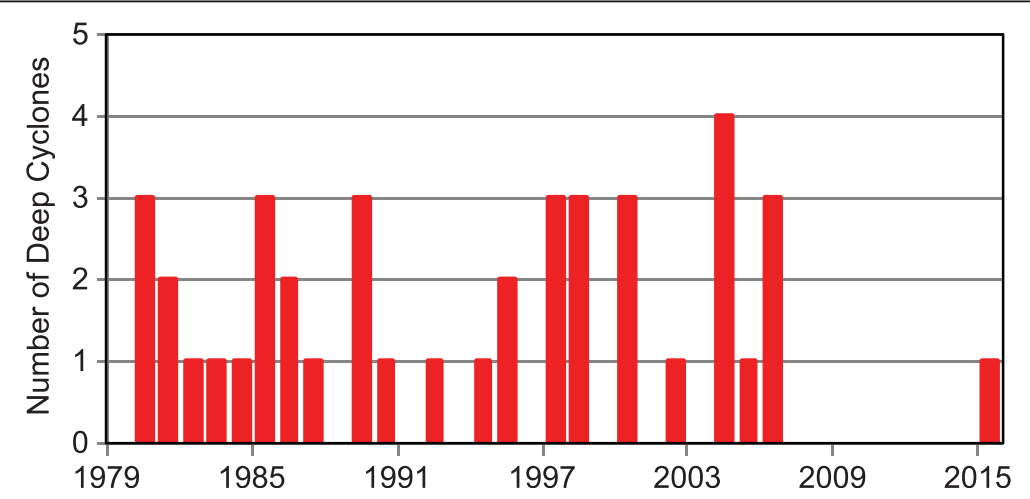

Fig. 8 Annual number of deep cyclones with sea surface atmospheric pressure in its center less than $980 \mathrm{hPa}$ entering sector $\left[45^{\circ} \mathrm{N}-50^{\circ} \mathrm{N} 60^{\circ} \mathrm{E}-90^{\circ}\right.$ E] that encompasses Central Asia according to ERA-interim reanalysis (Archive of Tilinina et al. 2013, updated) 
might have already been reached and will continue for the next decade (Hagg et al. 2006, 2013; Shahgedanova et al. 2016). However, on longer time-scales (> 50 years), the crucial dry season glacier runoff will be substantially reduced, as glaciers will lose most or all of their ice storage. In the same period, the melt of ground ice (initially trapped and accumulated in the permafrost) could become an increasingly important source of freshwater in the region. Currently few projections of future climate using regional climate modeling exist for Central Asia (Mannig et al. 2013; Shahgedanova et al. 2016). While all existing simulations project an increase in air temperature for the region, there is substantial disagreement among the models on the future trends in precipitation.

In the last 30-40 years, observations have indicated a warming of permafrost in many northern regions with a resulting degradation of ice- and carbon-rich permafrost. Increases of permafrost temperatures observed in Northern Eurasia and North America have resulted in the thawing of permafrost in natural, undisturbed conditions in areas close to the southern boundary of the permafrost zone (Romanovsky et al. 2010, 2017). Most of the permafrost observatories in Northern Eurasia show its substantial warming since the 1980s. The magnitude of warming has varied with location, but was typically from 0.5 to $3{ }^{\circ} \mathrm{C}$. In the regions where permafrost surface is already "warm" (i.e., where its temperature is close to the freezing point: Arctic shelf seas, riverbeds, edges of the present permafrost boundaries), such warming causes multiple changes in the terrestrial hydrological cycle, land cover, and man-made infrastructure (Pokrovsky et al. 2012; Shvidenko et al. 2013; Shiklomanov et al. 2017). The close proximity of the exceptionally icerich soil horizons to the ground surface, which is typical for the arctic tundra biome, makes tundra surfaces extremely sensitive to the natural and human-made changes that resulted in the development of processes such as thermokarst, thermal erosion, and retrogressive thaw slumps that strongly affect the stability of ecosystems and infrastructure (see "Research focus 7: changes in infrastructure"). Figure $7 \mathrm{~b}$ shows the number of newly emerging thermokarst lakes in West Siberia which indicate the rate of degradation there of the upper layer of the permafrost. A main aim of the future NEFI efforts related to permafrost is to evaluate its vulnerability under climate warming across the permafrost regions of the northern and high-elevation Eurasia with respect to ecosystems stability, infrastructure, and socioeconomic impact. A second aim is to estimate the volume of newly thawed soils, which could be a potential source or sink of an additional amount of carbon in the Earth system.

During the NEESPI studies of the past decade, the cryosphere retreat and its major manifestations were documented (Fig. 7) and it was shown that this process plays a critical role in environmental changes across Northern Eurasia.

\section{Research focus 4: changes in the terrestrial water cycle}

The mountains of Northern Eurasia cut its landmass off from the major sources of water supply from the tropics. Even in the regions of "sufficient" moisture, this sufficiency is secured not by an abundance of water, but rather by suppressed evapotranspiration during the lengthy cold season, soil insulation from the atmosphere by seasonal snow cover, and by external water supply from cryospheric storage. The rest of the water is provided through unstable atmospheric circulation (e.g., cyclones). Changes caused by global warming can decrease and/or redistribute water supplies from the cryosphere, increase the vegetation period, and affect the water vapor transport from the oceans into the continental interiors where both absolute changes and variation in the water vapor transport are of great consequence. Both natural ecosystems and human activities rely upon the stability of the water supply. Looming changes include (a) depletion of relatively stable water sources (cryosphere; Khromova et al. 2014), (b) an already unstable water source (atmospheric circulation) becoming even more variable (Schubert et al. 2014), and (c) a longer and warmer period for vegetation growth ("greening") increasing the biospheric water demand (Park et al. 2016). Given these, it becomes clear that changes in the terrestrial water cycle across Northern Eurasia can adversely affect the well-being of local societies as well as the world economy.

There is ample evidence of changes in the terrestrial water cycle across Northern Eurasia (AMAP 2011; Barros et al. 2014; Fig. 9), including reduced snow cover (Brown and Robinson 2011; Callaghan et al. 2011a; AMAP 2011, 2017), intensifying spring melt (Bulygina et al. 2011), increasing river flow (Shiklomanov and Lammers 2009, 2013; Georgiadi et al. 2011, 2014a, 2014b; Georgiadi and Kashutina 2016; Holmes et al. 2015), disappearance of lakes (Smith et al. 2005; Shiklomanov et al. 2013) lengthened ice-free period in lakes and rivers (Shiklomanov and Lammers 2014), degradation of permafrost (Streletskiy et al. 2015), and melting of glaciers (Velicogna and Wahr 2013; Duethmann et al. 2015) among others.

River flow is a dynamic characteristic that integrates numerous environmental processes and aggregates their changes over large areas. River runoff plays a significant role in the fresh-water budget of the Arctic Ocean and its water supply especially during low flow seasons (fallwinter). Ocean salinity and sea ice formation are critically affected by river input (Rawlins et al. 2009). Changes in the fresh water flux to the Arctic Ocean can exert significant control over global ocean circulation by 


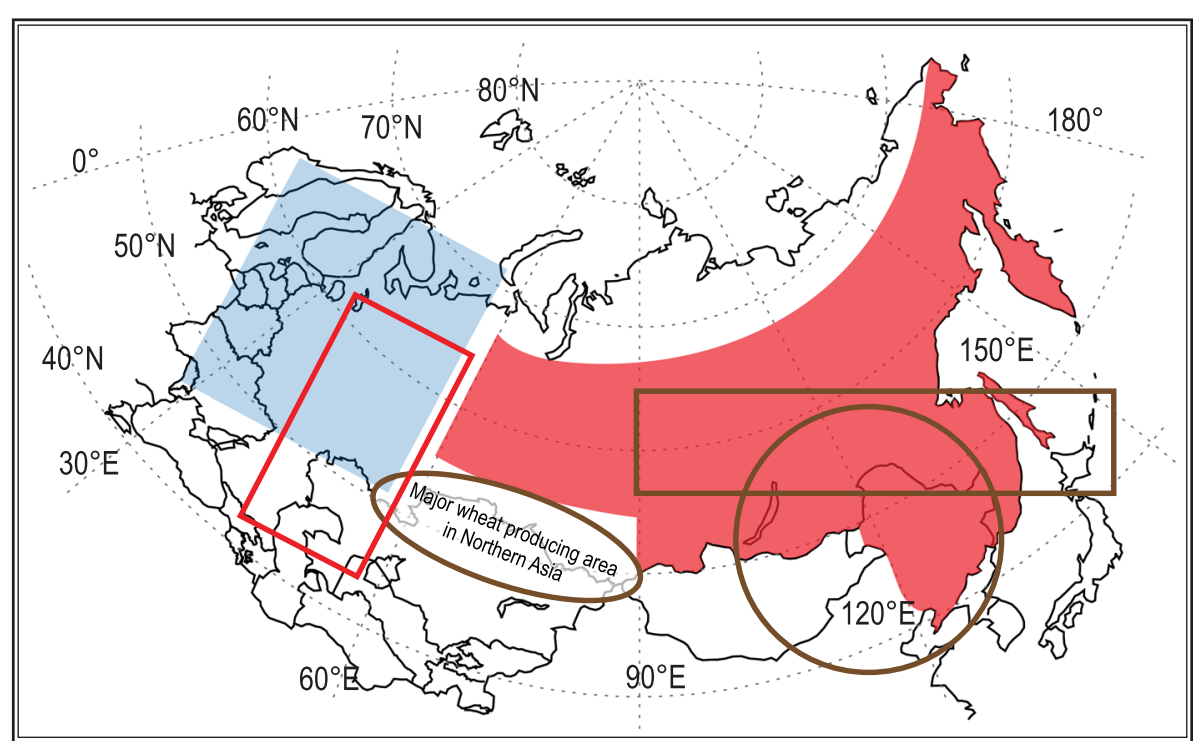

Fig. 9 Changes in the surface water cycle over Northern Eurasia that have been statistically significant in the twentienth century; areas with more humid conditions (blue), with more dry conditions (red), with more agricultural droughts (circles and ovals), and with more prolonged dry episodes (rectangles) (Groisman et al. 2009, updated). In the westernmost region of this map (Eastern Europe), blue and red rectangles overlap indicating "simultaneous" (although in different years) increases of heavy rainfall frequency and of occurrences of prolonged no-rain periods

affecting the North Atlantic deep water formation with irreversible consequences for Northern Hemisphere climate (Peterson et al. 2002; Rahmstorf 2002; Fichot et al. 2013). Eurasia contributes $74 \%$ of the total terrestrial runoff to the Arctic Ocean. The total annual discharge of six large Eurasian rivers increased from 1936 to 2010 by approximately $210 \mathrm{~km}^{3}$ - more than the annual discharge of the Yukon River (Shiklomanov and Lammers 2011), with a new historical maximum in 2007 (Fig. 10; Shiklomanov and Lammers 2009; Holmes et al. 2015).

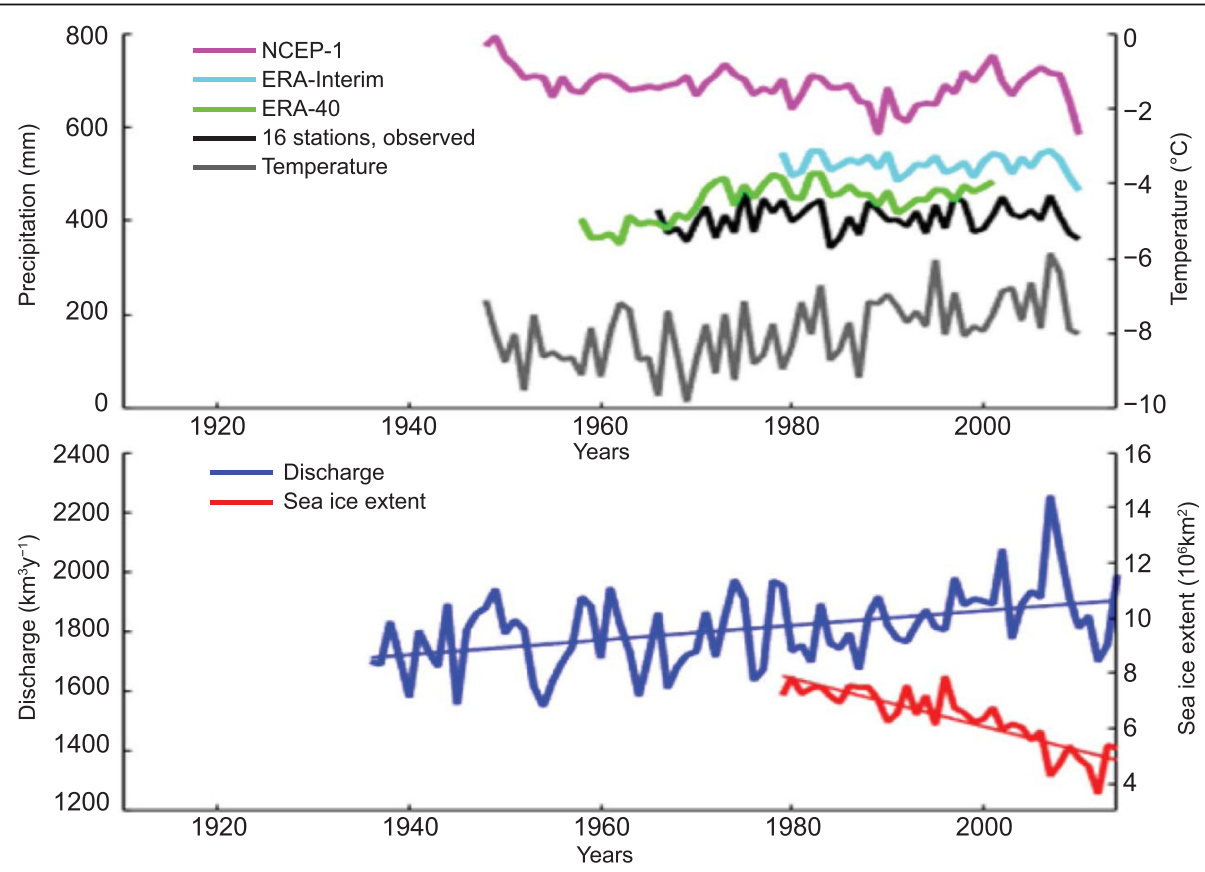

Fig. 10 Top panel: annual precipitation and surface air temperature in Siberia (east of the Ural Mountains, excluding Chukotka) from 18 Siberian stations and reanalysis fields. Lower panel: total annual river discharge to the Arctic Ocean from the six largest rivers in the Eurasian Arctic for the observational period 1936-2014 (Holmes et al. 2015) and annual minimum sea ice extent for 1979-2014 (source of the sea ice extent data: US National Snow and Ice Data Center, Boulder, CO, USA website, http://nsidc.org/data) 
River discharge into the Arctic Ocean is a highly effective conveyor in transporting continental heat across Eurasia (Nghiem et al. 2014) under a warming climate with increasing temperatures (Fig. 2). Eurasian rivers with immense watersheds, particularly the Severnaya Dvina, Pechora, Ob, Yenisei, Lena, and Kolyma Rivers, provide a massive flux of warm waters into the Arctic Ocean or peripheral seas contributing to melt sea ice in spring and summer. The massive river energy flux to the Arctic Ocean carries an enormous heating power of $1.0 \times 10^{19} \mathrm{~J} /$ year for each $1{ }^{\circ} \mathrm{C}$ of the warm river waters above freezing, which is equivalent to the power release from detonation of $2.5 \times 10^{9} \mathrm{TNT} /{ }^{\circ} \mathrm{C} /$ year $(\mathrm{Nghiem}$ et al. 2014). With increased water temperatures (Lammers et al. 2007) and longer ice-free periods of the Arctic rivers (Shiklomanov and Lammers 2014), the role of river heat input is increasing and must be incorporated in sea ice prediction and projection models. These changes of river discharge in Northern Eurasia have a predictive potential to force Arctic change at interannual to decadal timescales and beyond (Richter-Menge et al. 2012).

The Northern Eurasian freshwater cycle has been an important focus of ongoing research, and a great deal of work has been carried out to understand the increases in the river discharge to the Arctic Ocean and to identify whether or not the regional hydrological system is accelerating (e.g., Smith et al. 2007; White et al. 2007; Rawlins et al. 2010; Holmes et al. 2013). Although a variety of theories have been put forward, the physical mechanisms driving the observed runoff changes are not yet fully understood. Comprehensive analyses of water balance components (Rawlins et al. 2005, 2010; Serreze et al. 2006; Shiklomanov et al. 2007), human impacts (McClelland et al. 2004, 2006; Yang et al. 2004; Adam et al. 2007; Shiklomanov and Lammers 2009; Zhang et al. 2012a), and hydrological modeling experiments (Bowling and Lettenmaier 2010, Troy et al. 2012) have not revealed a clear cause of the observed increase in river discharge. Precipitation in the Eurasian pan-Arctic, which is the most important water balance component for the runoff generation, does not show a significant change to support the observed increasing trend in river flow (Adam and Lettenmaier 2008; Groisman et al. 2014).

In contrast, the increase in air temperature across the pan-Arctic has been widely and consistently documented (Overland et al. 2014), and it is expected to continue with the higher rates in the future (Barros et al. 2014). The air temperature rise leads to significant changes in the regional cryosphere including spring snow cover retreat, less frozen soil in the winter season, deeper annual thaw propagation in the permafrost zone (deeper active layer), and melting of glaciers. Several local or regional studies have shown the important influence of changes in different cryospheric components including permafrost thaw (Davydov et al. 2008; Woo 2012; Streletskiy et al. 2015), glacier melt (Bennett et al. 2015), less thickness of seasonally frozen soil (Markov 1994, 2003; Frauenfeld et al. 2004; Frauenfeld and Zhang 2011; Shiklomanov et al. 2017), and river ice on river runoff generation (Gurevich 2009; Shiklomanov and Lammers 2014). However, it is not clear from these studies how these locally observed changes will interact among each other and with spatially varying precipitation changes to affect the river flow over the entire region and the freshwater flux to the ocean. There is also considerable uncertainty about how these local changes will scale up to regional and continental scale impacts.

Terrestrial evaporation and transpiration (evapotranspiration) are the components of the terrestrial hydrological cycle that are the most difficult to measure given few direct observations (Speranskaya 2011, 2016). Nearsurface air temperatures are increasing, and one can expect that the evaporation from wet land surfaces should increase. However, the near-surface wind speeds over the entire territory of Russia have been decreasing in the past several decades (Bulygina et al. 2013 updated to 2016; such studies have not been completed for other parts of Northern Eurasia), and this may reduce the airsurface water vapor exchange. Furthermore, most Northern Eurasian land surfaces are not "wet" so a temperature increase does not automatically induce an increase in evaporation. Opposite processes may prevail due to evaporation suppression by dry upper soil layer (Golubev et al. 2001). Thawing of permafrost and less seasonally frozen ground can significantly change underground hydrological pathways. This will lead to an increase in ground flow, higher runoff during the cold season and, correspondingly, to a decrease in total evapotranspiration. Finally, future ecosystem shifts can dramatically change the vegetation composition (Fig. 4) and the transpiration rate of the new communities can induce further fundamental changes to the regional water cycle. All of the processes above suggest that changes in this component of the hydrological cycle are not trivial and should be assessed within new models that properly account for the interactions among the atmosphere, soil, and biosphere. Large-scale geochemical and geophysical runoff changes (biological and inorganic matter transports) also should be considered.

Recently, there were a number of assessments of trends in the discharge from glaciered catchments of Central Asia. A detailed review of changes in river discharge in the Tien-Shan has been provided by UngerShayesteh et al. (2013) who reported contrasting trends for its different sectors including increasing summer runoff in the northern and inner Tien-Shan, and decreasing summer runoff in the central and western Tien-Shan and at the lower elevations in the inner Tien- 
Shan. More recently, Shahgedanova et al. (2016) reported an increase in discharge from the glaciered catchments unaffected by human activities in the northern Tien-Shan using homogenized long-term records. Positive trends in the discharge from the headwater catchments of the Tarim River were reported by Duethmann et al. (2015), Krysanova et al. (2015), and Kundzewicz et al. (2015) who also attributed these changes primarily to the increasing glacier melt, but highlighted their inability to quantify water withdrawal and its contribution to the long-term trends as a limitation of these studies.

It is important to recognize that the increases in discharge due to glacier melt (if any) have been a temporary relief for water resources in the interior regions of Central Asia and Caucasus. In these regions, water stored in the cryosphere is limited and, if the current tendencies of the cryosphere depletion persist, they will result in severe water deficits in future decades. Therefore, it is time to begin preparations to mitigate and/or adapt to these deficits beforehand by developing management routines for water preservation and responsible consumption as well as by modifying agriculture and pastoral practices accordingly.

Accelerated climate- and anthropogenic-induced changes in the hydrological cycle raise societal concern because changes in the water level, streamflow, snow, ice, and frozen ground have pronounced effects on local and regional economies and the well-being of the Northern Eurasian residents. In particular, there may be immediate implications for water supply, irrigation, energy production, navigation, land and water transport, and structural engineering.

Presently, changes of the hydrological regime in Northern Eurasia are producing more and more freshwater input to the Arctic Ocean. The changes in river discharge, along with the sea ice decline, and higher precipitation over the ocean may exert a significant control over the North Atlantic meridional overturning (thermohaline) circulation with potentially dramatic consequences for climate of the entire Northern Hemisphere. Accordingly, we should expand our knowledge to better understand these hydrological processes, to better project possible extreme events, and better adapt to ongoing and upcoming environmental changes.

\section{Research focus 5: changes in the biosphere}

Ecosystems in Northern Eurasia are subjected to the impacts of climate change and human activities over the entire sub-continent. In the northern part on sites with permafrost, anthropogenic changes are primarily due to oil and gas exploration and extraction, mining, and infrastructure development. Further south, timber harvest (along with oil/gas) is predominant in the boreal and temperate forest zones, as are agricultural and pastoral activities in the forest-steppe and steppe zones. Industrial development often leads to the physical destruction of landscapes, changes of the hydrological regime, and widespread contamination of air, soil, and water (Derome and Lukina 2011; Baklanov et al. 2013). Climate-induced changes in terrestrial ecosystems transform important ecosystems and their services, which in turn, require an adjustment in business planning, nature conservation, forest management, agricultural practices, and regional economic policies to mitigate or adapt to these changes. The Siberian Taiga and Far East zones together comprise the largest part of the world's most intact remaining boreal forests (Potapov et al. 2008). It is now recognized that the RFE in particular is home to unique ecosystems and biodiversity (Newell and Wilson 2004).

In the long term, terrestrial ecosystems function in a dynamic balance with the states of climate, water resources, the lithosphere, and cryosphere. When these four driving forces change, ecological systems also begin to change. Currently, significant changes in forest area and composition are predicted to occur within a few future decades (see Fig. 4 and discussion). Ongoing climate change already impacts the ecosystems of Northern Eurasia and may provide hints for projecting future changes. These impacts are manifold and relate to diverse features of ecosystem states and behavior like health, productivity, resilience, change of natural disturbance regimes, major biogeochemical cycles, among many others (Kharuk et al. 2017).

Forests disturbed within the last 30 years account for approximately $75 \times 10^{6}$ ha (9\%) of Russian forests (Loboda and Chen 2016). Dendrochronological data show that fire frequency has been increasing in different parts of Russia throughout the twentieth century (Voronin and Shubkin 2007; Kharuk et al. 2016). Recent satellite-based assessments show that the rates of forest disturbance have increased further since 2000 compared to the pre-2000 era across all forest biomes with the largest increase from 1.2 to $2.2 \times 10^{6}$ ha year ${ }^{-1}$ in Eastern Siberia associated with an increase in fire occurrence (Loboda and Chen 2016). The average extent of burnt area during the last 15 years over Russia is estimated at $10-13 \times 10^{6}$ ha year ${ }^{-1}$ with the post-fire forest mortality rate of $1.76 \times 10^{6}$ ha year $^{-1}$ (Krylov et al. 2014; Bartalev et al. 2015). In the future, the frequency and extent of a fire occurrence in boreal forests are expected to rise further under the projected scenarios of climate change by anywhere from 25 to $50 \%$ (Flannigan et al. 2000, 2013) to $300-400 \%$ (Shvidenko and Schepaschenko 2013; Abbot et al. 2016) with an accompanying 50\% increase in fire weather severity. These, in turn, are likely to result in large-scale ecosystem shifts. For example, an 
increase in fire frequency is expected to lead to the disappearance of the pure Siberian pine stands in southern Siberia and the replacement of Siberian pine forests by Scots pine stands in the northern regions (Sedykh 2014). Repeated disturbances have resulted in substantial decreases in fuel loads and led to soil erosion, overheating, the absence of nearby seed sources, and the proliferation of tall grasses. As a result, the lack of natural post-fire regeneration of forests has led to their conversion to steppe vegetation (Kukavskaya et al. 2016; Fig. 6). Based on the analysis of satellite vegetative indices combined with ground-based data, repeated fires have been found to have the most negative impact on reforestation, forcing the failure of post-fire regeneration in more than $10 \%$ of the forested area in the south-western part of the Transbaikal region (Shvetsov et al. 2016). Furthermore, Flannigan et al. (2013) project that cumulative fire severity would increase three times and fire season length could increase by 20 days by 2091 for Northern Eurasia. Thus, there is an urgent need for planning adaptive forestry and fire management activities designed specifically for the regions that take into account trends in conditions and local features (climatic, forest-vegetation, social, technical, and economic).

While productivity of forests at the continental level has increased during the last few decades at a rate of $0.2-0.3 \%$ per year due to increasing temperature and lengthening of the growth period, there are large territories with decreasing productivity (Schaphoff et al. 2015) and enhanced mortality of trees. This mirrors the general condition for the entire boreal belt (Allen et al. 2010). The forests over large territories in different regions of Northern Eurasia are exposed to substantial dryness, particularly those which are dominated by dark coniferous tree species (Shvidenko et al. 2013) resulting in increased water stress and impacts of forest pests and pathogens. Increasing climate aridity has caused the morphological structure of forests to change (Lapenis et al. 2005). High variability of climate and an increase in the frequency and severity of long dry and hot periods (heat waves) impact forest health and the productivity of ecosystems in a visibly negative way (Bastos et al. 2014; Gauthier et al. 2015). Impacts of seasonal weather on net primary production and soil heterotrophic respiration is ecosystem/soil type and bioclimatic zone specific (Shvidenko and Schepaschenko 2014; Mukhortova et al. 2015).

Influences of climate changes on vegetation are primarily manifested in the alteration of the basic biogeochemical functions-first of all, the exchange rates of water vapor and carbon dioxide between plant ecosystems and the atmosphere. When ecosystems respond to changes in ambient temperature and moisture conditions, the direct response can be quite rapid. For example, an increased frequency and duration of droughts result in a transformation of the functional role of wetlands to be a source rather than a sink of $\mathrm{CO}_{2}$ for the atmosphere (Bohn et al. 2013; Olchev et al. 2013, 2013).

Sustainability of the forest carbon sink under changing climate is a serious concern, given the huge task of limiting the growth of atmospheric greenhouse gases (GHG) concentrations to levels adopted under the Paris Agreement of 2015 (http://ec.europa.eu/clima/policies/ international/negotiations/paris_en). The global growth of $\mathrm{CO}_{2}$ in the atmosphere is significantly compensated by the terrestrial biosphere sequestering 2 to $4 \mathrm{Pg}$ of carbon every year as evidenced globally from atmospheric composition measurements (Le Quéré et al. 2015). Atmospheric inverse models (Dolman et al. 2012) estimate the sink, which amounts to less than $4 \%$ of global net primary production, to be disproportionally allocated to high and mid latitudes of the Northern Hemisphere, including Northern Eurasia. This result is especially convincing when atmospheric observations over Northern Eurasia are used (Stephens et al. 2007; Maksyutov et al. 2013; Jiang et al. 2012, 2016; Saeki et al. 2013). Terrestrial biosphere models and long-term atmospheric observations (Graven et al. 2013) reveal an increase of biospheric $\mathrm{CO}_{2}$ seasonal exchange during the past few decades that are driven by rising temperatures and atmospheric $\mathrm{CO}_{2}$ concentrations. Maintaining the size of the carbon sink in Northern Eurasia into the twenty-first century under the negative impacts of increased droughts and fires requires basically the same measures as those needed for sustaining forestry, namely, fire protection and efficient forest management (Hurtt et al. 2002, 2011; Shvidenko et al. 2013). Despite the high level of natural and human-induced disturbances, the ecosystems of Northern Eurasia currently serve as a net sink of carbon up to 0.5-0.6 $\mathrm{Pg} \mathrm{C}$ year $^{-1}$ (Dolman et al. 2012) with about $90 \%$ of this sink occurring in forested landscapes. However, Fig. 11 shows that large areas of disturbed forests, basically on permafrost, have already become a carbon source.

Current biosphere models predict diverse responses based on the acceleration of the carbon cycle by future climate change. A significant change is expected for ecosystems on permafrost, but many important features of ecosystems at high latitudes are not adequately incorporated in these models. For the permafrost-region in Russia, current estimates indicate that the end-of-the-century release of organic carbon from the Arctic rivers and collapsing coastlines may increase by $75 \%$ (Gustafsson et al. 2011). The carbon loss from wildfires may increase substantially (Shvidenko et al. 2013). The expected changes of ecosystems in permafrost regions include forest decline over large regions from changes in the hydrological regime and increasing water stress (Fig. 4). Still, it is not clear whether northern forest ecosystems will 


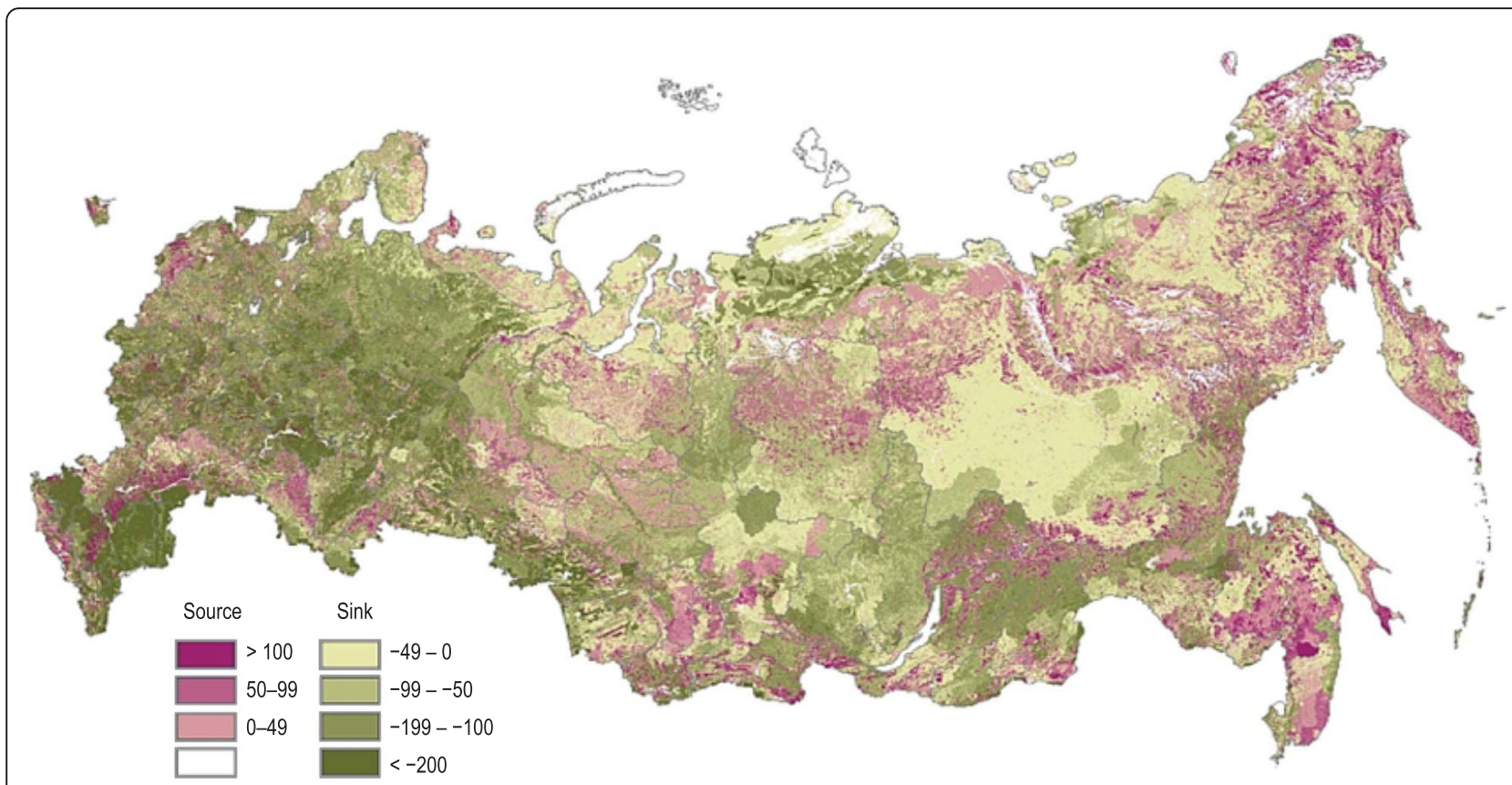

Fig. 11 Carbon sources and sinks by full carbon account of Russian terrestrial ecosystems (average for 2007-2009). Units of sinks and sources are g C mear ${ }^{-1}$ (Shvidenko and Schepaschenko 2014)

reach a tipping point, but this is very likely under regional warming above $7{ }^{\circ} \mathrm{C}$ (Gauthier et al. 2015; Schaphoff et al. 2015). The uncertainty of such a prediction is high. However, it is very likely that the permafrost region will become a carbon source to the atmosphere by the end of this century, regardless of which warming scenario is used. Purposeful forest management could substantially slow down this process (Abbot et al. 2016).

Logging is an important disturbance factor in many forest areas of Northern Eurasia (Achard et al. 2006; Gauthier et al. 2015). Logged sites are usually highly susceptible to fire due to a combination of high fuel loads in leftover debris and accessibility for human-caused ignition (Loboda and Csiszar 2007; Loboda et al. 2012). These sites typically experience higher severity fires than do unlogged forests, and these fires can spread to adjacent areas (Ivanov et al. 2011; Kukavskaya et al. 2013). In the dry lands, clear-cut logging accelerates the conversion from forest or forest-steppe to steppe vegetation.

Throughout the Taiga zone, timber harvesting (Bergen et al. 2008), and possibly human-exacerbated forest fires (Kasischke et al. 1999) are major contributors to change in the ecological systems of Northern Eurasia. Forest harvest in Russia as a whole, and in particular in Siberia and the RFE has changed over the past 50 years with high harvest rates characterizing the late Soviet era (Peterson et al. 2009). After the dissolution of the former Soviet Union, these rates dropped to less than to $100 \times 10^{6} \mathrm{~m}^{3}$ (Bergen et al. 2008) although more recently they have partially rebounded. The early
Soviet era saw an emphasis on harvest from western Russia. Since the 1980s, the greater development of logging in Siberia and the RFE was spurred by declining western Russia reserves, incentives to establish industry in the eastern reaches of Russia and agreements with Japan (in 1968 and 1974) for forestry infrastructure development in Siberia/RFE. Most recently (and in the foreseeable future), trade in eastern regions is influenced by increasing demand from China (Fig. 12), with significant potential to adversely impact the health and intactness of Siberian and RFE forests in particular (Bergen et al. 2013; Newell and Simeone 2014).

Predictions of the future distribution and state of ecosystems in Northern Eurasia vary considerably (Gustafson et al. 2011, 2011; Tchebakova and Parfenova 2012, 2013), with remaining large uncertainties in the vegetation dynamics. Progress in dynamic vegetation observations and modeling in North Eurasia has become more visible with the recent availability of high-resolution remote sensing data on topography, plant phenology, biomass, and soil wetness (Kharuk et al. 2017; Tchebakova et al. 2016, 2016). However, more efforts will be needed to expand the new data capabilities into lowlands and tundra regions.

Study results from the region suggest that further global warming will put at risk the sustainability of forest and forest landscapes (Gauthier et al. 2015; Schaphoff et al. 2015; Fig. 4). As mentioned earlier in this paper, models predict substantial shifts of vegetation to the north with forest steppe and steppe expected to be 


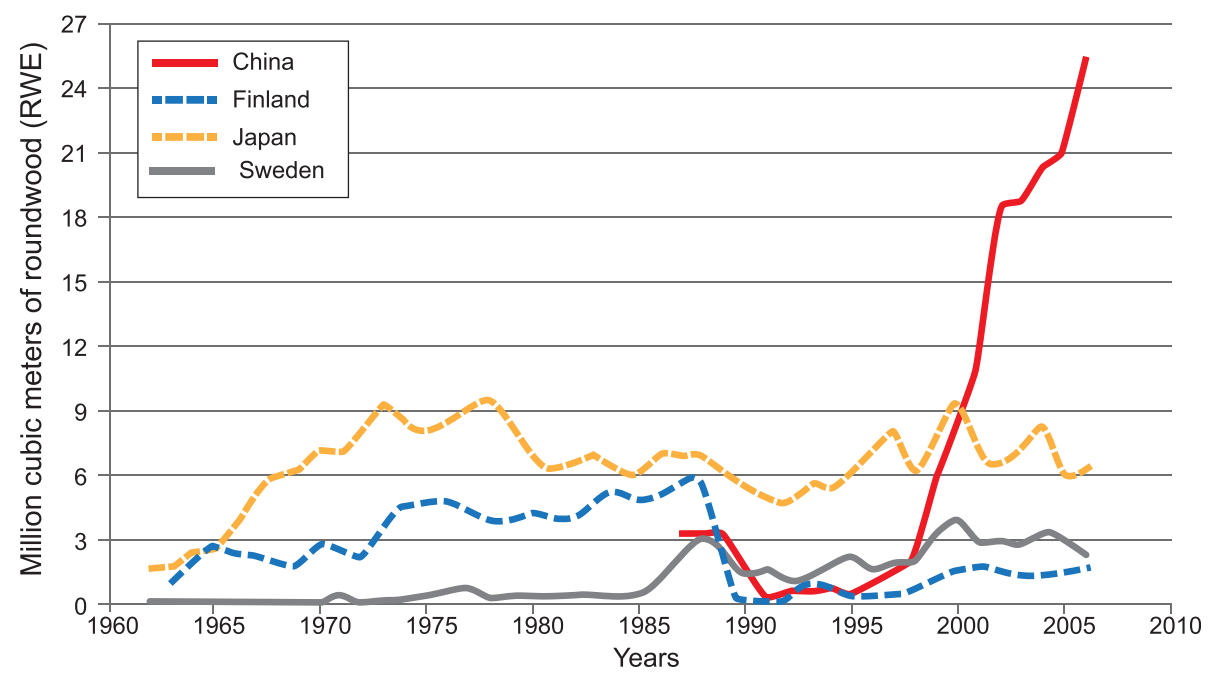

Fig. 12 Major export markets for Russian forest products 1960-2009 (archive of Newell and Simeone 2014; data source European Forest Institute 2014)

dominant across large southern territories of the present forest zone (Schaphoff et al. 2006; Tchebakova and Parfenova 2012). However, the changes in climatic conditions during the last several decades have occurred too rapidly for vegetation structure to completely adjust to the new conditions. The immediate response of vegetation cover to changes of climatic variables can be quite rapid, but the recovery can be characterized to occur over a longer time frame with significant delay. When the climate changes shift a region to conditions outside of the range of dominant species, the past and current seed dispersal rates (Udra 1988) are slower than the migration rate needed for vegetation to alter its composition to one appropriate to the predicted climate change.

A similar conclusion was reached based on comparisons of palynological data and radio-carbon dating in Western Europe (Huntley and Birks 1983) and in the European part of Russia (Velichko 2002; Velichko et al. 2004). It has been shown that under warming during the first half of the Holocene, the expansion rate of the majority of tree species was 200-300 m/year although the rate did reach 500-1000 m/year for pioneer species (birch and aspen). Similar estimates of the expansion rate of the boreal and temperate tree species in the early Holocene (from 100 to $1000 \mathrm{~m} /$ year) have been obtained from palynological data (Higgins and Richardson 1999; Tinner and Lotter 2001; Higgins and Harte 2006).

The results of paleoclimatic and paleogeographical reconstructions of the past epochs can be useful (as analogues) for prediction of the possible changes of the vegetation cover due to the projected change of climate conditions in the twenty-first century. Numerous refugia (areas with species that are different from the surrounding dominant ecosystems/populations) provide clues to the boundaries of the past ecosystems and also show the level of their resilience to a changing environment. Many global and regional paleoclimatic reconstructions have been compiled for various warming and cooling periods of the Late Pleistocene and Holocene (Velichko 2002). According to available paleogeographical data, the thermal maximum of the Holocene (about 6-5.5 ka BP) could be considered as an analogue of the climatic conditions for the middle of the twenty-first century and the optimum of the last Interglacial (Mikulino-Eemian-Sangamon, Stage $5 \mathrm{e}$ of the deep-sea oxygen curve, about $125 \mathrm{ka} \mathrm{BP}$ ) period could be considered as a paleo analogue for the end of the twenty-first century (Velichko et al. 2004). Still, it is not clear how much dispersal rates may accelerate under climate change, but it is very likely that the southern parts of the forest zone will be under very high risk, and the potential loss or decline of southern taiga forests will not be compensated for by increasing forest area beyond the current northern tree line.

Ecosystem changes in the present forest zone of Northern Eurasia may be quite rapid due to simultaneous effects of climate change that is among the largest over the planet (Fig. 3; Blunden and Arndt 2015, 2016) and of anthropogenic factors such as logging (Fig. 12), air, soil, and water pollution, and man-induced fires (see "Research focus: frequency and intensity of extremes"). First of all, the feedbacks from these changes directly affect the ecosystem services to societies of the region and, thus, their well-being. Secondly, the biogeochemical feedbacks of the carbon cycle changes in the forest and tundra zones of Northern Eurasia and its Arctic shelf seas may go far beyond the continent after the release of methane and $\mathrm{CO}_{2}$ from large carbon storage in forest, wetlands, and frozen soil to the atmosphere due to biomass decomposition, fires, and thawing (Friedlingstein et al. 2006; Shvidenko et al. 2011, 2013; Gao et al. 2013; Gauthier et al. 2015; 
Shakhova et al. 2015; Ruppel and Kessler 2017). These types of feedbacks affect the rates of global Earth system change and, therefore, represent a global concern.

In Central Europe, air pollution has been recognized as a key threat for forest ecosystems since the second half of the twentieth century. At the end of the twentieth century, sulfur and nitrogen depositions in Europe connected with lignite combustion and the high concentration of industry reached their highest levels. Thereafter, the deposition of $\mathrm{S}$ decreased by $>80 \%$ (Schöpp et al. 2003), with concurrent reductions in $\mathrm{NH}_{3}$ and $\mathrm{NO}_{x}$ (Kopáček and Posch 2011). The decrease of $\mathrm{SO}_{2}$ emissions in Czechia has been one of the most pronounced (Vestreng et al. 2007) and is believed to have profound consequences for ecosystem biogeochemistry (Oulehle et al. 2011). This reduction in pollution has to be continued and its monitoring remains an important task.

Norway spruce (Picea abies) is a tree species sensitive to air pollution. Thus, Norway spruce forests in the mountains of Central and Eastern Europe have been selected for regional studies of the interaction of climate and socio-economic drivers (Campbell et al. 2004; Mišurec et al. 2016; Kopačková et al. 2014, 2015). Since 1994, a network of 15 small forested watersheds (GEOMON) was established in Czechia to understand the forest response to air pollution. Since then, GEOMON has provided a testbed for exploration of element cycling on a watershed scale using modern remote and proximal sensing methods (Fottová 1995; Oulehle et al. 2008).

\section{Research focus 6: pressure on agriculture and pastoral production}

The temperate and steppe zones of East Europe are a breadbasket for a large part of Northern Eurasia (Swinnen et al. 2017). However, under pressure of growing population, the nations of these zones will need to invest in climate-smart agricultural techniques to sustain or continue to improve agricultural yields and livestock production given forecasted climate change. "Climatesmart" agricultural systems are resilient to climate change and offer carbon and GHG emissions mitigation potential without compromising productivity, food security, and the livelihoods of those working in the agricultural sector. So far, Iizumi and Ramankutty (2016) found that statistically significant increases in wheat yields in Ukraine were explained by improved agroclimatic conditions, i.e., warmer and longer growing seasons, and not by management strategies.

Land abandonment and recultivation During the past quarter-century, land abandonment in the Northern Eurasia region has been associated with fundamental changes in agricultural production and land use caused by the breakup of the Soviet Union in 1991 (Lerman et al. 2004). The guaranteed markets and subsidized production from the Soviet era, particularly in the livestock sector and less productive agricultural land, were lost. This caused an unprecedented drop in fodder-crop production, plummeting livestock numbers (Schierhorn et al. 2014), decline in grain yields (Trueblood and Arnade 2001), increased fallow periods (de Beurs and Ioffe 2014), and widespread agricultural land abandonment (Alcantara et al. 2012, 2013; Prishchepov et al. 2012; Griffiths et al. 2013; Lieskovský et al. 2015). According to official statistics, approximately, 59 Mha of farmland were abandoned from 1991 to 2000 across the post-Soviet countries (Fig. 13). A large portion of this change occurred in Russia. Two generalized trajectories of change resulted from this perturbation of 1991 and its subsequent effects up to the present: (1) some former agriculture lands have been taken out of production and have become reforested, and (2) others were temporarily taken out of production but have been later recultivated and/or otherwise put back into production under different ownership, management, or other socioeconomic processes.

With regards to the first trajectory, overall, the abandoned agricultural fields in Eastern Europe and Russia are driving an increase of forest cover, and have become a terrestrial carbon sink at the global scale over the late twentieth and early twenty-first centuries (Kuemmerle et al. 2011; Schierhorn et al. 2013; Kurganova et al. 2014, 2015). By 2010, approximately 5 Mha of new forests were observed on former agricultural fields in Eastern Europe that were cultivated during the Soviet era (Potapov et al. 2015). In the temperate zone, abandoned fields are often slowly but steadily encroached by shrubs and forests. Varying levels and timing of abandonment of agricultural lands were observed at the landscape level in three Landsat scene case study sites over the period 1975-2001 in the Siberian Taiga zone (Bergen et al. 2008), with most consistent decreases in agricultural land areas after 1990.

After the dissolution of the Soviet Union and subsequent cessation of the state subsidies for collective agriculture, large areas of less productive croplands were either abandoned (Alcantara et al. 2012, 2013; Prishchepov et al. 2012) or the fallow periods increased (de Beurs and Ioffe 2014). Potapov et al. (2015) reported that $32 \%$ of total forest regrowth between 1985 and 2012 was due to afforestation of former agricultural lands. However, afforestation of abandoned croplands is currently not included in the official forestry reports (Potapov et al. 2012), and the legal status of these lands remains uncertain.

The second trajectory which centers on land recultivation is more complex. First, agriculture abandonment rates varied across all of the former-USSR countries and 


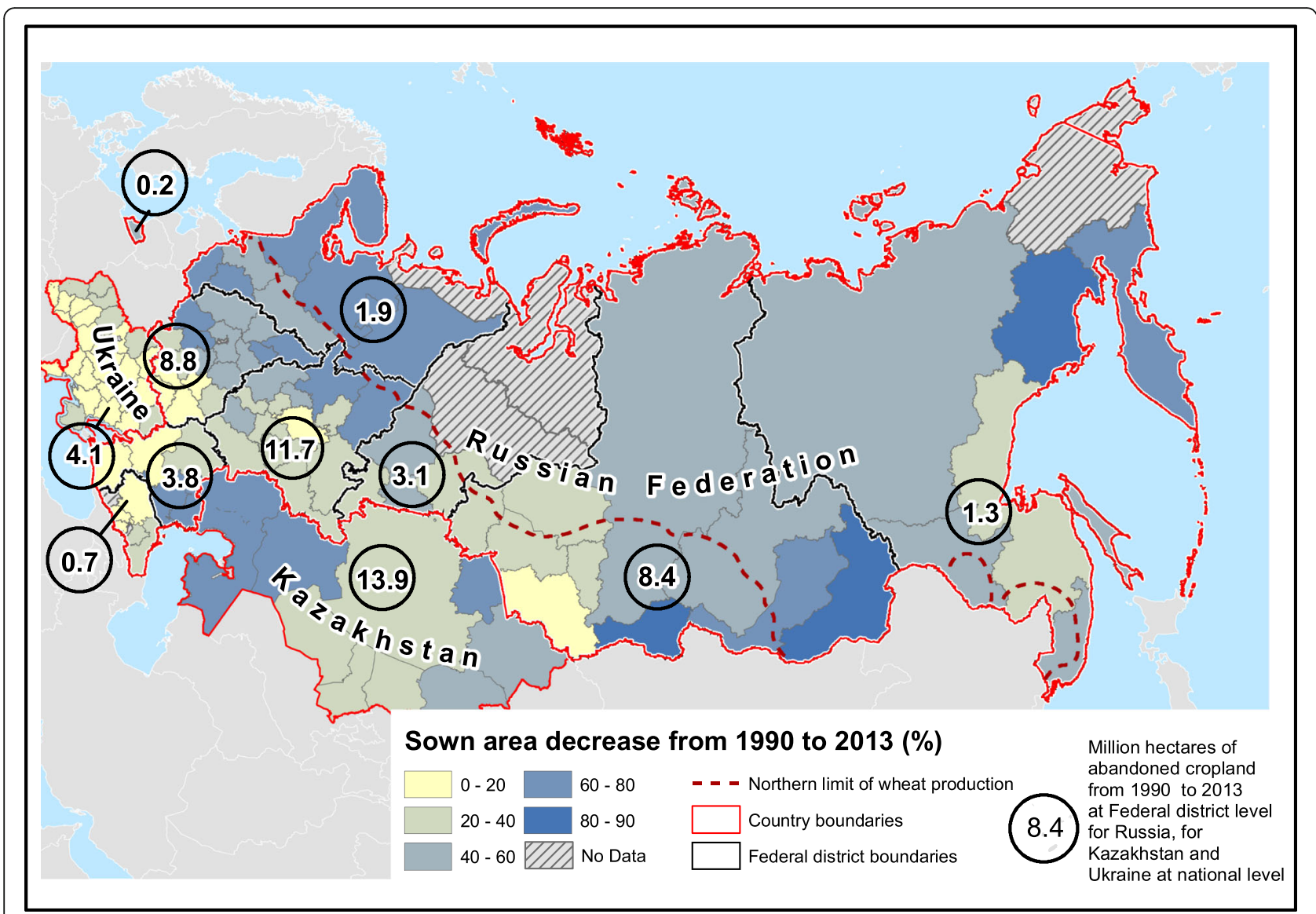

Fig. 13 Changes in sown areas across the former Soviet Union (Russia, Ukraine, and Kazakhstan) from 1990 to 2013 ; areas of abandoned sown areas for this period are 40 Mha in Russia (Rosstat 2016); 5.4 Mha in Ukraine (Ukrstat 2014); and 13 Mha in Kazakhstan (Kazstat 2014)

were mediated by national and regional policies regarding support of agriculture (Prishchepov et al. 2012), as well as access to new markets (de Beurs and Ioffe 2014). One of the lowest rates of abandonment was observed where land reforms were successfully completed in a short period (Poland) or, in an alternate case, where they were absent (Belarus). Strong regional differences were also observed within countries. For example, Ioffe et al. (2012) looked at the contrasting situation of Kostroma, an oblast in the north of European Russia and Samara, an oblast in southern European Russia. In the northern oblast, agriculture is now limited and in retreat beyond relatively small-scale operations in suburbia, while in Samara, the agricultural activity now appears to be sustainable, albeit on a somewhat less extensive spatial scale than in the past.

After 2000, a partial recultivation of abandoned lands has been observed, which is primarily driven by adjustment of agricultural policies and growing prices for agricultural commodities (de Beurs and Ioffe 2014; Estel et al. 2015; Meyfroidt et al. 2016; Smaliychuk et al. 2016). However, recultivation rates have been compensated by ongoing agricultural land abandonment-reaching 60 Mha by 2013 for three largest post-Soviet agricultural nations (Fig. 13). From 2000 to 2010, grain yields increased (Trueblood and Arnade 2001; Liefert et al. 2010). In southern Russia where the physical attributes, location, and human resources are best positioned to support agricultural activity (e.g., in Stravropol' Krai), there is growth potential for agriculture (Kattsov et al. 2012). Here, there is evolving specialization of former socialized farms in response to market conditions. In Stavropol, this involves a shrinkage of animal husbandry and a consequent release of surplus labor, increased levels of absentee (corporate) ownership of farmland in the more favorable locations, decoupling of the economic fate of successful large farms from deficient local municipal budgets, and an expansion of non-Russian ethnic communities in the countryside (Ioffe et al. 2014).

Dynamics of cultural landscapes in European countries of the former Soviet Bloc can also be characterized by two opposite processes-intensification and extensification (Fjellstad and Dramstad 1999; Bič́k et al. 2015). Intensification occurs when cropping intensity or livestock stocking increases on some land. This may be accompanied by abandonment of other, more marginal cropland, pastures, or rangeland. In contrast, extensification occurs 
when more cropland or pastures are needed so that additional natural lands are converted to agriculture. Land abandonment in Central and Eastern Europe since the 1950s has resulted from a complex multidimensional process with environmental, ecological, economic, and social consequences (Kuemmerle et al. 2008; Keenleyside and Tucker 2010). Detailed information about abandoned lands is missing from European national land resource statistics.

The combined abandonment-reforestation and abandonment-recultivation trajectories potentially provide future options for both biofuel production and cropland expansion. The Northern Eurasian region represents a great potential to boost agricultural production (Schierhorn et al. 2014), and also to provide other ecosystem services on abandoned lands. However, climate change and socio-economic and political development may substantially limit such opportunities (Meyfroidt et al. 2016). The future of some abandoned lands is uncertain due to the fluctuation of prices for agricultural commodities, growing interest in biofuel production, and development of national food security programs by the successors of the former Soviet Union. In some postSoviet countries (e.g., Ukraine), land reforms are not yet completed to this date (2017), limiting recultivation of abandoned lands. Adverse demographic conditions in Eastern Europe associated with an exodus of the rural population (Nikodemus et al. 2005; Prishchepov et al. 2013) and the depopulation of rural areas in China (Liu et al. 2010) may trigger additional land abandonment. Because of limited institutional and economic ability to adapt to changing weather patterns, the increase of weather extremes represents a real threat for future agricultural production in Northern Eurasia. This may reduce the possibility to close existing yield gaps (Dronin and Kirilenko 2010; Lioubimtseva and Henebry 2012; Schierhorn et al. 2014; Horion et al. 2016). Last but not least, the observed increases in cropping intensity (de Beurs and Ioffe 2014) without adequate application of fertilizers may reduce soil fertility and diminish yields.

With respect to the above, the importance of socioeconomic factors in land use is paramount. For example, the level of institutional suppression in two major cropproducing nations of the former Soviet Union, Ukraine and Russia, during the last 60 years of the Soviet period was so high, that the former Soviet Union imported grain in the last two decades of its history. Conversely, in recent years, even after the massive land abandonment in the 1990s, these two nations have become the second and third major wheat exporters globally.

Agriculture and pastoral production in the DLB Spanning $25-125^{\circ} \mathrm{E}$ and $24-55^{\circ} \mathrm{N}$ across 17 countries (Fig. 1), the DLB is the largest contiguous dryland in the extratropics. The region has served as the historical trade route between the Chinese East and the Mediterranean West, combining the Persian Royal Road and the Silk Road. The Silk Road was and is an important international trade route between China and the Mediterranean. Historically, the Silk Road has experienced major expansions and geopolitical conflicts among cultures and religions, political and institutional shifts including the collapse of the Soviet Union (Hostert et al. 2011). Especially in the last millennium, resource extractions (e.g., oil), rapid land use change (e.g., urban and agricultural expansion), climatic change, and natural disturbances (e.g., dust storms) have driven change in the region. The increased demand for meat and dairy products have produced strong pressure on agro-pastoral lands where transitional economies with frequent institutional shifts, water resource scarcity and climate conditions interact to alter DLB ecosystems and societies. The geopolitical systems are diverse, but most countries in the region are either developing or transitional economies with great demands for meat and dairy production (Ojima and Chuluun 2008).

While climate projection models agree that the DLB will become much warmer over the rest of the century, there is little agreement and considerable uncertainty about future precipitation patterns for the region. The Fifth IPCC Assessment Report (AR5; IPCC 2014) stated with high confidence that the Coupled Model Intercomparison Project Phase 5 (CMIP5) generation of models could project temperature distribution at a regional scale better than the previous generation of models. However, the AR5 report states with "a medium confidence" that there had been no improvements in model performance for precipitation. Moreover, global and regional climate models are seriously challenged by the rugged terrain found in much of the DLB (Parfenova et al. 2013; Lu et al. 2009; John et al. 2013, 2016).

Over the past three decades, the DLB has gone through several major changes that drive regional agricultural and pastoral land changes. First, the regional population has increased at a moderate rate similar to the global population trend. But some areas, especially around urban agglomerations in the East Asian part of the DLB, have increased more rapidly resulting in greater pressure on agricultural and pastoral lands (Qi et al. 2012, 2012; Kraemer et al. 2015). Second, there have been profound institutional shifts in the agricultural sector, primarily in post-Soviet Central Asia where the newly independent states have disparate natural resource endowments. To balance food security with commodities for export, these new nations have shifted their agricultural priorities (for example, replaced high water demanding cotton by wheat) that have altered regional water demands-resulting in agricultural abandonment 
in some locations and intensification in others (Wright et al. 2012; de Beurs et al. 2015; Kraemer et al. 2015).

Observations and biosphere models suggest that climate change is producing shifts of the ecotones in the drylands of Asia (Groisman and Soja 2009; Tchebakova et al. 2016). The northward movement of the tree line and the changing dynamics of cover types, such as shrublands and savannas in the grassland matrix, alter feedbacks to carbon, water, and energy balances. Warming trends along with land use and land cover change (LULCC) could substantially modify the carbon balance and biodiversity of the Eurasian Steppe. Natural and anthropogenic factors act in concert amplifying one another. Consequences of reckless land use and general drying of the continental interiors include water scarcity, lowered water quality, soil salinization from agriculture intensification, and the disappearance of lakes/rivers due to reduced snow packs, glacier loss, and aggressive fresh water extraction (Klein et al. 2012).

The region has also experienced a rapid transformation in land cover. Grasslands have been converted to croplands in Central Asia and in portions of East Asia. Changes from cropland to vacant land have accompanied the collapse of the Soviet Union as farms were abandoned en masse (Lioubimtseva and Henebry 2009; Chen et al. 2015; Fig. 13). The net gain in carbon sequestration due to abandonment of croplands is offset by grassland degradation from the increased grazing pressures following dramatic increases in land privatization (e.g., herding policy on the Mongolia Plateau, Chen et al. 2015), and increased food demands (Qi et al. 2012).

LULCC has simultaneously occurred at an alarming scale across the DLB. A transition matrix based on the Moderate Resolution Imaging Spectroradiometer (MODIS) Land Cover Type Product (MCD12Q1) between 2001 and 2012 revealed that shrublands and savannas (i.e., steppe) show a high degree of turnover across the entire region, at 38\% for shrublands and $73 \%$ for savannas, respectively (Fig. 14). Regionally, shrublands and savannas showed a greater turnover (77 and $89 \%$, respectively) during the decade, with East Asian and Central Asia at 47 and $88 \%$, respectively, and the Middle East at 39 and 54\%, respectively. Similarly, croplands and cropland/natural vegetation mosaics have high turnover in East Asia (53 and 72\%, respectively), in Central Asia ( 49 and 66\%, respectively), and in the Middle East (25 and $73 \%$, respectively). Barren and water cover types represent about 35 and $1 \%$ of total land area, respectively, but showed a 15 and $18 \%$ turnover across the region, respectively. Intensive use of exposed barren areas has escalated dust storms, drought severity, and water shortages (e.g., Xuan et al. 2000; Chen and Liu 2014). Worse yet, in the Fifth IPCC Report, Barros et al. (2014) predicts that this water-limited region will experience a warming trend significantly higher than the global mean, which would alter

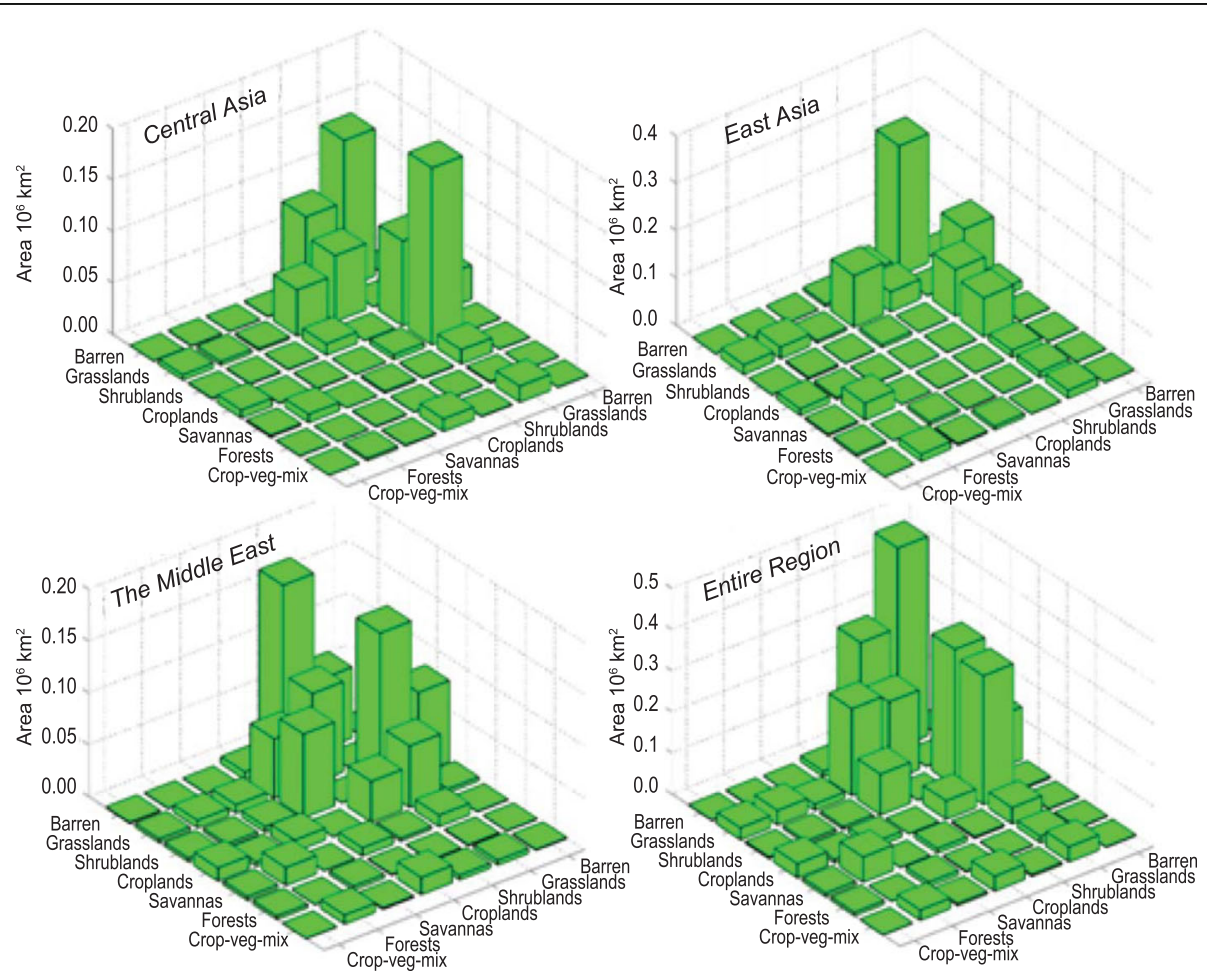

Fig. 14 Land cover change from 2001 to 2012 based on MODIS LC products for the three regions within DLB 
summer and winter precipitation patterns and increase the frequency of extreme climate events with longer, more intense, and more frequent summer heat waves. Cook et al. (2016) reports that, since 1998, the drought in the eastern Mediterranean Levant region (Cyprus, Israel, Jordan, Lebanon, Palestine, Syria, and Turkey) is the worst drought of the past nine centuries. Furthermore, the LULCC in DLB is expected to be significantly higher in the upcoming decades than now (Kelley et al. 2015; Chen et al. 2017), jeopardizing the regional stability and sustainability of the DLB. All of these factors along with its landlocked geographic location make DLB a hotspot for the scientific community concerned with negative consequences of ongoing global change.

By shifting $\mathrm{C}$ stocks in soils and vegetation, both abandonment and intensification strongly impact the regional carbon budget. For instance, the total extra C sink in abandoned croplands in Kazakhstan (12.9 Mha) over 1991-2010 is estimated to be nearly $31 \pm 2 \mathrm{Mt}$. C year ${ }^{-1}$, which could compensate annually for about $49 \%$ of the current fossil fuel emissions in this country (Kurganova et al. 2015). Most countries within the DLB implemented various reform policies to promote economic growth while improving quality of life. The new governance and policies increased GDPs, but at the same time resulted in shifting food demands, moving towards more processed, high protein animal products, which can drive increases in grasslands-based livestock production (Chen et al. 2015, 2015).

A regional land use change analysis using MODIS data suggests differential land use change across the DLB (Fig. 15) with cropland abandonment in the west (zoom windows at the bottom) and expansion in the east (zoom windows at right) are driven primarily by shifts in governance and economic development. Therefore, the DLB has seen increasing demands for food quantity and quality as well as decreasing food production, resulting in unbalanced pressure on agricultural and pastoral lands (Chen et al. 2015, 2015).

From the perspective of cultural and social norms, the Asian part of DLB shares similarities in history of nomadic herding lifestyles and in geographic proximity. Totaling 8.82 million $\mathrm{km}^{2}$, Central Asia, Mongolia, and Northern China includes the largest land-locked countries (Kazakhstan and Mongolia) and has been influenced by some of the most severe geopolitical, biophysical, and socioeconomic disturbances affecting societies and simultaneously their livestock, a major source of food in the region. The region's total livestock of 209.16 million animals in 1992 increased to 278.3 million in 2011 (33.1\% increase). However, livestock in

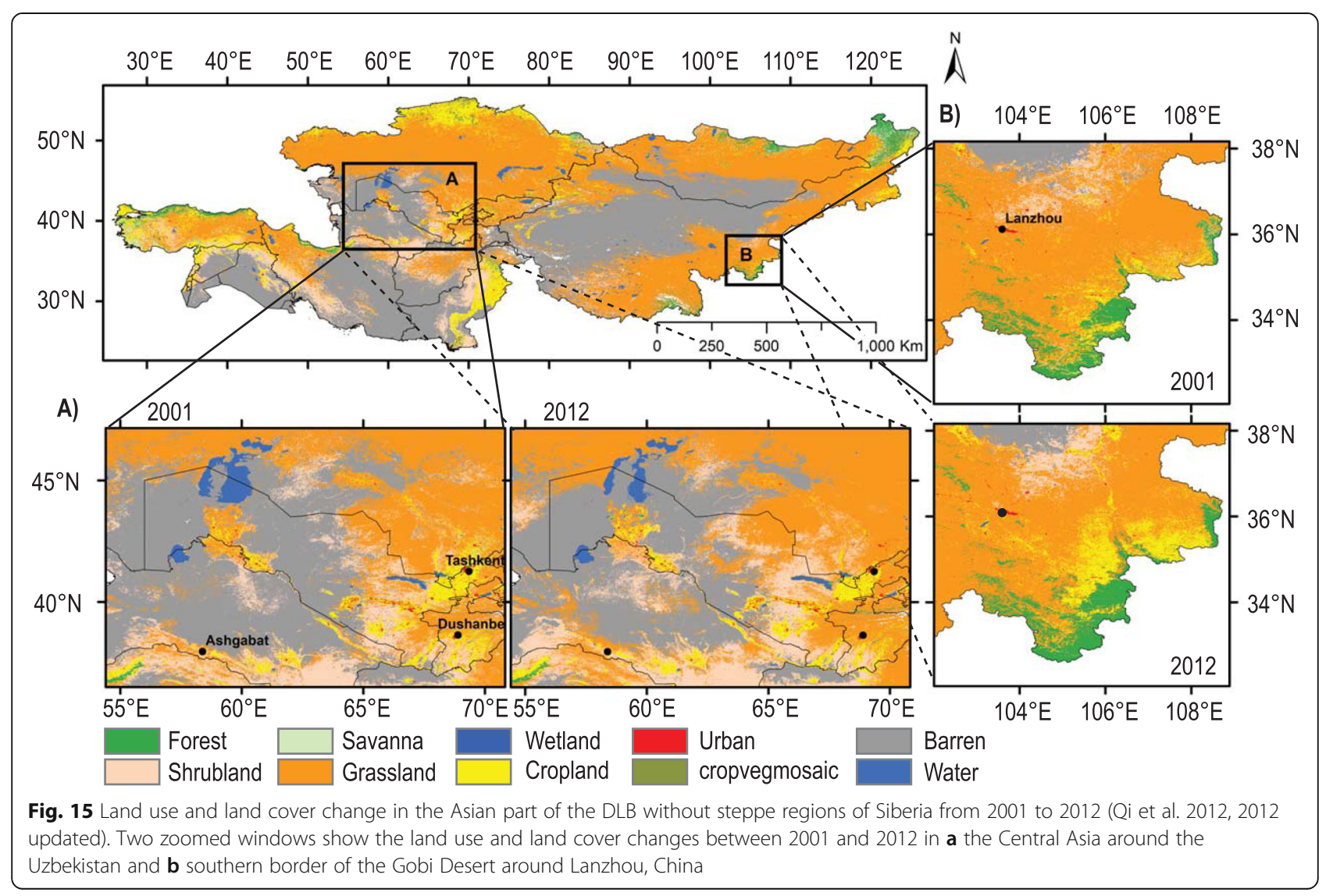


Kazakhstan and Kyrgyzstan decreased substantially (by 43.8 and $34.1 \%$, respectively) likely due to the collapse of the Soviet Union. Empirical relationships among ecosystem production, population density, gross domestic production, and land use remain intrinsically connected even with major policy shifts (such as the collapse of the Soviet Union or the new status of China within the World Trade Organization (Chen et al. 2015, 2015). The underlying mechanisms responsible for these consistent relationships, as well as their dynamics, remain unknown.

Food security in the Central Asian part of the DLB critically depends on the water availability from the mountains, especially given the drying, browning, and brightening trends that characterize the region during the past 15 years (de Beurs et al. 2015). Some countries started taking practical measures by constructing reservoirs in order to ensure their economic development. These actions will have short-term benefits, but estimates of contemporary and future water resources that will originate from the high mountain cryosphere at the regional scale are needed to develop long-term adaptation and mitigation strategies. These estimates will be used for socio-economic vulnerability assessments of the benefits to local communities whose livelihood depend on the quantity and seasonality of water discharges from the Central Asian mountains with respect to regional and national priorities. This specific objective will require the blending of geosciences with social sciences to evaluate the role of high-elevation ice storage in permafrost and glaciers for levels of vulnerability and the resilience of mountain and downstream ecosystems along with their inhabitants.

\section{Research focus 7: changes in infrastructure}

In the previous sections, we mostly describe environmental and climatic changes in Northern Eurasia in recent decades. They have affected infrastructure of the region. In particular, the Arctic and Siberia have been substantially affected by the permafrost changes and its impact on man-made infrastructure (e.g., buildings, factories, mines, bridges, roadways, and pipelines). In the boreal zone, gradual onset of drier climate conditions accompanied with more frequent wild fires endangers human settlements, silviculture, and agriculture. In the DLB, a general depletion of already scarce water resources affects the general well-being of all population groups, and all aspects of human activity. These climate-related impacts on the infrastructure have been compounded by the marked social, economic, and institutional changes over Northern Eurasia during the past three decades. Therefore, this section is devoted mostly to the socio-economic changes attributable to the dramatic political and economic transformations that have affected infrastructures of Northern Eurasia.
In Russia, these transformations have been most pronounced in its Arctic regions where regional welfare critically depends upon the well-being of the entire country (e.g., Stammler 2005; Forbes et al. 2009; Kumpula et al. 2011; Pelyasov 2011; Hitztaler and Bergen 2013; Andrew 2014). Here, several socioeconomic processes are major anthropogenic drivers of environmental change since the 1960s. These include migration, urbanization, and industrialization (e.g., Heleniak 2010, 2014). Ongoing and projected climateinduced changes in natural systems will impact the human environment with direct, immediate implications for land use, the economy, subsistence, and social life.

Although some climatic changes may be economically beneficial (e.g., decrease in climate severity and associated heating costs, longer navigation season), other changes negatively impact the natural environment, both traditional and non-traditional sectors of the economy, and the regional socioeconomic conditions. Overall, these climatic-induced changes in natural conditions exert additional pressure on the marginal environments of Eurasian Arctic, which are already stressed by human activities (Fondahl 1996; Crate 2006; Forbes et al. 2009). For example, infrastructure development and climate change are interacting in complex ways to alter permafrost over large areas of the Eurasian Arctic (Shur and Goering 2009; Polishchuk and Polishchuk 2013, 2014). Communities, urban environments, and industrial infrastructure built on ice-rich soils can be catastrophically affected by thawing permafrost (Streletskiy et al. 2012; Shiklomanov and Streletskiy 2013; Shiklomanov et al. 2017). Simultaneously, permafrost thawing, caused by both climate and infrastructure changes, affects natural landscapes and ecosystems (Raynolds et al. 2014; Khrustalev and Davidova 2007; Khrustalev et al. 2011).

Permafrost thawing and its associated impacts on natural and built environments have been identified as priority issues for all Arctic regions (Walker and Pierce 2015). Due to unprecedented levels of urban and industrial development, this problem is most pronounced for the Arctic regions of Northern Eurasia.

The Taiga ecoregion of Northern Eurasia has also seen dramatic pendulum-like shifts in population, infrastructure, and forest resource use between the late Soviet, early post-Soviet, and the present-day eras. Over this time span, additional changes in the ecosystems driven by climate factors have also been accompanied by multiple severe wildfire years. Siberia's population expanded by 9 million people ( 23.5 to 32.5 million) between the years 1959 to 1989; a similar trend occurred in the RFE. This was due in large part to state incentives encouraging settlement of these eastern reaches of the Soviet domain. Thus in these 'peripheral' regions away from the 'center' (Moscow and St. Petersburg), population 
growth was strongly a product of in-migration and not intrinsic population growth.

With the relatively sudden withdrawal of statesupported programs, this situation precipitated significant shifts in population and natural resource use in the immediate post-Soviet era (Voinova et al. 1993; Bergen et al. 2013). Driven by significant economic hardship, subsequent population out-migration began $\sim 1990$, which pervaded East Siberia and the RFE and has only recently been lessening. In addition to high rates of migration out of the regions altogether, residents also migrated within the regions from rural areas to the few main cities, resulting in a more urban population.

During the final three decades of the Soviet era, the forestry sector sustained high rates of timber production in Siberia. Some of this timber was exported to Japan based on official agreements with Japan in 1958 and 1974 (Mathieson 1979) and, in the last decades, to China (Fig. 12). This brought investments in infrastructure. Despite the otherwise successful commitment of the Federal Forest Service to scientific forestry including the creation of forest inventory and an exceptional scientific knowledge (Kukuev et al. 1997), late Soviet-era forest harvest itself was surprisingly inefficient (Shvidenko and Nilsson 1994). Immediately after political dissolution in 1991, total harvest volumes significantly declined across Russia to approximately 175 million $\mathrm{m}^{3}$ compared to approximately $400 \mathrm{~m}^{3}$ in 1989 (Bergen et al. 2013). Significant growth did not occur again in the forest industry until approximately 2009.

As governance and institutions have regrouped after the early post-Soviet transition era, new or renewed developments in forest and energy sectors have emerged. Resource use in the taiga of Siberia and the RFE is influenced by its proximity to China, Japan, and Korea. These countries have (a) some of the world's highest human population density numbers, (b) either naturally limited or depleted forest resources, and (c) far-reaching globalindustrial and trade conglomerates (Crowley 2005; Bergen et al. 2013). Thus, in Russia, the geographic location of forest exploitation is shifting to eastern reaches that can easily supply and transport logs to the growing Asian market (Newell and Simeone 2014). This occurs both through legal forest management and harvest but also through illegal harvest (Vandergert and Newell 2003).

Siberia and the RFE Taiga regions are also rich in oil, gas, and minerals, i.e., natural resources which are of great current economic and strategic importance. Within Russia, there may be a greater shift in oil and gas extraction to East Siberia and the RFE given that the historic large oil reserves of Western Siberia are thought to be approximately $75 \%$ tapped (Dienes 2004). The Eastern Siberia-Pacific Ocean pipeline has recently been completed, along with a spur directly into Northern
China. Most significantly, Russia sees its energy sector as a strategic central pillar to its re-establishment as a global economic power (Dienes 2004; Hashim 2010). Thus, it is likely that energy extraction and associated infrastructure will increase.

Communities in the Asian part of DLB are poised between dry and cold weather conditions. Their position is precarious in the face of multiple forces: climatic variations, extremes, and their changes; environmental degradation and loss of ecosystem services; globalization of markets; rapid population growth and changes to demographic structure; out-migration of the young and able segments of society with the subsequent brain drain and remittances to the left-behind families. Rural dryland communities in Central and East Asia face further challenges and opportunities due to the lingering consequences of the institutional upheaval and uncertainty following the end of the Soviet Union, China's market reforms and increasing regional influence of China. The DLB region has a low population, but the population is rapidly increasing. The total population in Central Asia and Mongolia in 1992 was 54.05 million. In 2011, it increased to 67.09 million, a $24.1 \%$ increase over the 20 year period. As might be expected, this population increase is coupled with rapid urbanization, agricultural development, and desertification (caused by heavy grazing) across Central and East Asia. The average regional increase of urban population from 1992 to 2011 was $27.3 \%$ with the largest increases occurring in China and Tajikistan (both of $\sim 50 \%$ ) and the lowest increase occurring in Kazakhstan (6.4\%). In contrast, there is a $10.1 \%$ decrease in urban population in Mongolia.

Along with drastic changes in economics, institution, and governance, land use in the dryland Asia region includes the improvements of major infrastructures, which have facilitated the transition of these nations. An obvious example is the region-wide installation of mobile communication facilities enabling information exchanges for effective and efficient communications. A second major infrastructure improvement is the development of transportation networks including aviation, railways, and highways across the region that enabled more efficient logistics management and distribution of goods within countries as well as trade across countries.

A crucial infrastructure factor in these DLB regions is a rapid rate of urbanization (Koch and Valiyev 2015). In particular, real estate development in the decade of the 2000s has led to major lateral expansion as well as vertical build-up that have transformed small cities into major metropolises. For example, in Kazakhstan, the extent of the Almaty urban agglomeration has increased substantially as observed by the dense sampling method (DSM) (Nghiem et al. 2009) using NASA satellite scatterometer data in 2000-2009 (Fig. 16). With the 


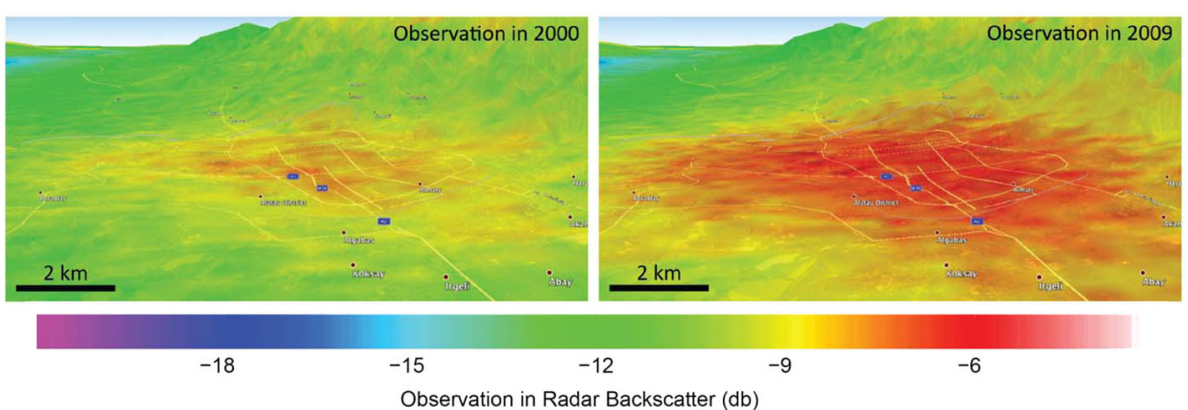

Fig. 16 Almaty urban region in Kazakhstan from DSM satellite observations in 2000 (left) and 2009 (right), translucently draped over 3D topography. Red represents main urban areas, transitioned into orange for urban area with less development, then to yellow for suburban, and finally to green for $\mathrm{rural} /$ natural/wilderness areas. Blue indicates surface water (lakes, reservoirs, etc.). Astounding expansion of the Almaty urban extent occurred between 2000 and 2009

capability to track urban change in three dimensions (Nghiem and Small 2016), DSM results also reveal the significant vertical build-up as observed in the Almaty urban core area with a fast growth rate of approximately $7 \%$ per year in terms of the total volume of building structures in the 2000s (Fig. 17). Such an overheated urbanization rate may result in an excessive building supply that surpasses the building occupancy rate and thereby may turn the real estate boom into a bust.

In Northern China, tremendous urban development quadrupled Beijing urban extent observed by DSM in the 2000s and brought along severe air pollution as a consequence (Jacobson et al. 2015). Similarly, in the
DLB cities such as the complex of Xiangfang, Nangang, and Harbin have experienced multi-fold lateral expansion and significant vertical build up shrouded in smog due to soaring air pollution from coal combustion and the petrochemical industry (Huang et al. 2016). Mongolia has also undergone rapid urbanization similar to that of many cities in Northern China, resulting in serious air pollution problems caused by automobiles and industrialization (Batmunkh et al. 2013). In any case, the rapid urban transformation exerts a high demand for rapid infrastructure development, such as road networks not only for intra-urban but also for inter-urban connectivity to support the commercial and industrial activities for the increasing population.

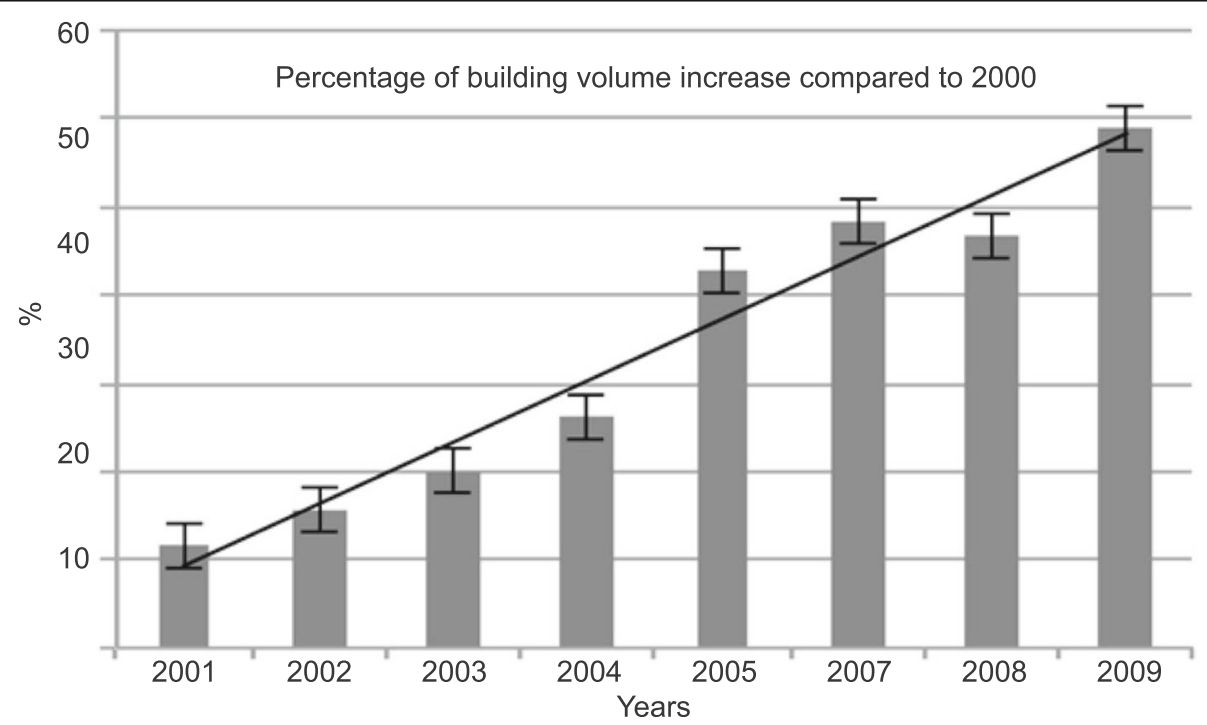

Fig. 17 Dramatic increase in the total building volume corresponding to the real estate boom since 2000 in an area of $\sim 6 \mathrm{~km}^{2}$ centered in the urban extent of Almaty in 2009 seen in red in the right panel of Fig. 16. Error bars show the accuracy of regional averaged values (columns) and incorporate together errors of the observation and area-averaging methods used. The linear trend line indicates the mean rate of the building volume increase during the study period and its comparison with error bars shows that the changes are clearly seen beyond the noise generated by observations and the averaging procedure 
Complex interactions among a rapidly changing climate and the continuously evolving social, economic, and political systems in Northern Eurasia require an integrative approach for studying the cumulative effects of infrastructure and climate change on high-latitude social-economic and natural systems. This research should focus on assessing the vulnerability of communities, industries, and ecosystems and should aim at developing adaptation and mitigation strategies and plans for the sustainable development of the Arctic infrastructure. The high latitudes of Eurasia, the largest and most dynamically complex northern region, can serve as a basis for developing effective climate mitigation policies and adaptation measures for global circumpolar north. The observed disparity of changes among the DLB countries hints that the socioeconomic factors define the resilience of these countries to ongoing changes and not so much the climatic factors.

\section{Research focus 8: societal feedbacks in response to environmental changes}

In the distant past, humans reacted to environmental changes passively-they migrated away from environments that became adverse or unsustainable. Nowadays, many societies are equipped with tools and resources to withstand the negative consequences of environment change, to some extent. Common approaches to addressing adverse environmental changes include irrigation, construction of dams and dikes, diversion of water streams, large-scale geo-engineering projects (e.g., reforestation), mandatory ecological standards to curb pollution, more effective agronomic practices and robust crops, new construction codes, and the application of ecological expertise to each new large development.

Planning is also now beginning to be practiced to reduce the adverse impact of disasters associated with environmental changes and to increase the resilience of the communities at risk. Implementation of these activities has associated costs and requires careful planning based upon numerical experiments with models that realistically describe processes of environmental changes in all their complexity and interactions. It should also consider disruptive effects of environmental hazards given the uncertainty of the future environment state and the trend of increasing frequency of loss events and damage produced by disasters and creeping environmental crises globally (Fig. 18) and also regionally (Porfiriev 2001, 2016). The need for a suite of such models is more urgent when the risks of negative consequences of environmental change are higher (Porfiriev 2012, 2013, 2014).

Human activities have been the drivers of certain ongoing environmental changes. It is important to recognize the loop: societal feedbacks in response to these changes may facilitate the recurrence of disasters or cause a second cycle of inadvertent environmental change if the response misses the target or is illdesigned. For instance, reforestation may cause more intense rainfall and dykes may increase flood peaks. Curbing industrial development may negatively impact human well-being and overall societal resilience. This means that studies of the impact of environmental changes on societies and the development of adaptation and mitigation measures in response to their detrimental consequences should be accompanied by thorough assessments of the "end state" resulting from the environmental changes and the actual and projected societal response to these changes. This can be implemented only by mainstreaming all these kinds of impacts and feedbacks into comprehensive Earth system and integrated assessment models (see the next section of this paper).

\section{Research focus 9: quantification of the role of Northern Eurasia in the global earth and socioeconomic system} Northern Eurasia is a key part of the global Earth and socioeconomic systems. It occupies a substantial portion of the land surface of the Earth (19\%) and 60\% of land surface north of $40^{\circ} \mathrm{N}$. Northern Eurasia is where some of the largest climatic, environmental, and socioeconomic changes have occurred during the past century. In many aspects, changes here presage the rates of global change including global temperature rise (cf., Fig. 3 versus Fig. 2). The strength of the snow covertemperature biogeophysical feedback, biogeochemical feedback due to depletion of the surface and upper soil layer carbon and frozen ice storages (Fig. 7; Romanovsky et al. 2010, 2010; Schepaschenko et al. 2013; Shakhova et al. 2015), atmospheric dust load from extensive DLB desert areas (Lioubimtseva and Henebry 2009, Sokolik 2013; Sokolik et al. 2013), and atmospheric pollution from industrial development (Lu et al. 2010) and from boreal forest fires (Soja et al. 2007) affect the global climate and environment. Large areas of natural and anthropogenic land cover change are closely related to the interaction of the cryosphere and terrestrial hydrology change (Tchebakova et al. 2009; Zhang et al. 2011, Mátyás and Sun 2014; Fig. 4) with human activities (Qi et al. 2012, 2012; Chen et al. 2013, 2015; Horion et al. 2016, Figs. 12 and 15). The importance of these changes and associated impacts on Northern Eurasia and potential feedbacks to the global Earth and socioeconomic systems may be quantified using models.

\section{Global change modeling for Northern Eurasia}

As discussed in the previous sections, Northern Eurasia is comprised of a complex and diverse set of physical, ecological, climatic, and human regional systems, which 

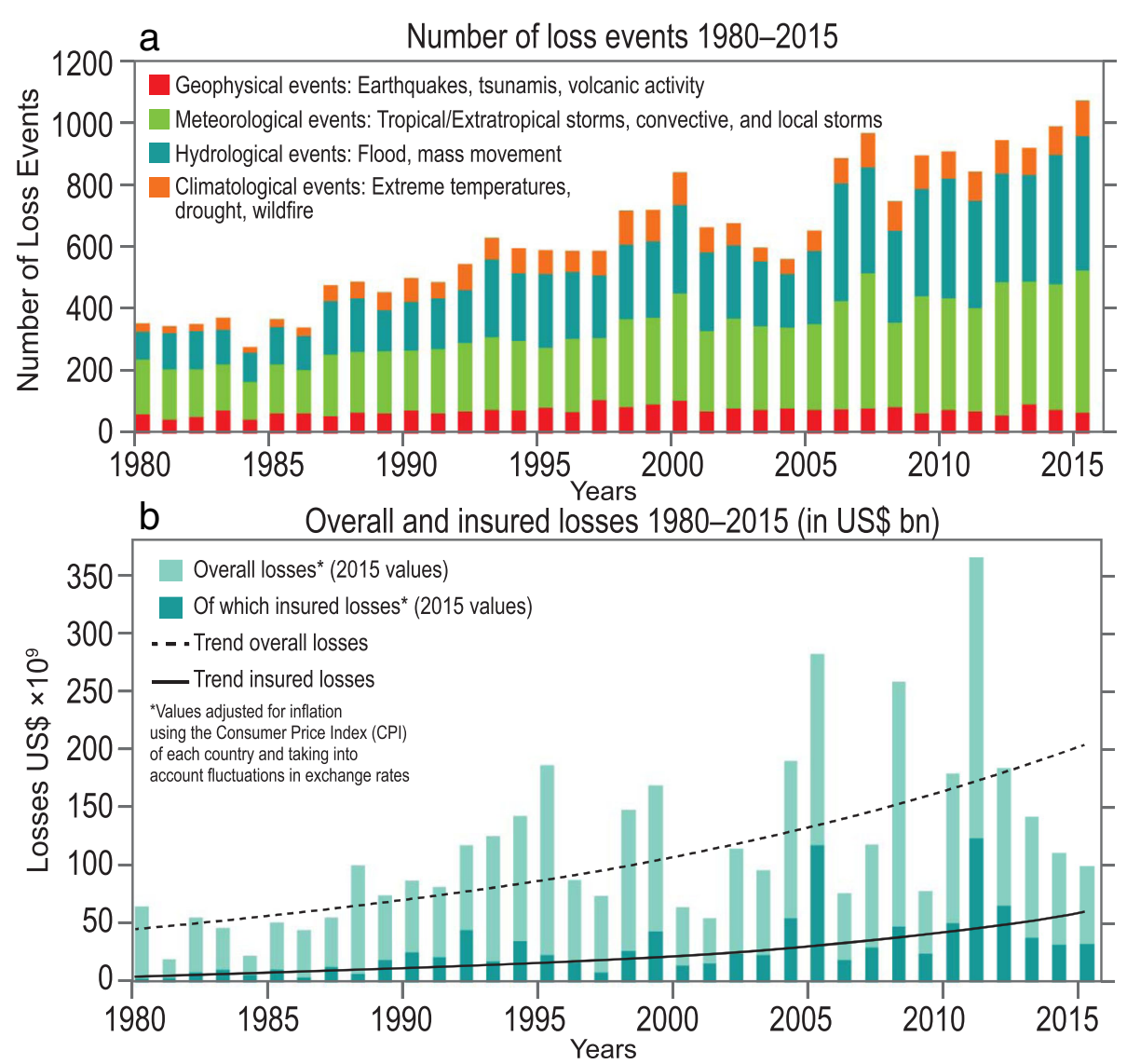

Fig. 18 The frequency (a) of and monetary losses (b) from the major natural and environmental disasters across the globe. Source: Munich Re-insurance NatCatSERVICE (http://www.munichre.com/en/reinsurance/business/non-life/natcatservice/index.html)

interact among themselves and can have potentially important feedbacks on the evolution of the global Earth and human systems. At the same time, the region has experienced dramatic climate, environmental, and socioeconomic changes, which leads us to argue that studying the fate of Northern Eurasia needs to be placed in the context of global change modeling (i.e., the modeling of the coupled human and Earth systems at the global scale) and include interactions with other regions of the globe. In this section, we review past and ongoing modeling studies over Northern Eurasia and provide new approaches for integrated modeling for Northern Eurasia.

\section{Past and ongoing modeling studies over Northern Eurasia}

Many models have been developed and used to study various components of the Earth system with a focus on Northern Eurasia. Monier et al. (2017) provides an overview of recent and ongoing modeling studies over Northern Eurasia and identifies the many ecological and geophysical processes comprising Earth system dynamics (i.e., the hydrological cycle, soil thermal dynamics, wildfires, dust emissions, carbon cycle, terrestrial ecosystem dynamics, climate and weather, sea ice) and the human dimensions (i.e., demography, risk management addressed, agriculture, forestry, water management) addressed by the Northern Eurasia modeling community. Because of the major role of Northern Eurasia in the global land system, they find that most studies focus on the land processes (i.e., land and water carbon cycle, energy balance) or on the fate of the land system under climate change (permafrost thawing, agriculture, wildfire). They also find that most studies focus on a single component of the Earth system, with generally little attention placed on interactions and feedbacks, and with climate change being imposed. Nonetheless, Monier et al. (2017) identify a few studies that try to integrate various aspects of the Earth system, in terms of scale, teleconnection or global feedbacks, and processes, as well as other studies focusing on integrated systems where multiple disciplines overlap, such as modeling studies of water management (Shiklomanov et al. 2013) or land management (Gustafson et al. 2011, 2011; Kuemmerle et al. 2011, 2011, 2014; Lebed et al. 2012; Loboda et al. 2012; Robinson et al. 2013; Shuman et al. 2013a; Blyakharchuk et al. 2014). This growing effort to integrate existing models through scale, processes, and feedback 
has translated into more coordinated and multidisciplinary research projects by NEESPI scientists along with the development and integration of models that can interact with each other, including weather and aerosol physics, permafrost, and terrestrial hydrology with water management, the carbon and water cycles, land carbon and atmospheric transport modeling, and biospheric and climate information (Table 1).
Modeling studies focusing on a specific component of the Earth system have provided valuable insight into processes controlling their behavior and the direct impact of climate change. Meanwhile, more integrated modeling studies have been useful for identifying and quantifying potential interactions and feedbacks among various components of the Earth system and societal activities associated with environmental changes over

Table 1 Non-exhaustive list of modeling studies with a focus on Northern Eurasia. The list is sorted by specific aspects of the Earth and human systems. Some studies are listed under several aspects of the Earth and human systems. From Monier et al. (2017 updated)

\begin{tabular}{|c|c|}
\hline $\begin{array}{l}\text { Specific aspects of the Earth } \\
\text { and human systems }\end{array}$ & References to modeling studies with a focus on Northern Eurasia \\
\hline $\begin{array}{l}\text { Agriculture } \\
\text { (crop modeling, economics) }\end{array}$ & $\begin{array}{l}\text { Dronin and Kirilenko 2010; Gelfan et al. 2012; lizumi and Ramankutty 2016; Magliocca et al. 2013; Peng et al. } 2013 \text {; } \\
\text { Schierhorn et al. 2014, 2014; Tchebakova et al. } 2011\end{array}$ \\
\hline $\begin{array}{l}\text { Air quality } \\
\text { (aerosols, ozone, pollen, dust) }\end{array}$ & $\begin{array}{l}\text { Baklanov et al. 2013; Darmenova et al. 2009; Lu et al. 2010; Siljamo et al. 2013; Sofiev et al. 2013; Soja et al. 2004; } \\
\text { Sokolik et al. 2013; Xi and Sokolik 2015a, 2015b }\end{array}$ \\
\hline Carbon (in land and water) & $\begin{array}{l}\text { Bohn et al. 2013, 2015; Cresto-Aleina et al. 2015; Dargaville et al. 2002, 2002; Dass et al. 2016; Dolman et al. 2012; } \\
\text { Gao et al. 2013; Glagolev et al. 2011; Gustafson et al. 2011; Hayes et al. 2011, 2011, 2014; John et al. 2013; } \\
\text { Kicklighter et al. 2013, 2014; Kim et al. 2011; Koven et al. 2011; Kuemmerle et al. 2011, 2011; Kurganova et al. 2014, 2015; } \\
\text { Lu et al. 2009; McGuire et al. 2010; Mukhortova et al. 2015; Narayan et al. 2007; Olchev et al. 2009, 2013; Rawlins et al. 2015; } \\
\text { Rossini et al. 2014; Sabrekov et al. 2014, 2016; Saeki et al. 2013; Schaphoff et al. 2015; Schierhorn et al. 2013; } \\
\text { Schulze et al. 2012; Shakhova et al. 2013, 2015; Shuman and Shugart 2009; Shuman et al. 2013a; Yue et al. 2016; } \\
\text { Zhang et al. 2012b; Zhao et al. 2009; Zhu et al. 2013, 2014; Zhu and Zhuang 2013; Zhuang et al. 2013 }\end{array}$ \\
\hline
\end{tabular}

Climate

Anisimov et al. 2013; Arzhanov et al. 2012, 2012; Miao et al. 2014; Monier et al. 2013; Onuchin et al. 2014; Shahgedanova et al. 2010; Shkolnik and Efimov 2013; Volodin 2013; Volodin et al. 2013; Zuev et al. 2012

Cryosphere

(snow, glaciers, sea ice)

Demography

Energy balance

Hydrological cycle

Land-use change

Infrastructure

Nitrogen

Permafrost

Terrestrial ecosystems characteristics

Vegetation shifts

Weather

(i.e., extreme events)

Wildfire
Callaghan et al. 2011a, 2011b; Farinotti et al. 2015; Hagg et al. 2006; Klehmet et al. 2013; Loranty et al. 2014; Mokhov et al. 2013; Pieczonka and Bolch 2015; Shahgedanova et al. 2010; Shakhova et al. 2015; Sokratov and Shmakin 2013; Sorg et al. 2012

Heleniak 2015

Brovkin et al. 2006; Gálos et al. 2013; Loranty et al. 2014; Olchev et al. 2009; Oltchev et al. 2002; Tchebakova et al. 2012

Bowling and Lettenmaier 2010; Cresto-Aleina et al. 2015; Gelfan 2011; Georgiadi et al. 2010, 2014a; Hagg et al. 2006; Karthe et al. 2015; Khon and Mokhov 2012; Kicklighter et al. 2013; Klehmet et al. 2013; Kuchment et al. 2011; Liu et al. 2013, 2014, 2015; McClelland et al. 2004; Motovilov and Gelfan 2013; Novenko and Olchev 2015; Olchev et al. 2009, 2013; Oltchev et al. 2002, 2002; Osadchiev 2015; Rawlins et al. 2010; Serreze et al. 2006; Shiklomanov et al. 2013; Shiklomanov and Lammers 2013; Shkolnik et al. 2017; Sorg et al. 2012; Streletskiy et al. 2015; Troy et al. 2012; Zhang et al. 2011

Blyakharchuk et al. 2014; Chen et al. 2017; Griffiths et al. 2013; Gustafson et al. 2011; Hayes et al. 2011; Hitztaler and Bergen 2013; Kicklighter et al. 2014; Kraemer et al. 2015; Kuemmerle et al. 2009; Meyfroidt et al. 2016; Peterson et al. 2009; Prishchepov et al. 2013, 2017; Robinson et al. 2013; Schierhorn et al. 2013, 2014, 2014; Smaliychuk et al. 2016; Zhang et al. 2015

Shiklomanov and Streletskiy 2013; Shiklomanov et al. 2017; Stephenson et al. 2011; Streletskiy et al. 2012 Kopáček et al. 2012; Kopáček and Posch 2011; Oulehle et al. 2012; Zhu and Zhuang 2013; Zhuang et al. 2013

Euskirchen et al. 2006; Gao et al. 2013; Gouttevin et al. 2012; Hayes et al. 2014; MacDougall and Knutti 2016; Marchenko et al. 2007; Shakhova et al. 2013, 2015; Shkolnik et al. 2012; Streletskiy et al. 2012, 2015; Zhang et al. 2011

Cresto-Aleina et al. 2013; Kopačková et al. 2014, 2015; Lapenis et al. 2005; Lebed et al. 2012; Li et al. 2016; Shuman et al. 2013a, 2013b; Shuman and Shugart 2012; Ziółkowska et al. 2014

Gustafson et al. 2011; Jiang et al. 2012, 2016; Khvostikov et al. 2015; Kicklighter et al. 2014; Li et al. 2014; Macias-Fauria et al. 2012; Novenko et al. 2014; Schaphoff et al. 2015; Shuman et al. 2015; Soja et al. 2007; Tchebakova et al. 2009, 2010, 2016, 2016; Tchebakova and Parfenova 2012; Velichko et al. 2004

Barriopedro et al. 2011; Meredith et al. 2015; Mokhov et al. 2013; Schubert et al. 2014; Shkolnik et al. 2012

Balshi et al. 2007; Dubinin et al. 2011; Gustafson et al. 2011; Kantzas et al. 2013; Loboda and Csiszar 2007; Malevsky-Malevich et al. 2008; Narayan et al. 2007; Park and Sokolik 2016; Schulze et al. 2012; Soja et al. 2004; Tchebakova et al. 2009, 2012; Vasileva and Moiseenko 2013 
Northern Eurasia. However, most studies of climate change impacts rely on standard socio-economic and climate change scenarios, thus limiting the possibility of conducting integrated studies. A common experimental design for these studies is to prescribe climate change and to examine the varied response of a particular component of the Earth system (Rosenzweig et al. 2014). In such an approach, many potential global and regional feedbacks that can have major implications for the climate system, both in Northern Eurasia and globally, are overlooked. The development of effective climate mitigation and adaptation strategies for Northern Eurasia depends on understanding how environmental conditions may evolve in the region within the context of global change, including the influence of feedbacks and potential thresholds (i.e., "tipping points"). Fortunately, modeling frameworks have already been developed to study these issues (see the next section), and they could be improved to better represent the important aspects of the Earth system that are unique to Northern Eurasia.

New approaches to integrated modeling for Northern Eurasia Earth System Models (ESMs; Brovkin et al. 2006, 2013; Friedlingstein et al. 2006; Arora et al. 2013; Eby et al. 2013; Zickfeld et al. 2013; Koven et al. 2015; Zaehle et al. 2015) have been developed by coupling together unique Earth system component models (e.g., atmosphere, land, cryosphere, oceans). These provide an ideal modeling framework to investigate interactions and feedbacks among these components as well as the impact of changes in Northern Eurasia on the global Earth system. For example, in an ESM, carbon emissions from land-use change in Northern Eurasia may increase atmospheric carbon dioxide concentrations to influence climate, the uptake of atmospheric carbon dioxide by oceans to influence ocean acidification, and the uptake of atmospheric carbon dioxide by land vegetation in the future. ESMs provide tools to investigate the response of the system to changes in external forcings that not only affect each of the components individually but also the interactions among them. For example, climate change impacts cannot be examined without considering the role of human activity. In current ESMs, however, there is a simple representation of the influence of human activity on earth system components. Anthropogenic effects related to industrial, residential, and agricultural activities may be represented by simply prescribing an input of greenhouse gases into the atmosphere. More sophisticated ESMs might also use prescribed changes in land use across the globe to simulate the effects of spatial and temporal variations in albedo, sensible and latent heat fluxes, and greenhouse gas fluxes on regional and global energy budgets. In these ESM studies, the simulated human activity is determined solely by prescribed policies without any consideration about how feedbacks from changing environmental conditions might modify these activities in the future. For example, the land use change prescribed in CMIP5 simulations is driven solely by socio-economic considerations and does not account for climate change impacts on land productivity (Hurtt et al. 2011).

Because ecological and social systems are interdependent and constantly co-evolving, their non-linear behavior is difficult to predict. Taking into account that human well-being and ecosystem integrity are fundamentally linked, these processes must be managed in a way that implies balancing economic capacity, environmental integrity, and resilience to future changes (Jones et al. 2013; DeLucia 2015). For this reason, another major effort has been put into the linkage between models of human activity, including the global economy, global trade, demography, technologies, and user preferences-which are essential to study the potential impacts of humans on the environment-and models of the physical climate system, generally simplified compared to ESMs. These models are known as integrated assessment models and allow economic decisions to respond to changing environmental conditions to support mitigation and adaptation efforts (IAMs; Rotmans et al. 1990; Alcamo et al. 1994; Weyant et al. 1996; Prinn et al. 1999; Sokolov et al. 2005, 2009; van Vuuren et al. 2006, 2007; Riahi et al. 2007; Hijioka et al. 2008; Melillo et al. 2009, 2016; Wise et al. 2009; Reilly et al. 2012; Hallgren et al. 2013; Prinn 2013; Nelson et al. 2014, 2014; Sue Wing et al. 2015).

IAMs have been at the core of the Representative Concentration Pathways (RCPs, van Vuuren et al. 2011), a set of socio-economic and emission scenarios, including socio-economic change, technological change, energy and land use, and emissions of greenhouse gases and air pollutants, developed for the climate modeling community in support of the IPCC AR5.

More recently, major efforts have focused on developing models with a detailed representation of all components of the coupled Human-Earth system, by coupling IAMs with ESMs, or essentially replacing the simplified representation of the climate system in IAMs with ESMs. Such models can provide novel insights into the complex issue of global change by accounting for an exhaustive number of feedbacks among the components of the Earth system and of the human system.

Figure 19 shows an example of a coupled humanEarth system model, with three pathways for feedbacks between the two systems. The first pathway includes the human activity model providing emissions of greenhouse gases, aerosols, and other precursors of atmospheric pollution, thus providing the footprint for both future climate change and air quality, with a feedback on the human system through health impacts. The second 


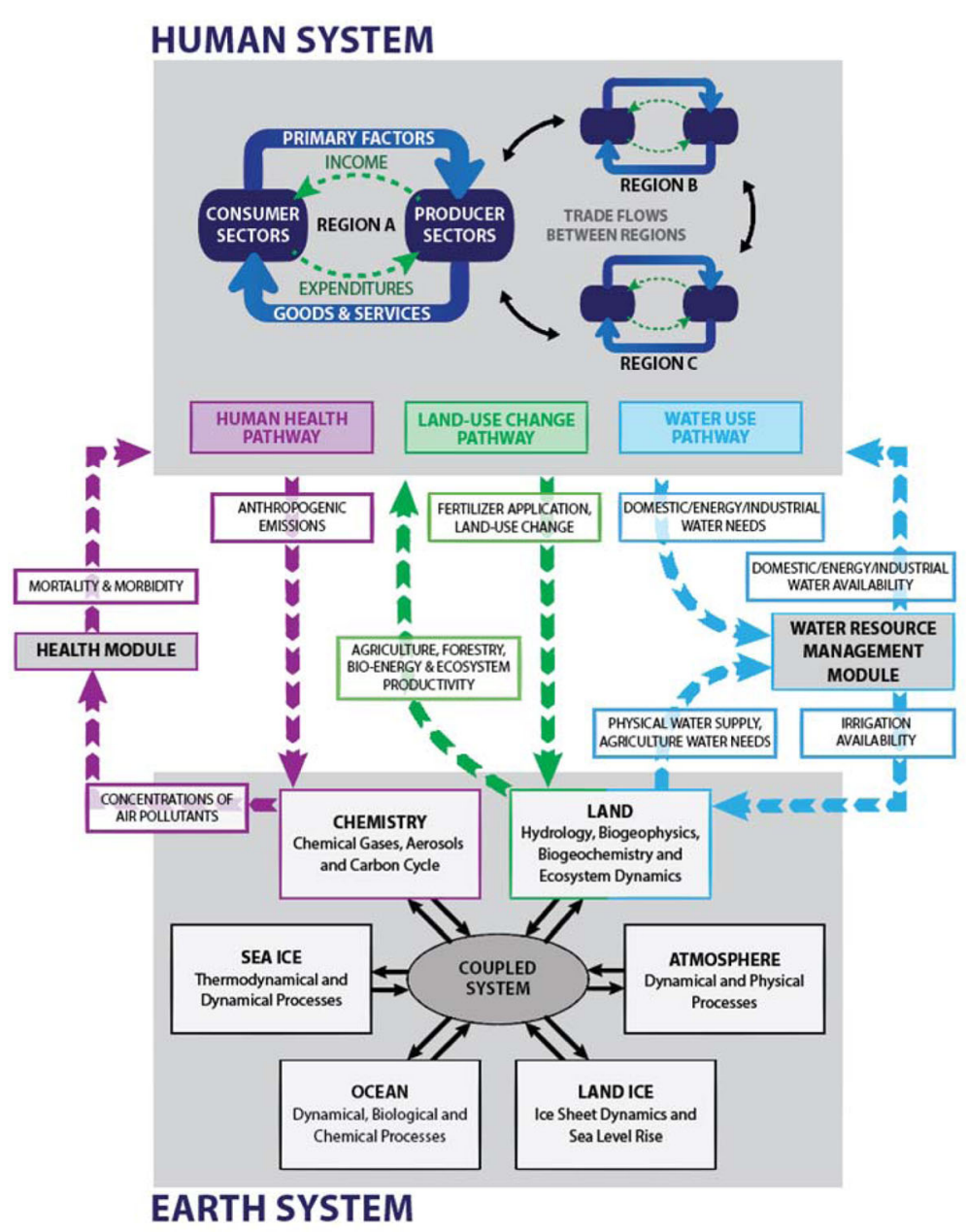

Fig. 19 An example schematic of an integrated assessment model (IAM) that couples a human activity model and an Earth system model (ESM) with a focus on three feedback pathways: health, land use change, and water resources (from Monier et al. 2017). See text for details

pathway centers on land, with the human activity model making decisions on land use change based on natural ecosystem productivity and crop yield. Finally, the third pathway centers on water, with the Earth system model computing basin-wide geophysical water resources and the irrigation demand from crops, and the human system model making economically based decisions on water availability for irrigation, with competition from municipal and energy use. The global and regional climate would in turn be affected by land use and land cover change and irrigation, through both emissions of greenhouse gases, changes in albedo and in the hydrological cycle.

At the frontier of integrated assessment modeling, a number of issues have emerged that can be better examined with the ongoing development of coupled humanEarth system models for Northern Eurasia (Monier et al. 2017) and include the following:

- The food-energy-water (FEW) nexus. While the FEW is a global issue and major efforts are underway to improve its representation in models of the coupled human-Earth system, it also has unique characteristics over Northern Eurasia that require specific improvements for such models to be useful, including thermokarst dynamics, permafrost degradation, scarcity of human infrastructure, varied levels of agricultural development and management practices, locally diverse hydrological conditions associated with complex biomes, and climate interactions.

- The air quality and health nexus. In addition to the traditional anthropogenic precursor emissions associated with the industry, energy and transportation sectors, or biogenic emissions of precursors, Northern Eurasia experiences varied and complex sources of air pollution, including wildfires, crop residue burning, and dust. Accounting for these sources of pollutants, specific to Northern Eurasia, along with the transport of pollutants to and from surrounding countries, to quantify the 
economic impact of future changes in air pollution in the region can prove key to accurately inform policy responses for Northern Eurasia.

- The new transnationalism of natural resources. The more porous international borders that have emerged after the dissolution of the former Soviet Bloc have considerable implications for Northern Eurasia's natural resources. In particular, forest resources, but also oil and gas, are at the nexus of regional demand due to uneven distributions within the countries of Northern Eurasia. Understanding and developing levels of sustainable use will have implications ranging from local human livelihoods to the global carbon budget. Integrated models will need to include local, regional and, now, even international drivers and consequences of these coupled human-natural systems pertaining to natural resources.

- The opening of new Arctic trade routes. New trade routes emerging as the result of the shrinking of Arctic sea ice extent could result in the ability of the timber industry and energy exploration to reach remote areas like Siberia. The development of infrastructures to respond to these new economic opportunities, including potential population migration within Northern Eurasia and from neighboring regions, will face challenges such as with climate-driven permafrost degradation or the disappearance of temporary roads constructed over frozen lakes and rivers. Investigating the fate of Northern Eurasia as these new trade routes emerge will require a detailed regional coupled human-Earth system model.

As with any model activity, the representation of interactions and feedbacks among Earth system components and societal activities in Northern Eurasia can be improved within models, in order for these models to address such emerging issues. Insights gained from previous and ongoing efforts by the NEESPI/NEFI research community, such as those on the unique features and processes of Northern Eurasia described above, could be incorporated to guide these model improvements to create a new generation of coupled humanEarth system models to study the role of Northern Eurasia on global change. For example, most ESMs do not have a representation of permafrost dynamics, which is important for Northern Eurasia as the presence of permafrost affects the availability of soil moisture and the timing and magnitude of runoff (which are important for the FEW nexus), the ability to support buildings and other infrastructure (which is important for the socio-economic development of remote regions in
Siberia as Arctic trade routes open up after the sea ice retreat), and vegetation primary production rates and decomposition rates of organic matter (which influence the ability of the landscape to provide food, energy, and timber and impact the timing, extent, and severity of wildfires, which in turn, impact air quality and health). In addition, the degradation of permafrost might also be associated with several important tipping points including those related to water availability and the release of land carbon to the atmosphere. The representation of permafrost dynamics in ESMs could strongly benefit from an improved representation of soil thermal dynamics, as influenced by water, ice, organic matter and soil texture in the soil profile, and of the surface insulating layer and its modification by snow cover, moss, litter, or wildfires. Furthermore, we suggest that to improve key processes relevant to Northern Eurasia in ESM and IAM, like permafrost degradation, a stronger involvement of the Northern Eurasia modeling community and local stakeholders is needed.

\section{Conclusions}

The major goal of this paper is to introduce the reader to the present challenges in Northern Eurasia and to outline the pathways forward to address these challenges in the coming decades. In doing so, we have provided the reader with a sample of exemplars of NEESPI's accomplishments. The science questions of the "Northern Eurasia Future Initiative" or NEFI derive from an urgent need to incorporate and expand our knowledge of the consequences of human and social dimensions in assessing current and future change in Northern Eurasia. Across this region, the future strongly depends upon this incorporation and the amelioration of environmental change, the effects of these changes on human societies, and bridging the considerable gaps in research procedures, capacity for prediction, and in time- and space-scales that complicate the integration of human dynamics with environmental dynamics.

When the embryonic NEESPI project began over a decade ago, there were concerns that a program spanning Eurasia involving scientists from multiple disciplines based in a score of nations with complex and sometimes opposing diplomatic missions could have been a failure. However, there were several significant factors that brightened and opposed such a dark forecast. Truly, interdisciplinary interactions among engaged scientists who tackled a shared problem are a remarkable glue for holding research projects together, and they proved that creativity can prosper in "bottom-up" research programs. The role of Northern Eurasia as a recipient and generator of planetary climatic change is an important "big question" that captures the imagination 
of many scientists and transcends disciplines, cultures, languages, and national politics. It is also a challenge whose unraveling requires teams working together openly in earnest and in good faith. The consequences of environmental and socio-economic change in Northern Eurasia that may spread well beyond its boundaries have been simply too dire to leave them unstudied and, generally speaking, unknown. NEESPI was born to reverse the situation by elucidating both negative and beneficial aspects of these changes to inform societies and, thus, better prepare them for resilient future development. An objective of NEFI is that this development must now be secured by science-based strategies provided to regional decision-makers at different levels that will lead their societies to prosperity.

Northern Eurasia has undergone significant environmental change, having experienced warming in the past few decades that already exceeds the 1.5 to $2.0{ }^{\circ} \mathrm{C}$ warming limits adopted as a target at the United Nations Climate Change Conference (30 November-12 December 2015, Paris, France). Several aspects of this warming are manifested in changes in the regional energy and hydrological cycles, which affect and interact with the biosphere and with socio-economic activities. These changes are multifaceted. Some of them seem and are inevitable (e.g., ecosystems' shift, glacial retreat and permafrost thawing, increased fire regimes, the new state of the regional environment); however, it is imperative they are acknowledged and comprehended. Some of these changes, particularly if their consequences are adverse for human well-being, can be reversed, moderated, or mitigated-hopefully to levels that will completely or substantially negate their undesirable impacts. These latter instances include proactive and sometimes quite expensive interventions in water management, forestry and agricultural practices, environmental protection, infrastructure and urban planning, and resource consumption. In any case, the scientist's duty is to propose and justify strategies for resilient future development in the region. "To justify" is a key word here. Scientists must strive to know the Earth system in its functional entirety to develop the tools necessary to project the future state in response to natural and societal impacts, as well as to estimate the overall consequences of the realization of these scenarios on human wellbeing.

To these ends, we have formulated three major science questions to be answered by NEFI:

1) How can we quantify and project ecosystem dynamics in Northern Eurasia when these dynamics may be internally unstable, are controlled by components that have been systematically changing, and have a potential to impact the global Earth system with unprecedented rates of change over the next few decades?

2) What are the major drivers of the ongoing and future changes in the water cycles of Northern Eurasia and how will their changes affect regional ecosystems and societies, and feedback to the Earth system and global economy?

3) How can the sustainable development of societies of Northern Eurasia be secured in the near future by overcoming the 'transitional' nature of their economics, environmental and climatic change challenges, and by disentangling restrictive institutional legacies?

To address these science questions, nine research foci are identified and their selection has been briefly justified in this paper. These research foci are (1) global change influence, particularly warming in the Arctic; (2) increasing frequency and intensity of extremes and changes in the spatial and temporal distributions of inclement weather conditions; (3) retreat of the cryosphere; (4) changes in the terrestrial water cycle; (5) changes in the biosphere; (6) pressures on agriculture and pastoral production; (7) changes in infrastructure; (8) societal actions to mitigate the negative consequences of environmental change and to benefit from the positive consequences; and (9) quantification of the role of Northern Eurasia in the global Earth and socioeconomic systems to advance research tools with an emphasis on observations and models. The socio-economic research challenges are integral to and a top priority for these research foci.

Taking into account the numerous powerful feedbacks between the Earth and human systems in Northern Eurasia, we propose to employ integrated assessment models (IAMs) at the final stage of this global change assessment. The purpose of these IAMs is to couple Earth system component models with the result being a functioning integrated Earth system model. Simultaneously, models of the human system that represent the global economy, global trade, demography, technologies, and user preferences will be incorporated. These will provide support to economic and societal decisionmakers, so they are able to thoughtfully respond to changing environmental conditions to support mitigation and adaptation efforts. Development of IAMs which include detailed representation of all components of the human-Earth coupled system to account for the exhaustive number of feedbacks among these components is the overarching goal of NEFI global change research. These models will provide information and guidance to decision-makers in their efforts to secure sustainable and prosperous societal development and resiliencebased ecosystem stewardship in Northern Eurasia. 
Finally, Northern Eurasia presents a range of complex human and environmental systems varying from modern industrial societies to traditional indigenous cultures, all undergoing significant social and environmental change. Certainly, the continuing transformation of the former USSR, China, Mongolia, and Eastern Europe represents one of the largest and most profound social changes of recent decades. Through NEFI, the work in Northern Eurasia is moving to more effectively address shared goals with interdisciplinary programs at the global level. The research record that will stand as the basis from which to launch NEFI is a logical consequence of the accomplishments of NEESPI. This situation and the need for progress is critical. Now is the time to press forward with this opportunity. The challenge lies before us.

\section{Abbreviations}

ACIA: Arctic Climate Impact Assessment; AMAP: Arctic Monitoring and Assessment Programme; AR5: The Fifth IPCC Assessment Report; BP: Before present; CGCM3.1: Canadian Centre for Climate Modeling and Analysis Model, 3rd version; CMIP5: Coupled Model Intercomparison Project Phase 5; DLB: Dry land belt of Northern Eurasia; DSM: Dense sampling method; ERA-interim: Global atmospheric reanalysis developed at the European Centre for Medium-Range Weather Forecasts; ESM: Earth system model; GCM: Global climate model; GHG: Greenhouse gases; GLABTOP2: Glacier base topography model, 2nd version; GPR: Ground-penetrating radar; GRACE: Gravity Recovery Satellite Experiment; GTN-P: Global Terrestrial Network for Permafrost; GTOS: Global Terrestrial Observing System; HadCM3: UK Hadley Centre Climate Model, 3rd version; IAM: Integrated assessment model; ICSU: International Council for Science Union; IPCC: Intergovernmental Panel on Climate Change; IPCLCM4: Institute Pierre Simon Laplace Climate Model, 4th version; LC/LU: Land cover/land use; LCLUC: Land cover and land use change; MODIS: Moderate resolution imaging spectroradiometer; NEESPI: Northern Eurasia Earth Science Partnership Initiative; NEFI: Northern Eurasia Future Initiative; RFE: Russian Far East; RubCliM: Large-scale bioclimatic envelope model; SibCliM: Siberian bioclimatic model; SIE: Sea ice extent; WMO: World Meteorological Organization

\section{Acknowledgements}

All authors of this paper are also the authors and the members of the NEFI Science Plan Preparation Team. Other Members of the NEFI Science Plan Preparation Team are the following:

Elena Parfenova, Russia; Daniel Brown, USA; Yizhao Chen, China; Alexander Georgiadi, Russia; Vladimir Gershenzon, Russia; Evgeny Gordov, Russia; Serguei Ivanov, Ukraine; Martin Kappas, Germany; Julia Kurbatova, Russia; Richard Lawford, USA; Guoping Lei, China; Sergey Marchenko, USA; Alexander Olchev, Russia; Irina Danilovich, Belarus; Vladimir Romanovsky, USA; Dmitry Schepaschenko, Austria; Andrei Sokolov, USA; Dmitry Streletskiy, USA; Margarita Syromyatina, Russia; Natalia Tilinina, Russia; Xiaoping Xin, China; Panmao Zhai, China; Tatiana Blyaharchuk, Russia; Lin Zhen, China. Special credit to Alan Cantin, Canadian Forest Service, Natural Resources Canada, who prepared climate change scenarios used in biosphere model simulations for Fig. 4 of this paper and Deborah Misch, Telesolv Consulting, USA for preparation of high quality figures of this paper.

\section{Funding}

Support for most of the US authors and contributors of this paper as well as the multiannual support for the office of the NEESPI Project Scientist was provided by the NASA Land Cover and Land Use Change (LCLUC) Program, in particular, by grants NNX13AC66G, NNX11AB77G, NNX13AN58G, NNX15AD10G, NAG5-11084, 08-LCLUC08-2-0003, NNX14AD88G, NNX08AW51G, NNX12AD34G, NNX14AD91G, and NNX15AP81G. The research carried out at the Jet Propulsion Laboratory, California Institute of Technology, was also supported by the NASA LCLUC Program. Support of NASA grants 08-TE08-029 and NNH09ZDA001N-IDS for AS and NT are acknowledged. Research of MS is supported by Newton-al-Farabi Fund (grant 172722855). Grant 14.B25.31.0026 of the Ministry of Education and Science of the Russian Federation provided support to PG, SG, NT, AS, OB, BP, and IP for their work conducted at the P.P.
Shirshov Institute of Oceanology. The Project "ARCTIC-ERA: ARCTIC climate change and its impact on Environment, infrastructures, and Resource Availability" sponsored by: ANR (France), RFBR (Russia), and the US NSF (grants 1717770 and 1558389) in response to Belmont Forum Collaborative Research Action on Arctic Observing and Research for Sustainability provided support for $\mathrm{OZ}, \mathrm{SG}, \mathrm{BP}, \mathrm{PG}$, and NS. A part of the paper is based on the research carried out with the financial support of the Russian Foundation for Basic Research (Project No. 15-06-08163 "Assessment and forecast of the socioeconomic and environmental implications of the climate change in the Arctic region"). Support for AP is provided by the Russian Government Program of Competitive Growth of Kazan Federal University (OpenLab Initiative). Support for JA is provided by grant NPUILO1417 of the Ministry of Education, Youth and Sports of Czechia.

\section{Authors' contributions}

PG, HS, GG, SM, and SG proposed the topic, conceived, and designed this overview. They wrote the "Introduction" part of the manuscript. Other major contributors to the Introduction Section are NS, ASo, and JQ. Major contributors to section on "Three unique features of Northern Eurasia of global concern and their related major science questions" are PG, NT, JQ, HS, $\mathrm{NS}, \mathrm{GH}, \mathrm{KB}, \mathrm{TL}, \mathrm{AP}$, and DK. Each author of the paper has contributed to the "Major research foci" section of the paper. EM and DK are the major contributors to section devoted to "Global change modeling in Northern Eurasia" of the paper. HS and PG were the major contributors to the "Conclusions" section. All authors read and approved the final manuscript. All Authors suggested numerous editorial corrections to the manuscript. In addition to scientific contributions, the language editorial service was provided by the authors, who are the native English speakers: $\mathrm{HS}, \mathrm{DK}, \mathrm{GH}$, $\mathrm{KB}, \mathrm{KdB}, \mathrm{ASo}$, and $\mathrm{JM}$.

\section{Authors' information}

All authors and contributors of this paper are the members of the Northern Eurasia Earth Science Partnership Initiative (NEESPI) and the Northern Eurasia Future Initiative (NEFI) (http://neespi.org).

\section{Competing interests}

The authors declare that they have no competing interest.

\section{Publisher's Note}

Springer Nature remains neutral with regard to jurisdictional claims in published maps and institutional affiliations.

\section{Author details}

${ }^{1}$ NEESPI Project Scientist, NC State University Research Scholar, at at NOAA National Centers for Environment Information, Federal Building, 151 Patton Avenue, Asheville, NC 28801, USA. ²Department Environmental Sciences, University of Virginia, 291 McCormick Drive, Charlottesville, Virginia 22904-4123, USA. ${ }^{3}$ The Ecosystems Center, Marine Biological Laboratory, Woods Hole, MA 02543, USA. ${ }^{4}$ Geospatial Sciences Center of Excellence, South Dakota State University, 1021 Medary Avenue, Wecota Hall 506B, Brookings, SD 57007-3510, USA. ${ }^{5}$ Sukachev Institute of Forest, SB RAS-Federal Research Center "Krasnoyarsk Science Center SB RAS", 50/28

Akademgorodok, Krasnoyarsk 660036, Russia. ${ }^{6}$ National Institute for Environmental Studies, 16-2 Onogawa, Tsukuba, Ibaraki 305-8506, Japan. ${ }^{7}$ Joint Program of the Science and Policy of Global Change, Massachusetts Institute of Technology, Cambridge, MA 02139-4307, USA. ${ }^{\circ}$ NASA Headquarters, The NASA Land-Cover/Land-Use Change Program, Mail Suite 3B74, Room 3Y77, 300 E Street, SW, Washington, DC 20546, USA. ${ }^{9}$ P.P. Shirshov Institute of Oceanology, RAS, 36 Nakhimovsky Ave, 117218 Moscow, Russia. ${ }^{10}$ Department of Geography, Michigan State University, 673 Auditorium Rd, East Lansing, MI 48824, USA. " 1 Department Geosciences and Natural Resource Management, Section of Geography, University of Copenhagen, Øster Voldgade 10, 1350 København K, Denmark. ${ }^{12}$ Institute for Economic Forecasting, RAS, 47 Nakhimovsky Ave, 117418 Moscow, Russia. ${ }^{13}$ Earth Systems Research Center, University of New Hampshire, Morse Hall, 8 College Rd, Rm. 21, Durham, NH 03824, USA. ${ }^{14}$ Department Geographical Sciences, University of Maryland-College Park, 1121 LeFrak Hall, 7251 Preinkert Drive, College Park, MD 20742, USA. ${ }^{15}$ Department of Geography, George Washington University, Old Main Bldg, 1922 F Street, NW, Washington, DC 20052, USA. ${ }^{16}$ Jet Propulsion Laboratory, California Institute of Technology, MS 300-235, 4800 Oak Grove Drive, Pasadena, CA 91109, USA. 
${ }^{17}$ School of Natural Resources and Environment, University of Michigan, 440 Church St, Ann Arbor, MI 48109, USA. ${ }^{18}$ Department of Experimental Plant Biology, Faculty of Science, Charles University in Prague, Vinicna 5, 12844 Prague, Czechia. ${ }^{19} \mathrm{Center}$ for Global Change and Earth Observations, Michigan State University, 1405 S. Harrison Road, East Lansing, MI 48823, USA. ${ }^{20}$ Department of Geography and Environmental Science, The University of Reading, Whiteknights, Reading RG6 6AB, UK. ${ }^{21}$ Ecosystems Services and Management Program, International Institute for Applied Systems Analysis (IIASA), Schlossplatz 1, A-2361 Laxenburg, Austria. ${ }^{22}$ State Hydrological Institute, 2nd Lane, Basil Island, St. Petersburg 199053, Russia. ${ }^{23}$ National Institute of Aerospace, NASA Langley Research Center, 21 Langley Boulevard, MS 420, Hampton, VA 23681, USA. ${ }^{24}$ Department of Geography and Environmental Sustainability, University of Oklahoma, 100 East Boyd Street, SEC Suite 510, Norman, OK 73019, USA. ${ }^{25}$ Russian Institute for Hydrometeorological Information, 6 Koroleva Street, Obninsk 249020, Kaluga Area, Russia. ${ }^{26}$ Michigan Tech Research Institute, 3600 Green Court, Suite 100, Ann Arbor, MI 48105, USA. ${ }^{27}$ Department of Geography, Miami University, 250 S. Patterson Ave, Oxford, OH 45056, USA. ${ }^{28}$ Purdue University, 550 Stadium Mall Drive, West Lafayette, IN 47907, USA. ${ }^{29}$ Laboratoire de Glaciologie et Géophysique de l'Environnement, Joseph Fourier University-Grenoble 1, 54 rue Moliere, BP 96, 38402 Saint Martin d'Heres Cedex, France. ${ }^{30} \mathrm{Hydrology}$ Science and Service Corporation, 920 Rockhold Drive, Asheville, NC 28804, USA. ${ }^{31}$ Institute of Environmental Sciences, Kazan Federal University, Kazan, Tovarishcheskaya str.5, Kazan 420097, Russia.

Received: 15 December 2016 Accepted: 29 November 2017 Published online: 27 December 2017

\section{References}

Abbot BW, Jones JB, Schuur EAG, Chapin FS III, Bowden WB, Bret-Harte MS, Epstein HE, Flannigan MD, Harms TK, Hollingsworth TN, Mack MC, Mc Guire A, Natali SM, Rocha AV, Tank SE, Turetsky MR, Vonk JE, Wickland KP, Aiken GR (2016) Biomass offsets little or none of permafrost carbon release from soils, streams and wildfire: an expert assessment. Environ Res Lett 11:034014. doi: 10.1088/1748-9326/11/3/034014

Achard F, Mollicone D, Stibig H-J, Aksenov D, Laestadius L, Li Z, Potapov P, Yaroshenko A (2006) Areas of rapid forest-cover change in boreal Eurasia. For Ecol Manag 237:322-334. doi: 10.1016/j.foreco.2006.09.080

Adam JC, Haddeland I, Su F, Lettenmaier DP (2007) Simulation of reservoir influences on annual and seasonal streamflow changes for the Lena, Yenisei, and Ob' rivers. J Geophys Res 112:D24114. doi: 10.1029/2007JD008525

Adam JC, Lettenmaier DP (2008) Application of new precipitation and reconstructed streamflow products to streamflow trend attribution in northern Eurasia. J Clim 21(8):1807-1828. doi: 10.1175/2007JCLI1535.1

Aizen VB (2011) Altai-Sayan Glaciers. In: Singh VP, Singh P, Haritashiya UK (eds) Encyclopedia of snow, ice and glaciers. Springer, New York

Aizen VB, Kuzmichenok VA, Surazakov AB, Aizen EM (2007) Glacier changes in the Tien Shan as determined from topographic and remotely sensed data. Glob and Planet Change 56:328-340

Alcamo J, Kreileman GJJ, Krol MS, Zuidema G (1994) Modeling the global societybiosphere-climate system: part 1: model description and testing. Water Air Soil Pollut 76(1-2):1-35. doi: 10.1007/BF00478335

Alcantara C, Kuemmerle T, Baurmann M, Radeloff V (2013) Mapping the extent of abandoned farmland in central and Eastern Europe using MODIS time series satellite data. Environ Res Lett 8(3):035035. doi: 10 1088/1748-9326/8/3/035035

Alcantara C, Kuemmerle T, Prishchepov AV, Radeloff VC (2012) Mapping abandoned agriculture with multi-temporal MODIS satellite data. Remote Sens Environ 124:334-347. doi: 10.1016/j.rse.2012.05.019

Allen CD, Macalady AK, Chenchouni H, Bachelet D, McDowell NG, Vennetier M, Kitzberger T, Rigling A, Breshears D, Hogg T, Gonzalez P, Fensham R, Zhang Z, Castro J, Demidova N, Lim JH, Allard G, Running S, Semerci A, Cobb NS (2010) A global overview of drought and heat-induced tree mortality reveals emerging climate risk for forests. For Ecol Manag 259:660-684. doi: 10.1016/j. foreco.2009.09.001

AMAP (Arctic Monitoring and Assessment Programme) (2011) Snow, water, ice and permafrost in the Arctic (SWIPA): climate change and the cryosphere. Report to the Arctic Council [Available at http://amap.no/swipa/. AMAP, Oslo

AMAP (Arctic Monitoring and Assessment Programme) (2017) Snow, water, ice, permafrost in the Arctic (SWIPA). Update. http://www.amap.no/swipa2017
Andrew R (2014) Socio-economic drivers of change in the Arctic. AMAP Technical Report No. 9 Arctic Monitoring and Assessment Programme (AMAP), Oslo

Anisimov O, Kokorev V, Zhil'tsova Y (2013) Temporal and spatial patterns of modern climatic warming: case study of Northern Eurasia. Climate Change 118(3):871-883. doi: 10.1007/s10584-013-0697-4

Arctic Climate Impact Assessment (ACIA) (2005) Scientific report, chapter 2 "Arctic climate: past and present". Cambridge University Press, Cambridge

Arora VK, Boer GJ, Friedlingstein P, Eby M, Jones CD, Christian JR, Bonan Bopp GL, Brovkin V, Cadule P, Hajima T, llyina T, Lindsay K, Tjiputra JF, Wu T (2013) Carbon-concentration and carbon-climate feedbacks in CMIP5 earth system models. J Clim 26:5289-5314. doi: 10.1175/JCLI-D-12-00494.1

Arzhanov MM, Eliseev AV, Klimenko W, Mokhov II, Tereshin AG (2012) Estimating climate changes in the northern hemisphere in the 21st century under alternative scenarios of anthropogenic forcing. Izvestiya Atmos Ocean Phys 48(6):573-584. doi: 10.1134/50001433812060023

Arzhanov MM, Eliseev AV, Mokhov II (2012) A global climate model based, Bayesian climate projection for northern extra-tropical land areas. Glob Planet Change 86-87:57-65. doi: 10.1016/j.gloplacha.2012.02.001

Baklanov AA, Penenko V, Mahura A, Vinogradova A, Elansky N, Tsvetova E, Rigina O, Maksimenkov L, Nuterman R, Pogarskii F, Zakey A (2013) Aspects of atmospheric pollution in Siberia. In: Groisman PY, Gutman G (eds) Environmental changes in Siberia: regional changes and their global consequences. Springer, New York

Balshi MS, McGuire AD, Zhuang Q, Melillo J, Kicklighter DW, Kasischke E, Wirth C, Flannigan M, Harden J, Clein JS, Burnside TJ, McAllister J, Kurz WA, Apps M, Shvidenko A (2007) The role of historical fire disturbance in the carbon dynamics of the pan-boreal region: a process-based analysis. J Geophys Res Biogeosci 112(G2):G02029. doi: 10.1029/2006JG000380

Barriopedro D, Fischer EM, Luterbacher J, Trigo RM, Garcia-Herrera R (2011) The hot summer of 2010: redrawing the temperature record map of Europe. Science 332(6026):220-224. doi: 10.1126/science.1201224

Barros VR, Field CB, Dokken DJ, Mastrandrea MD, Mach KJ, Bilir TE, Chatterjee M, Ebi KL, Estrada YO, Genova RC, Girma B, Kissel ES, Levy AN, Mac Cracken S, Mastrandrea PR, White LL (eds) (2014) Climate change 2014: impacts, adaptation, and vulnerability. Part B: regional aspects. Contribution of working group II to the fifth assessment report of the inter-governmental panel on climate change. Cambridge University Press, Cambridge, UK and New York

Bartalev SA, Stysenko FV, Egorov BA, Lupyan EA (2015) Satellite estimate of death of Russian forests caused by fire. Forest Science (Lesovedenie) 2: 83-94 (in Russian)

Bastos A, Gouvenia CV, Trigo RM (2014) Analysing the spatio-temporal impacts of the 2003 and 2010 extreme heatwaves on plant productivity in Europe. Biogeosciences 11(13):3421-3435. doi: 10.5194/bg-11-3421-2014

Batmunkh T, Kim YJ, Jung JS, Park K, Tumendemberel B (2013) Chemical characteristics of fine particulate matters measured during severe winter haze events in Ulaanbaatar, Mongolia. J Air and Waste Management Assoc 63(6):659-670. doi: 10.1080/10962247.2013.776997

Bennett KE, Cannon AJ, Hinzman L (2015) Historical trends and extremes in boreal Alaska river basins. J Hydrol 527:590-607. doi: 10.1016/j.jhydrol.2015.04.065

Bergen KM, Hitztaler S, Kharuk V, Krankina ON, Loboda T, Zhao TT, Shugart HH, Sun G (2013) Human dimensions of environmental change in Siberia. In: Groisman P, Gutman G (eds) Regional environmental changes in Siberia and their global consequences. Kluwer Academic Publishers, Dordrecht, pp 251-302

Bergen KM, Zhao T, Kharuk V, Blam Y, Brown DG, Peterson LK, Miller N (2008) Changing regimes: forested land cover dynamics in central Siberia 1974 to 2001. Photogramm Eng Remote Sens 74(6):787-798. doi: 10.14358/PERS.74.6.787

Bičík I, Kupková L, Jeleček L, Kabrda J, Štych P, Janoušek Z, Winklerová J (2015) Land use changes in the Czech Republic 1845-2010. Socio-Economic Driving Forces Springer, New York ISBN: 978-3-319-17670-3

Blunden J, Arndt DS (eds) (2015) State of the climate in 2014. Bull Amer Meteor Soc 96(7):S1-S267. doi: 10.1175/2015BAMSStateoftheClimate.1

Blunden J, Arndt DS (eds) (2016) State of the climate in 2015. Bull Amer Meteor Soc 97(8):S1-S275

Blyakharchuk TA, Tchebakova NM, Parfenova EI, Soja AJ (2014) Potential influence of the late Holocene climate on settled farming versus nomadic cattle herding in the Minusinsk Hollow, south-central Siberia. Environ Res Lett 9(6): 065004. doi: 10.1088/1748-9326/9/6/065004

Bohn TJ, Melton JR, Ito A, Kleinen T, Spahni R, Stocker BD, Zhang B, Zhu X, Schroeder R, Glagolev MV, Maksyutov S, Brovkin V, Chen G, Denisov SN, 
Eliseev AV, Gallego-Sala A, McDonald KC, Rawlins MA, Riley WJ, Subin ZM, Tian H, Zhuang Q, Kaplan JO (2015) WETCHIMP-WSL: Intercomparison of wetland methane emissions models over West Siberia. Biogeosciences 12: 3321-3349. doi: 10.5194/bg-12-3321-2015

Bohn TJ, Podest E, Schroeder R, Pinto N, McDonald KC, Glagolev M, Filippov I, Maksyutov S, Heimann M, Chen X, Lettenmaier DP (2013) Modeling the large-scale effects of surface moisture heterogeneity on wetland carbon fluxes in the west Siberian lowland. Biogeosciences 10:6559-6576. doi: 10. 5194/bg-10-6559-2013

Bolch T, Marchenko SS (2009) Significance of glaciers, rockglaciers and ice-rich permafrost in the northern Tien Shan as water towers under climate change conditions. In: Braun L, Hagg W, Severskiy IV, Young GJ (eds) Selected papers from the workshop "assessment of snow, glacier and water resources in Asia", vol 8. IHP/HWRP-Berichte, Almaty, pp 132-144

Bowling LC, Lettenmaier DP (2010) Modeling the effects of lakes and wetlands on the water balance of Arctic environments. J Hydrometeorol 11:276-295. doi: 10.1175/2009JHM1084.1

Bragina EV, Ives AR, Pidgeon AM, Kuemmerle T, Baskin LM, Gubar YP, PiquerRodríguez M, Keuler NS, Petrosyan VG, Radeloff VC (2015) Rapid declines of large mammal populations after the collapse of the soviet union: wildlife decline after collapse of socialism. Conserv Biol 10.1111/cobi.12450

Brovkin V, Boysen L, Arora VK, Boisier JP, Cadule P, Chini L, Claussen M, Friedlingstein P, Gayler V, Van Den Hurk BJJM, Hurtt GC (2013) Effect of anthropogenic land-use and land-cover changes on climate and land carbon storage in CMIP5 projections for the twenty-first century. J Clim 26(18):68596881. doi: $10.1175 /$ JCLI-D-12-00623.1

Brovkin V, Claussen M, Driesschaert E, Fichefet T, Kicklighter D, Loutre MF, Matthews HD, Ramankutty N, Schaeffer M, Sokolov A (2006) Biogeophysical effects of historical land cover changes simulated by six earth system models of intermediate complexity. Clim Dyn 26(6):587-600. doi: 10.1007/s00382005-0092-6

Brown RD, Robinson DA (2011) Northern hemisphere spring snow cover variability and change over 1922-2010 including an assessment of uncertainty. Cryosphere 5:219-229. doi: 10.5194/tc-5-219-2011

Bulygina ON, Arzhanova NM, Groisman PY (2015) Icing conditions over northern Eurasia in changing climate. Environ Res Lett 10(2):025003. doi: 10.1088/17489326/10/2/025003

Bulygina ON, Groisman PY, Razuvaev VN, Korshunova NN (2011) Changes in snow cover characteristics over northern Eurasia since 1966. Environ Res Lett 6(4):045204. doi: 10.1088/1748-9326/6/4/045204

Bulygina ON, Korshunova NN, Razuvaev VN (2013) Change of the near-surface winds over Russia during the past decades. Transact Voeikov Main Geophys Observ 568:156-172 (in Russian)

Bulygina ON, Razuvaev VN, Korshunova NN (2009) Changes in snow cover over northern Eurasia in the last few decades. Environ Res Lett 4(4):045026. doi: 10.1088/1748-9326/4/4/045026

Callaghan TV, Johansson M, Brown RD, Groisman PY, Labba N, Radionov V, Barry RS, Bulygina ON, Essery RLH, Frolov DM, Golubev VN, Granfell TC, Petrushina MN, Razuvaev VN, Robinson DA, Romanov P, Shindell D, Shmakin AB, Sokratov SA, Warren S, Yang D (2011a) The changing face of Arctic snow cover: a synthesis of observed and projected changes. Ambio 40(Suppl 1): 17-31. doi: 10.1007/s13280-011-0212-y

Callaghan TV, Johansson M, Brown RD, Groisman PY, Labba N, Radionov V, Bradley RS, Blangy S, Bulygina ON, Christensen TR, Colman JE, Essery RLH, Forbes BC, Forchhammer MC, Golubev VN, Honrath NE, Juday JP, Meshcherskaya AV, Phoenix GK, Pomeroy J, Rautio A, Robinson DA, Schmidt $\mathrm{NH}$, Serreze MC, Shevchenko VP, Shiklomanov Al, Shmain AB, Skold P, Sturm M, Woo M, Wood EF (2011 b) Multiple effects of changes in Arctic snow cover. Ambio 40(Suppl. 1):32-45. doi: 10.1007/s13280-011-0213-x

Campbell PKE, Rock BN, Martin ME, Neefus CD, Irons JR, Middleton EM, Albrechtová J (2004) Detection of initial damage in Norway spruce canopies using hyperspectral airborne data. Int J Remote Sens 25(24):5557-5584. doi: 10.1080/01431160410001726058

Chen F-H, Chen J-H, Holmes J, Boomer I, Austin P, Gates JB, Wang N-L, Brooks SJ, Zhang J-W (2010) Moisture changes over the last millennium in arid central Asia: a review, synthesis and comparison with monsoon region. Quat Sci Rev 29(7-8):1055-1068. doi: 10.1016/j.quascirev.2010.01.005

Chen F-H, Yu Z, Yang M, Ito E, Wang S, Madsen DB, Huang X, Zhao Y, Sato T, Birks HJB, Boomer I, Chen J, An C, Wünnemann B (2008) Holocene moisture evolution in arid central Asia and its out-of-phase relationship with Asian monsoon history. Quat Sci Rev 27(3-4):351-364. doi: 10.1016/j.quascirev.2007.10.017
Chen J, John R, Shao C, Fan Y, Zhang Y, Amarjargal A, Brown DG, Qi J, Han J, Lafortezza R, Dong G (2015) Policy shifts influence the functional changes of the CNH systems on the Mongolian plateau. Environ Res Lett 10(8):085003. doi: 10.1088/1748-9326/10/8/085003

Chen J, John R, Zhang Y, Shao C, Brown DG, Batkhishig O, Amarjargal A, Ouyang Z, Dong G, Qi J (2015) Divergences of two coupled human and natural systems on the Mongolia plateau. Bioscience 65(6):559-570. doi: 10.1093/ biosci/biv050

Chen J, Liu Y (eds) (2014) Coupled natural and human systems: a landscape ecology perspective. Landsc Ecol 29:1641

Chen J, Wan S, Henebry G, Qi J, Gutman G, Sun G, Kappas M (eds) (2013) Dryland East Asia: land dynamics amid social and climate change. Higher Education Press Berlin: De Gruyter, Beijing

Chen Y, Zhai P (2014) Two types of typical circulation pattern for persistent extreme precipitation in central-eastern China. Quart J Roy Meteorol Soc 140(682):1467-1478

Chen YZ, Ju W, Groisman PY, Li J, Propastin P, Xu X, Zhou W, Ruan H (2017) Quantitative assessment of carbon sequestration reduction induced by disturbances in temperate Eurasian steppe. Environ Res Lett 12. doi: 10.1088/ 1748-9326/aa849b

Conard SG, Sukhinin Al, Stocks BJ, Cahoon DR, Davidenko EP, Ivanova GA (2002) Determining effects of area burned and fire severity on carbon cycling and emissions in Siberia. Clim Chang 55(1-2):197-211. doi: 10.1023/A: 1020207710195

Cook BI, Anchukaitis KJ, Touchan R, Meko DM, Cook ER (2016) Spatiotemporal drought variability in the Mediterranean over the last 900 years. J Geophys Res Atmos 121:2060-2074. doi: 10.1002/2015JD023929

Core Writing Team, Pachauri RK, Reisinger A. (eds) (2007) Climate change 2007: synthesis report. Contribution of working groups I, II and III to the fourth assessment report of the intergovernmental panel on climate change. IPCC, Geneva

Crate SA (2006) Cows, kin, and globalization: an aethnography of sustainability. Rowman Altamira, Lanham

Cresto-Aleina F, Brovkin V, Muster S, Boike J, Kutzbach L, Sachs T, Zuyev S (2013) A stochastic model for the polygonal tundra based on Poisson-Voronoi diagrams. Earth System Dynamics 4:187-198. doi: 10.5194/esd-4-187-2013

Cresto-Aleina F, Runkle BRK, Kleinen T, Kutzbach L, Schneider J, Brovkin V (2015) Modeling micro-topographic controls on boreal peatland hydrology and methane fluxes. Biogeosciences 12:5689-5704. doi: 10.5194/bg-12-5689-2015

Crowley RM (2005) Stepping on to a moving train: the collision of illegal logging, forestry policy, and emerging free trade in the Russian far east. Pacific Rim Law and Pol J

Dargaville RJ, Heimann M, McGuire AD, Prentice IC, Kicklighter DW, Joos F, Clein JS, Esser G, Foley J, Kaplan J, Meier RA, Melillo JM, B Moore B III, Ramankutty $\mathrm{N}$, Reichenau T, Schloss A, Sitch S, Tian H, Williams L, Wittenberg U (2002) Evaluation of terrestrial carbon cycle models with atmospheric $\mathrm{CO}_{2}$ measurements: results from transient simulations considering increasing $\mathrm{CO}_{2}$, climate and land-use effects. Glob Biogeochem Cycles 16(4):1092. doi: 10. 1029/2001GB001426

Dargaville RJ, McGuire AD, Rayner P (2002) Estimates of large-scale fluxes in high latitudes from terrestrial biosphere models and an inversion of atmospheric CO2 measurements. Clim Chang 55(1-2):273-285. doi: 10.1023/A: 1020295321582

Darmenova K, Sokolik IN, Shao Y, Marticorena B, Bergametti G (2009) Development of a physically-based dust emission module within the weather research and forecasting (WRF) model: assessment of dust emission parameterizations and input parameters for source regions in Central and East Asia. J Geophys Res 114:D14201. doi: 10.1029/2008JD011236

Dass P, Rawlins MA, Kimball JS, Kim Y (2016) Environmental controls on the increasing GPP of terrestrial vegetation across northern Eurasia. Biogeosciences 13:45-62. doi: 10.5194/bg-13-45.2016

Davydov SP, Fedorov-Davydov DG, Neff JC, Shiklomanov NI, Davydova Al (2008) Changes in active layer thickness and seasonal fluxes of dissolved organic carbon as a possible baseline for permafrost monitoring. In: Proceedings of the 9th International Conference on Permafrost, Institute of Northern Engineering. University of Alaska, Fairbanks

de Beurs KM, Henebry GM, Owsley BC, Sokolik I (2015) Using multiple remote sensing perspectives to identify and attribute land surface dynamics in Central Asia 2001-2013. Remote Sens Environ 170:48-61 http://dx.doi.org/10. 1016/j.rse.2015.08.018

de Beurs KM, loffe G (2014) Use of Landsat and MODIS data to remotely estimate Russia's sown area. J Land Use Sci 9(4):377-401 http://doi.org/10.1080/ 1747423X.2013.798038 
DeLucia EH (2015) How biofuels can cool our climate and strengthen our ecosystems. Eos 96(4):14-19. doi: 10.1029/2015EO041583

Derevyagin VA (1987) Practical guidance on straw utilization as fertilizer. AllUnion Research and Development, USSR State Agro-Industrial Committee on Design and Technological Institute for Organic Fertilizers and Peat, Moscow http://quickr.mtri.org/croplandburning

Derome J, Lukina N (2011) Interaction between environmental pollution and landcover/land-use change in arctic areas. In: Gutman G, Reissell A (eds) Eurasian Arctic land cover and land use in a changing climate. Springer, Dordrecht

Dienes $L$ (2004) Observations on the problematic potential of Russian oil and the complexities of Siberia. Eurasian Geogr Econ 45(5):319-345. doi: 10.2747/ 1538-7216.45.5.319

Dolman AJ, Shvidenko A, Schepaschenko D, Ciais P, Tchebakova NM, Chen T, van der Molen MK, Belelli Marchesini L, Maximov TC, Maksyutov S, Schulze E-D (2012) An estimate of the terrestrial carbon budget of Russia using inventorybased, eddy covariance and inversion methods. Biogeosciences 9:5323-5340. doi: 10.5194/bg-9-5323-2012

Dronin N, Kirilenko A (2010) Climate change, food stress, and security in Russia. Reg Environ Chang 11(Supplement 1):167-178 http://doi.org/10.1007/s10113-010-0165-x

Drozdov OA (1966) On the variation of precipitation over the northern hemisphere with variation of the temperature of the polar basin. Transactions of the Main Geophys Observ 138:3-16 (in Russian)

Dubinin M, Lushchekina A, Radeloff VC (2011) Climate, livestock and vegetation: what drives fire increase in the arid ecosystems of Southern Russia? Ecosystems 14(4):547-562. doi: 10.1007/s10021-011-9427.9

Duethmann D, Bolch T, Farinotti D, Kriegel D, Vorogushyn S, Merz B, Pieczonka T, Jiang T, Su B, Guntner A (2015) Attribution of streamflow trends in snow and glacier melt-dominated catchments of the Tarim River, Central Asia. Water Resourc Res 51(6):4727-4750. doi: 10.1002/2014WR016716

Eby M, Weaver AJ, K. Alexander K, Zickfeld K, A. Abe-Ouchi A, Cimatoribus AA, Crespin E, DrijfhoutSS ENR, Eliseev AV, Feulner G, T. Fichefet T, Forest CE, Goosse H, Holden PB, Joos F, Kawamiya M, Kicklighter D, Kienert H, Matsumoto K, Mokhov II, Monier E, Olsen SM, JOP P, Perrette M, PhilipponBerthier G, Ridgwell A, Schlosser A, Schneider von Deimling T, Shaffer G, Smith RS, Spahni R, Sokolov AP, Steinacher M, Tachiiri K, K. Tokos K, Yoshimori M, Zeng N, Zhao F (2013) Historical and idealized climate model experiments: an intercomparison of Earth system models of intermediate complexity. Clim Past 9:1111-1140. doi: 10.5194/cp-9-1111-2013

Estel S, Kuemmerle T, Alcántara C, Levers C, Prishchepov A, Hostert P (2015) Mapping farmland abandonment and recultivation across Europe using MODIS NDVI time series. Remote Sens Environ 163:312-325 http://doi.org/10. 1016/j.rse.2015.03.028

European Forest Institute (2014) Trade reports database, Joensuu. (URL: http:// www.efi.int/portal/virtual_library/databases/forest_products_trade_flow_ database/. Accessed 21 Aug 2017

Euskirchen ES, McGuire AD, Kicklighter DW, Zhuang Q, Clein JS, Dargaville RJ, Dye DG, Kimball JS, MCDonald KC, Melillo JM, Romanovsky VE, Smith NV (2006) Importance of recent shifts in soil thermal dynamics on growing season length, productivity and carbon sequestration in terrestrial high-latitude ecosystems. Glob Chang Biol 12(4):731-750. doi: 10.1111/j.1365-2486.2006.01113.x

Farinotti D, Longuevergne L, Moholdt G, Duethmann D, Mölg T, Bolch T, Vorogushyn S, Güntner A (2015) Substantial glacier mass loss in the Tien Shan over the past 50 years. Nat Geosci 8:716-722. doi: 10.1038/ngeo2513

Farré AB, Stephenson S, Chen L, Wighting J (2014) Commercial Arctic shipping through the northeast passage: routes, resources, governance, technology, and infrastructure. Polar Geogr 37(4):298-324. doi: 10.1080/ 1088937X.2014.965769

Fausto RS, van As D, Box JE, Colgan W, Langen PL, Mottram RH (2016) The implication of non-radiative energy fluxes dominating Greenland ice sheet exceptional ablation area surface melt in 2012. Geophys Res Lett 43:26492658. doi: 10.1002/2016GL067720

Fichot CG, Kaiser K, Hooker SB, Amon RMW, Babin M, Bélanger S, Walker SA, Benner R (2013) Pan-Arctic distributions of continental runoff in the Arctic Ocean. Sci Rep 3:1053. doi: 10.1038/srep01053

Fjellstad WJ, Dramstad WE (1999) Patterns of change in two contrasting Norwegian agricultural landscapes. Landsc Urban Plan 45(4):177-191. doi: 10. 1016/S0169-2046(99)00055-9

Flannigan MD, Cantin AS, de Groot WJ, Wotton M, Newbery A, Gowman LM (2013) Global wildland fire season severity in the 21st century. For Ecol Manag 294:54-61. doi: 10.1016/j.foreco.2012.10.022
Flannigan MD, Stocks BJ, Wotton BM (2000) Climate change and forest fires. Sci Total Environ 262(3):221-229. doi: 10.1016/S0048-9697(00)00524-6

Fondahl GA (1996) Contested terrain: changing boundaries and identities in southeastern Siberia. Post Soviet Geography and Economics 37(1):3-15. doi: 10.1080/10889388.1996.10641011

Forbes BC, Kumpula T, Meschtyb N, Laptander R, Macias-Fauria M, Zetterberg P, Verdonen M, Skarin A, Kim KY, Boisvert LN, Stroeve JC, Bartsch A (2016) Sea ice, rain-on-snow and tundra reindeer nomadism in Arctic Russia. Biol Lett 12:2160466 http://dx.doi.org/10.1098/rsbl.2016.0466

Forbes BC, Stammler F, Kumpula T, Meschtyb N, Pajunen A, Kaarlejärvi E (2009) High resilience in the Yamal-Nenets social-ecological system, West Siberian Arctic, Russia. Proc Natl Acad Sci U S A 106(52):22041-22048. doi: 10.1073/ pnas.0908286106

Fottová D (1995) Regional evaluation of mass element fluxes: GEOMON network of small catchments. Environ Monit Assess 34(2):215-221. doi: 10.1007/ BF00546037

Francis JA, Vavrus SJ (2012) Evidence linking Arctic amplification to extreme weather in mid-latitudes. Geophys Res Lett 39:L06801. doi: 10.1029/ 2012GL051000

Frauenfeld OW, Zhang T (2011) An observational 71-year history of seasonally frozen ground changes in the Eurasian high latitudes. Environ Res Lett 6: 044024. doi: 10.1088/1748-9326/6/4/044024

Frauenfeld OW, ZhangT BRG, Gilichinsky D (2004) Interd2ecadal changes in seasonal freeze and thaw depths in Russia. J Geophys Res 109:D5101

Friedlingstein P, Cox P, Betts R, Bopp L, von Bloh W, Brovkin V, Cadule P, Doney S, Eby M, Fung I, Bala G, John J, Jones C, Joos F, Kato T, Kawamiya M, Knorr W, Lindsay K, Matthews HD, Raddatz T, Rayner P, Reick C, Roeckner E, Schnitzler KG, Schnur R, Strassmann K, Weaver AG, Yoshikawa C, Zeng N (2006) Climate-carbon cycle feedback analysis: results from the C4MIP model intercomparison. J Clim 19(14):3337-3353. doi: 10.1175/JCLI3800.1

Gálos B, Hagemann S, Hänsler A, Kindermann G, Rechid D, Sieck K, Teichmann C, Jacob D (2013) Case study for the assessment of the biogeophysical effects of a potential afforestation in Europe. Carbon Balance Manag 8(3). doi: 10. 1186/1750-0680-8-3

Gannon M (2016) Arctic sea ice extent may shrink below 2012 record low. Eos 97. doi: 10.1029/2016EO051183

Gao X, Schlosser CA, Sokolov A, Walter Anthony K, Zhuang Q, Kicklighter D (2013) Permafrost degradation and methane: low risk of biogeochemical climate-warming feedback. Environ Res Lett 8(3):035014. doi: 10.1088/17489326/8/3/035014

Gauthier S, Bernier P, Kuuluvainen T, Shvidenko AZ, Schepaschenko DG (2015) Boreal forest health and global change. Science 349(6250):819-822. doi: 10. 1126/science.aaa9092

Gelfan A (2011) Modelling hydrological consequences of climate change in the permafrost region and assessment of their uncertainty. In: Yang D, Marsh D, Gelfan A (eds) Cold region hydrology in a changing climate, vol 346. IAHS Publications, pp 92-97

Gelfan A, Muzylev E, Uspensky A, Startseva Z, Romanov P (2012) Remote sensing based modeling of water and heat regimes in a vast agricultural region. Chapter 6. In: Escalante-Ramirez B (ed) Remote sensing - applications ISBN: 978-953-51-0651-7. InTechOpen d.o.o, Rijeka. doi: 10.5772/37076

Georgiadi AG, Kashutina EA (2016) Long-term runoff changes of the largest Siberian rivers. Izvestiya Rossiiskoi Akademii Nauk. Seriya Geograficheskaya 2016(5):70-81. doi: 10.15356/0373-2444-2016-5-70-81 (in Russian)

Georgiadi AG, Koronkevich N, Milyukova IP, Barabanova EA (2014a) The ensemble scenarios projecting runoff changes in large Russian river basins in the 21st century, evolving water resources systems: understanding, predicting and managing water-society interactions. Proceedings of ICWRS 2014. IAHS Publ, Bologna, p 364. doi: 10.5194/piahs-364-210-2014

Georgiadi AG, Koronkevich NI, Miliukova IP, Kislov AV, Anisimov OA, Barabanova EA, Kashutina EA, Borodin $\mathrm{OO}$ (2011) Scenario assessment of probable river runoff changes of the largest rivers of Russia. Part 1. Lena River basin. Max Press, Moscow (in Russian)

Georgiadi AG, Koronkevich NI, Milyukova IP, Kashutina EA, Barabanova EA (2014b) Contemporary and scenario river runoff changes in the largest rivers of Russia. Part 2. The Volga and Don River basins. Maks Press, Moscow (in Russian)

Georgiadi AG, Milyukova IP, Kashutina EA (2010) Response of river runoff in the Cryolithic zone of eastern Siberia (Lena River basin) to future climate warming. In: Environmental change in Siberia. Springer, Netherlands, pp 157-169. doi: 10.1007/978-90-481-86419_10 
Glagolev M, Kleptsova I, Filippov I, Maksyutov S, Machida T (2011) Regional methane emission from West Siberia mire landscapes. Environ Res Lett 6(4): 045214. doi: 10.1088/1748-9326/6/4/045214

Goldammer JG (ed) (2013) Vegetation fires and global change: challenges for concerted international action. A white paper directed to the United Nations and international organizations. A publication of the global fire monitoring center (GFMC). Kessel Publ House ISBN 978-3-941300-78-1 (http://www.forestrybooks.com/)

Golubev VS, Lawrimore JH, Groisman PY, Speranskaya NA, Zhuravin SA, Menne MJ, Peterson TC, Malone RW (2001) Evaporation changes over the contiguous United States and the former USSR: a reassessment. Geophys Res Lett 28:2665-2668. doi: 10.1029/2000GL012851

Goudie AS, Middleton NJ (1992) The changing frequency of dust storms through time. Clim Chang 20(3):197-225. doi: 10.1007/BF00139839

Gouttevin I, Krinner G, Ciais P, Polcher J, Legout C (2012) Multi-scale validation of a new soil freezing scheme for a land-surface model with physically-based hydrology. Cryosphere 6:407-430. doi: 10.5194/tc-6-407-2012

Graven HD, Keeling RF, Piper SC, Patra PK, Stephens BB, Wofsy SC, Welp LR, Sweeney C, Tans PP, Kelley JJ, Daube BC, Kort EA, Santoni GW, Bent JD (2013) Enhanced seasonal exchange of $\mathrm{CO}_{2}$ by northern ecosystems since 1960. Science 341:1085-1089. doi: 10.1126/science.1239207

Griffiths P, Müller D, Kuemmerle T, Hostert P (2013) Agricultural land change in the Carpathian ecoregion after the breakdown of socialism and expansion of the European Union. Environ Res Lett 8(4):045024. doi: 10.1088/1748-9326/8/4/045024

Groisman PY, Bartalev SA (2007) Northern Eurasia earth science partnership initiative (NEESPI): science plan overview. Glob Planet Chang 56(3-4):215234. doi: 10.1016/j.gloplacha.2006.07.027

Groisman PY, Blyakharchuk TA, Chernokulsky AV, Arzhanov MM, Belelli Marchesini L, Bogdanova EG, Borzenkova II, Bulygina ON, Karpenko AA, Karpenko LV, Knight RW, Khon VCh, Korovin GN, Meshcherskaya AV, Mokhov II, Parfenova El, Razuvaev VN, Speranskaya NA, Tchebakova NM, Vygodskaya NN (2013) Climate changes in Siberia. Ch. 3 In: Groisman PY, Gutman G (eds) Environmental changes in Siberia: regional changes and their global consequences. Springer, Dordrecht. doi: 10.1007/978-94-007-4569-8

Groisman PY, Bogdanova EG, Alexeev VA, Cherry JE, Bulygina ON (2014) Impact of snowfall measurement deficiencies on quantification of precipitation and its trends over Northern Eurasia. Ice Snow 2(126):29-43

Groisman PY, Bulygina ON, Yin X, Vose RS, Gulev SK, Hanssen-Bauer I, Førland E (2016) Recent changes in the frequency of freezing precipitation in North America and Northern Eurasia. Environ Res Lett 11:045007. doi: 10.1088/1748 9326/11/4/045007

Groisman PY, Clark EA, Lettenmaier DP, Kattsov VM, Sokolik IN, Aizen VB, Cartus O, Chen J, Schmullius CC, Conard S, Katzenberber J, Krankina O, Kukkonen J, Sofiev M, Machida T, Maksyutov S, Ojima D, Qi J, Romanovsky VE, Walker D, Santoro M, Shiklomanov Al, Vöröshmarty C, Shimoyama K, Shugaart HH, Shuman JK, Sukhinin Al, Wood EF (2009) The Northern Eurasia earth science partnership: an example of science applied to societal needs. Bull Amer Meteorol Soc 90(5):671-688. doi: 10.1175/2008BAMS2556.1

Groisman PY, Gutman G (eds) (2013) Environmental changes in Siberia: regional changes and their global consequences. Springer, Dordrecht

Groisman PY, Knight RW, Zolina OG (2013) Recent trends in regional and global extreme precipitation patterns. Chapter 5.03. In: Pielke R Sr, Hossain F (eds) Climate vulnerability: understanding and addressing threats to essential resources. Volume 5, vulnerability of water resources to climate. Elsevier Publishing House, Amsterdam ISBN 978-0-12-384703-4

Groisman PY, Lyalko VI (eds) (2012) Earth systems change over Eastern Europe. Akademperiodyka, Kiev ISBN 978-966-360-195-3

Groisman PY, Soja AJ (2009) Ongoing climatic change in northern Eurasia: justification for expedient research. Environ Res Lett 4(4):045002. doi: 10. 1088/1748-9326/4/4/045002

Groisman PY, Sun B, Vose RS, Lawrimore JH, Whitfield PH, Førland E, HanssenBauer I, Serreze MC, Razuvaev VN, Alekseev GV (2003) Contemporary climate changes in high latitudes of the northern hemisphere: daily time resolution. WMO/TD - 1172, [proc. of the international symposium on climate change, Beijing, China, 31 March - 3 April, 2003]. World Meteorol Organ 1172:51-55

Guha-Sapir D (2010) Disasters in numbers 2010 - presentations. EM-DAT: the international disaster database centre for research on the epidemiology of disasters - CRED. Available via: http://cred.be/sites/default/files/Disaster_ numbers_presentation_2010.pdf Accessed 23 Oct 2012

Gurevich E (2009) Influence of air temperature on the river runoff in winter (the Aldan river catchment case study). Russ Meteorol Hydrol 34(9):628-633. doi: $10.3103 /$ S1068373909090088
Gustafson EJ, Shvidenko AZ, Scheller RM (2011) Effectiveness of forest management strategies to mitigate effects of global change in south-central Siberia. Canadian J Forest Res 41(7):1405-1421. doi: 10.1139/x11-065

Gustafson EJ, Shvidenko AZ, Sturtevant BR, Sheller RM (2011) Using landscape disturbance and succession models to support forest management. In: Li C, Lafortezza R, Chen J (eds) Landscape ecology in forest management and conservation. HEP and Springer, Beijing and Berlin

Gustafsson Ö, van Dongen BE, Vonk JE, Dudarev OV, Semiletov IP (2011) Widespread release of old carbon across the Siberian Arctic echoed by its large rivers. Biogeosciences 8:1737-1743. doi: 10.5194/bg-8-1737-2011

Gutman G, Radeloff VC (eds) (2016) Land use and land cover change in Eastern Europe after the collapse of the soviet union in 1991. Springer, Dordrecht

Gutman G, Reissell A (eds) (2011) Arctic land cover and land use in a changing climate: focus on Eurasia. VI, Springer, Amsterdam

Hagg W, Braun LN, Weber M, Becht M (2006) Runoff modelling in glacierized central Asian catchments for present-day and future climate. Hydrol Res 37(2):93-105. doi: 10.2166/nh.2006.001

Hagg W, Hoelzle M, Wagner S, Mayr E, Klose Z (2013) Glacier and runoff changes in the Rukhk catchment, upper Amu-Darya basin until 2050. Glob Planet Chang 110:62-73. doi: 10.1016/j.gloplacha.2013.05.005

Hallgren W, Schlosser CA, Monier E, Kicklighter D, Sokolov A, Melillo J (2013) Climate impacts of a large-scale biofuels expansion. Geophys Res Lett 40(8): 1624-1630. doi: 10.1002/grl.50352

Hashim SM (2010) Power-loss of power-transition? Assessing the limits of using the energy sector in reviving Russia's geopolitical stature. Communist Post Communist Stud 43:263-274

Hayes DJ, Kicklighter DW, McGuire AD, Chen M, Zhuang Q, Yuan F, Melillo JM, Wullschleger SD (2014) The impacts of recent permafrost thaw on landatmosphere greenhouse gas exchange. Environ Res Lett 9:045005. doi: 10. 1088/1748-9326/9/4/045005

Hayes DJ, McGuire AD, Kicklighter DW, Burnside TJ, Melillo JM (2011) The effects of land cover and land use change on the contemporary carbon balance of the arctic and boreal terrestrial ecosystems of northern Eurasia. In: Gutman G, Reissell A (eds) Eurasian Arctic land cover and land use in a changing climate. Springer, New York, pp 109-136. doi: 10 1007/978-90-481-9118-5 6

Hayes DJ, McGuire AD, Kicklighter DW, Gurney KR, Burnside TJ, Melillo JM (2011) Is the northern high-latitude land-based $\mathrm{CO}_{2}$ sink weakening? Glob Biogeochem Cycles 25(3):GB3018. doi: 10.1029/2010GB003813

Heleniak T (2010) Migration and population change in the Russian far north during the 1990s. In: Southcott C, Huskey L (eds) Migration in the circumpolar north: issues and contexts. Canadian Circumpolar Institute Press, University of Alberta, Edmonton

Heleniak T (2014) Migration, Arctic. In: Michalos AC (ed) Encyclopedia of quality of life research. Springer, Dordrecht

Heleniak T (2015) Population change in the former communist states of Europe and Asia. Intern Encycl Social Behavioral Sci:545-552. doi: 10.1016/B978-0-08097086-8.31037-6

Henebry GM, de Beurs KM, Wright CK, John R, Lioubimtseva E (2013) Dryland East Asia in hemispheric context. In: Chen J, Wan S, Henebry GM, Qi J, Gutman G, Sun G, Kappas M (eds) Dryland East Asia: land dynamics amid social and climate change. Higher Education Press Berlin: De Gruyter, Beijing

Higgins PAT, Harte J (2006) Biophysical and biogeochemical responses to climate change depend on dispersal and migration. Bioscience 56(5):407-417. doi: 10.1641/0006-3568(2006)056[0407: BABRTC]2.0.CO;2

Higgins SI, Richardson DM (1999) Predicting plant migration rates in a changing world: the role of long-distance dispersal. Amer Naturalist 153(5):464-475. doi: 10.1086/303193

Hijioka Y, Matsuoka M, Nishimoto H, Masui T, Kainuma M (2008) Global GHG emission scenarios under GHG concentration stabilization targets. J Glob Environ Eng 13:97-108

Hitztaler SK, Bergen KM (2013) Mapping resource use over a Russian landscape: an integrated look at harvesting of a non-timber forest product in Central Kamchatka. Environ Res Lett 8(4):045020. doi: 10.1088/1748-9326/8/4/045020

Holmes RM, Coe MT, Fiske GJ, Gurtovaya T, McClelland JW, Shiklomanov Al, Spencer RG, Tank SE, Zhulidov AV (2013) Climate change impacts on the hydrology and biogeochemistry of Arctic rivers. Climatic change and global warming of inland waters: impacts and mitigation for ecosystems and societies, pp 3-26

Holmes RM, Shiklomanov Al, Tank SE, McClelland JW, Tretiakov M (2015) River discharge, Arctic report card: update for 2015. http://www.arctic.noaa.gov/ report-card/ 
Horion S, Prishchepov AV, Verbesselt J, de Beurs K, Tagesson T, Fensholt R (2016) Revealing turning points in ecosystem functioning over the northern Eurasian agricultural frontier. Glob Chang Biol 22:2801-2817. doi: 10.1111/gcb.13267

Hostert P, Kuemmerle T, Prishchepov A, Sieber A, Lambin EF, Radeloff VC (2011) Rapid land use change after socio-economic disturbances: the collapse of the soviet union versus Chernobyl. Environ Res Lett 6(4):045201. doi: 10.1088/ 1748-9326/6/4/045201

Huang LK, Wang GZ, Mu DY, Xia Z, Wang W (2016) Seasonal-varied chemical characteristics and pollution sources of PM2.5 in Harbin, China. Fresenius Env Bull 25(4):1183-1198

Huntley B, Birks HJB (1983) An atlas of past and present pollen maps for Europe. Cambridge University Press, Cambridge-London-New York-New RochelleMelbourne-Sydney

Hurtt GC, Chini LP, Frolking S, Betts RA, Feddema J, Fischer G, Fisk GP, Hibbard K, Houghton RA, Janetos A, Jones CD, Kindermann G, Kinoshita T, Klein Goldewijk K, Riahi K, Shevliakova E, Smith S, Stehfest E, Thomson A, Thornton $P$, van Vuuren DP, Wang YP (2011) Harmonization of land-use scenarios for the period 1500-2100: 600 years of global gridded annual land-use transitions, wood harvest, and resulting secondary lands. Clim Chang 109: 117-161. doi: 10.1007/s10584-011-0153-2

Hurtt GC, Pacala SW, Moorcroft PR, Caspersen J, Shevlaikova E, Houghton RA, Moore B 3rd (2002) Projecting the future of the U.S. carbon sink. Proc Nat Acad Sci USA 99:1389-1394

lizumi T, Ramankutty N (2016) Changes in yield variability of major crops for 1981-2010 explained by climate change. Environ Res Lett 11(3):034003. doi: 10.1088/1748-9326/11/3/034003

Intergovernmental Panel on Climate Change (IPCC) (2014) Summary for policymakers. In: Stocker TF, Qin D, Plattner GK, Tignor M, Allen SK, Boschung J, Nauels A, Xia Y, Midgley PM BV (eds) Climate change 2013: the physical science basis. Contribution of working group I to the fifth assessment report of the intergovernmental panel on climate change. Cambridge University Press, Cambridge, UK and New York

loffe G, Nefedova T, deBeurs K (2012) Land abandonment in Russia. Eurasian Geography Econ 53(4):527-549. doi: 10.2747/1539-7216.53.4.527

loffe G, Nefedova T, deBeurs K (2014) Agrarian transformation in the Russian breadbasket: contemporary trends as manifest in Stavropol. Post Soviet Affairs 30(6):441-463. doi: 10.1080/1060586X.2013.858509

Ivanov VA, Ivanova GA, Korchunov NA, Moskalchenko SA, Ponomarev El (2011) Correlation of forest fire occurrence with disturbance level of forest territories in the lower Angara region. Forestry 1:39-41 (In Russian)

Jacob T, Wahr J, Tad Pfeffer W, Swenson S (2012) Recent contributions of glaciers and ice caps to sea level rise. Nat Geosci 482:514-518. doi: 10.1038/nature10847

Jacobson M, Nghiem SV, Sorichetta A, Whitney N (2015) Ring of impact from the mega-urbanization of Beijing between 2000 and 2009. J Geophys Res Atmos 120(12). doi: 10.1002/2014JD023008

Jiang Y, Zhuang Q, Schaphoff S, Sitch S, Sokolov A, Kicklighter D, Melillo J (2012) Uncertainty analysis of vegetation distribution in the northern high latitudes during the 21st century with a dynamic vegetation model. Ecol Evol 2(3): 593-614. doi: 10.1002/ece3.85

Jiang Y, Zhuang Q, Sitch S, O'Donnell JA, Kicklighter D, Sokolov A, Melillo J (2016) Importance of soil thermal regime in terrestrial ecosystem carbon dynamics in the circumpolar north. Glob Planet Chang 142:28-40. doi: 10.1016/j. gloplacha.2016.04.011

Jin H, Li S, Cheng G, Shaoling W, Li X (2000) Permafrost and climatic change in China. Glob Planet Chang 26(4):387-404. doi: 10.1016/S0921-8181(00)00051-5

Jin HJ, Chang XL, Wang SL (2007) Evolution of permafrost on the Qinghai-Xizang (Tibet) Plateau since the end of the late Pleistocene. J Geophys Res 112: F02S09. doi: 10.1029/2006JF000521

John R, Chen J, Kim Y, Ouyang Z, Xiao J, Park H, Shao C, Zhang Y, Amarjargal A, Qi J (2016) Differentiating anthropogenic modification and precipitation-driven change on vegetation productivity on the Mongolian plateau. Landsc Ecol 31:547-566

John R, Chen J, Noormets A, Xiao X, Xu J, Lu N, Chen S (2013) Modeling gross primary production in semi-arid Inner Mongolia using MODIS imagery and eddy covariance data. Intern J Remote Sensing 34(8):2829-2857. doi: 10. 1080/01431161.2012.746483

John R, Chen J, Ouya Z, Xiao J, Becker R, Samanta A, Ganguly S, Yuan W, Batkhishig O (2013) Vegetation response to extreme climate events on the Mongolian plateau from 2000-2010. Environ Res Lett 8:035033. doi: 10.1088/ 1748-9326/8/3/035033

Jones AD, Collins WD, Edmonds J, Torn MS, Janetos A, Calvin KV, Thomson A, Chini LP, Mao J, Shi X, Thornton P, Hurtt GC, Wise M (2013) Greenhouse gas policy influences climate via direct effects of land-use change. J Clim 26(11): 3657-3670. doi: 10.1175/JCLI-D-12-00377.1

Kantzas E, Lomas M, Quegan S (2013) Fire at high latitudes: data-model comparisons and their consequences. Glob Biogeochem Cycles 27(3):677691. doi: 10.1002/gbc.20059

Karl TR, Arguez A, Huang B, Lawrimore JH, McMahon JR, Menne MJ, Peterson TC, Vose RS, Zhang H-M (2015) Possible artifacts of data biases in the recent global surface warming hiatus. Science 348(6242):1469-1472. doi: 10.1126/ scienceaaa5632

Karthe D, Chalov S, Kasimov N, Kappas M (2015) Water and environment in the Selenga-Baikal Basin. Ibidem-Publisher, Stuttgart ISSN: 1614-4716, ISBN-13: 978-3-8382-0853-4

Kasischke ES, Bergen K, Fennimore R, Sotelo F, Stephens G, Janetos A, Shugart $\mathrm{HH}$ (1999) Satellite imagery gives clear picture of Russia's boreal forest fires. Eos 80(13):141-147. doi: 10.1029/99EO00094

Kattsov VM, Meleshko VP, Khlebnikova El, Shkolnik IM (2012) Assessment of climate impacts on agriculture in Russia over the first half of the 21st century: current opportunities provided by numerical modelling. Agrophysics 3:22-30

Kazstat (2014) Agriculture, forestry and fishing in Kazakhstan in 1990-2014 (Sel'skoe, Lesnoe I Rybnoe Hozjajstvo Kazahstana v 1990-2014). A set of statistical yearbooks for 1990-2014. Agency of Statistics of Kazakhstan, Almaty

Keenleyside C, Tucker GM (2010) Farmland abandonment in the EU: an assessment of trends and prospects. Report prepared for WWF. Institute for European Environmental Policy, London

Kelley CP, Mohtadi S, Cane MA, Seager R, Kushnir Y (2015) Climate change in the fertile crescent and implications of the recent Syrian drought. Proc Nat Acad Sci USA 112(11):3241-3246

Kharuk VI, Dvinskaya ML, Petrov IA, Im ST, Ranson KJ (2016) Larch forests of middle Siberia: long-term trends in fire return intervals. Reg Environ Chang. doi: 10.1007/s10113-016-0964-9

Kharuk VI, Im ST, Petrov IA, Golyukov AS, Ranson KJ, Yagunov MN (2017) Climate-induced mortality of Siberian pine and fir in the Lake Baikal watershed, Siberia. For Ecol Manag 384:191-199 http://dx.doi.org/10. 1016/j.foreco.2016.10.050

Kharuk VI, Im ST, Petrov IA, Ranson KJ, Yagunov MN (2017) Climate-induced northerly expansion of Siberian Silkmoth range. Forests 8:301. doi: 10. 3390/f8080301

Khon VC, Mokhov II (2012) The hydrological regime of large river basins in northern Eurasia in the XX-XXI centuries. Water Res 39(1):1-10. doi: 10.1134/ S0097807812010058

Khromova T, Nosenko G, Kutuzov S, Muraviev A, Chernova L (2014) Glacier area changes in northern Eurasia. Environ Res Lett 9(1):015003. doi: 10.1088/17489326/9/1/015003

Khrustalev LN, Davidova IV (2007) Forecast of climate warming and account of it at estimation of foundation reliability for buildings in permafrost zone. Earth Cryosphere 11(2):68-75 (in Russian)

Khrustalev LN, Parmuzin SY, Emelyanova LV (2011) Reliability of northern infrastructure in conditions of changing climate. University Book Press, Moscow

Khvostikov S, Venevsky S, Bartalev S (2015) Regional adaptation of a dynamic global vegetation model using a remote sensing data derived land cover map of Russia. Environ Res Lett 10(12):125007

Kicklighter DW, Cai Y, Zhuang Q, Parfenova El, Paltsev S, Sokolov AP, Melillo JM, Reilly JM, Tchebakova NM, Lu X (2014) Potential influence of climate-induced vegetation shifts on future land use and associated land carbon fluxes in northern Eurasia. Environ Res Lett 9:035004. doi: 10. 1088/1748-9326/9/3/035004

Kicklighter DW, Hayes DJ, McClelland JW, Peterson BJ, McGuire AD, Melillo JM (2013) Insights and issues with simulating terrestrial DOC loading of arctic river networks. Ecol Appl 23(8):1817-1836. doi: 10.1890/11-1050.1

Kim H-S, Maksyutov S, Glagolev MV, Machida T, Patra PK, Sudo K, Inoue G (2011) Evaluation of methane emissions from West Siberian wetlands based on inverse modeling. Environ Res Lett 6(3):035201. doi: 10.1088/1748-9326/6/3/035201

Kirschke $S$, Bousquet $P$, Ciais $P$, Saunois M, Canadell JG, Dlugokencky EJ, Bergamaschi P, Bergmann D, Blake DR, Bruhwiler L, Cameron-Smith P, Castaldi S, Chevallier F, Feng L, Fraser A, Heimann M, Hodson El, Houweling S, Josse B, Fraser PJ, Krummel PB, Lamarque JF, Langenfelds RL, Le Quéré C, Naiket $V$, al. (2013) Three decades of global methane sources and sinks. Nat Geosci 6:813-823. doi: 10.1038/NGEO1955

Klehmet K, Geyer B, Rockel B (2013) A regional climate model hindcast for Siberia: analysis of snow water equivalent. Cryosphere 7:1017-1034. doi: 10. 5194/tc-7-1017-2013 
Klein I, Gessner U, Kuenzer C (2012) Regional land cover mapping and change detection in Central Asia using MODIS time-series. Appl Geogr 35(1-2):219-234

Knorn J, Kuemmerle T, Szabo A, Hostert P (2012) Forest restitution and protected area effectiveness in post-socialist Romania. Biol Conserv 146(1):204-212. doi: 10.1016/j.biocon.2011.12.020

Koch N, Valiyev A (2015) Urban boosterism in closed contexts: spectacular urbanization and second-tier mega-events in three Caspian capitals. Eurasia Geograp Econ 56(5):575-598. doi: 10.1080/15387216.2016.1146621

Kopáček J, Posch M (2011) Anthropogenic nitrogen emissions during the Holocene and their possible effects on remote ecosystems. Glob Biogeochem Cycles 25(2):GB2017. doi: 10.1029/2010GB003779

Kopáček J, Posch M, Hejzlar J, Oulehle F, Volková A (2012) An elevation-based regional model for interpolating sulphur and nitrogen deposition. Atmos Environ 50:287-296. doi: 10.1016/j.atmosenv.2011.12.017

Kopačková V, Lhotáková Z, Oulehle F, Albrechtová J (2015) Assessing forest health via linking the geochemical properties of soil profile with the biochemical parameters of vegetation. Int J Environ Sci Technol 12(6):19872002. doi: 10.1007/s13762-014-0602-3

Kopačková V, Misurec J, Lhotakova Z, Oulehle F, Albrechtová J (2014) Using multi-date high spectral resolution data to assess physiological status of macroscopically undamaged foliage on a regional scale. Int J Appl Earth Obs Geoinform 27:169-186

Koven CD, Lawrence DM, Riley WJ (2015) Permafrost carbon-climate feedback is sensitive to deep soil carbon decomposability but not deep soil nitrogen dynamics. Proc Nat Acad Sci USA 112(12):3752-3757. doi: 10.1073/pnas. 1415123112

Koven CD, Ringeval B, Friedlingstein $P$, Ciais $P$, Cadule $P$, Khvorostyanov D, Krinner G, Tarnocai C (2011) Permafrost carbon-climate feedbacks accelerate global warming. Proc Nat Acad Sci USA 108(36):14769-14774. doi: 10.1073/ pnas.1103910108

Kozharinov AV, Borisov PV (2013) Distribution of oak forests in Eastern Europe over the last 13000 years. Contemp Probl Ecol 6(7):755-760 Pleiades Publishing, Ltd. (original paper was published in Lesovedenie 2012 (5):22-28 in Russian)

Kraemer R, Prishchepov AV, Müller D, Kuemmerle T, Radeloff VC, Dara A, Terekhov A, Frühauf M (2015) Long-term agricultural land-cover change and potential for cropland expansion in the former virgin lands area of Kazakhstan. Environ Res Lett 10(5):054012. doi: 10.1088/1748-9326/10/5/ 054012

Krylov A, McCarty JL, Potapov P, Loboda T, Tyukavina A, Turubanova S, Hansen MC (2014) Remote sensing estimates of stand-replacement fires in Russia, 20022011. Environ Res Lett 9(10):105007. doi: 10.1088/1748-9326/9/10/105007

Krysanova V, Wortmann M, Bolch T, Merz B, Duethmann D, Walter J, Huang S, Tong J, Buda S, Kundzewicz ZW (2015) Analysis of current trends in climate parameters, river discharge and glaciers in the Aksu River basin (Central Asia). Hydrol Sci J 60(4):566-590

Kuchment LS, Gelfan AN, Demidov VN (2011) Modeling of the hydrological cycle of a forest river basin and hydrological consequences of forest cutting. The Open Hydrology Journal 5:9-18

Kuemmerle T, Baskin L, Leitão P, Prishchepov AV, Thonicke K, Radeloff VC (2014) Potential impacts of oil and gas development and climate change on migratory reindeer calving grounds across the Russian Arctic. Divers Distrib 20(4):416-429. doi: 10.1111/ddi.12167

Kuemmerle T, Chaskovskyy O, Knorn J, Radeloff VC, Kruhlov I, Keeton WS, Hostert P (2009) Forest cover change and illegal logging in the Ukrainian Carpathians in the transition period from 1988 to 2007. Remote Sens Environ 113(6):1194-1207. doi: 10.1016/j.rse.2009.02.006

Kuemmerle T, Hostert P, Radeloff VC, van der Linden S, Perzanowski K, Kruhlov I (2008) Cross-border comparison of post-socialist farmland abandonment in the Carpathians. Ecosystems 11(4):614-628. doi: 10.1007/s10021-008-9146-z

Kuemmerle T, Olofsson P, Chaskovskyy O, Baumann M, Ostapowicz K, Woodcock C, Hougton RA, Hostert P, Keeton W, Radeloff VC (2011) Post-Soviet farmland abandonment, forest recovery, and carbon sequestration in western Ukraine. Glob Chang Biol 17(3):1335-1349. doi: 10.1111/j.1365-2486.2010.02333.x

Kuemmerle T, Perzanowski K, Akcakaya HR, Beaudry F, van Deelen TR, Parnikoza I, Khoyetskyy P, Waller DM, Radeloff VC (2011) Cost-effectiveness of different conservation strategies to establish a European bison metapopulation in the Carpathians. J Appl Ecol 48(2):317-329. doi: 10.1111/j.1365-2664.2010.01954.x

Kukavskaya EA, Buryak LV, Ivanova GA, Conard SG, Kalenskaya OP, Zhila SV, McRae DJ (2013) Influence of logging on the effects of wildfire in Siberia. Environ Res Lett 8(4):045034. doi: 10.1088/1748-9326/8/4/045034
Kukavskaya EA, Buryak LV, Shvetsov EG, Conard SG, Kalenskaya OP (2016) The impact of increasing fire frequency on forest transformations in southern Siberia. For Ecol Manag 382:225-235 http://dx.doi.org/10.1016/j. foreco.2016.10.015

Kukavskaya EA, Soja AJ, Petkov AP, Ponomarev El, Ivanova GA, Conard SG (2013) Fire emissions estimates in Siberia: evaluation of uncertainties in area burned, land cover, and fuel consumption. Canadian J Forest Res 43(5):493-506. doi: 10.1139/cjfr-2012-0367

Kukuev YA, Krankina ON, Harmon ME (1997) The forest inventory system in Russia: a wealth of data for western researchers. J Forestry 95:15-20

Kumpula T, Pajunen A, Kaarlejärvi E, Forbes BC, Stammler F (2011) Land use and land cover change in Arctic Russia: ecological and social implications of industrial development. Glob Environ Change 21(2):550-562. doi: 10.1016/j. gloenvcha.2010.12.010

Kundzewicz ZW, Merz B, Vorogushyn S, Hartmann H, Duethmann D, Wortmann M, Huang S, Su B, Jiang T, Krysanova V (2015) Analysis of changes in climate and river discharge with focus on seasonal runoff predictability in the Aksu River basin. Hydrol Sci J 60(4):501-516

Kurganova I, Lopes de Gerenyu V, Kuzyakov Y (2015) Large-scale carbon sequestration in post-agrogenic ecosystems in Russia and Kazakhstan. Catena 133:461-466. doi: 10.1016/j.catena.2015.06.002

Kurganova I, Lopes de Gerenyu V, Six J, Kuzyakov Y (2014) Carbon cost of collective farming collapse in Russia. Glob Chang Biol 20(3):938-947. doi: 10. $1111 /$ gcb.12379

Kutuzov S, Lavrentiev I, Vasilenko E, Macheret YY, Petrakov DA, Popov GV (2015) Estimation of the greater Caucasus glaciers volume, using radioecho sounding data and modelling. Earth's Cryosphere XIX(1):78-88

Kutuzov S, Shahgedanova M (2009) Changes in the extent of glaciers in the eastern Terskey Alatoo, the central Tien-Shan, in response to climatic fluctuations in between the end of the 19th and the beginning of the 21st century. Glob Planet Chang 69(1-2):59-70

Lambrecht A, Mayer C, Hagg W, Popovnin V, Rezepkin A, Lomidze N, Svanadze D (2011) A comparison of glacier melt on debris-covered glaciers in the northern and southern Caucasus. Cryosphere 5:525-538

Lammers RB, Pundsack JW, Shiklomanov AI (2007) Variability in river temperature, discharge, and energy flux from the Russian pan-Arctic landmass. J Geophys Res 112:G04S59. doi: 10.1029/2006JG000370

Lapenis A, Shvidenko A, Schepaschenko D, Nilsson S, Aiyyer A (2005) Acclimation of Russian forests to recent change in climate. Glob Chang Biol 11(12):20902102. doi: 10.1111/j.1365-2486.2005.001069.x

Le Quéré C, Moriarty R, Andrew RM, Canadell JG, Sitch S, Korsbakken J, Friedlingstein P, Peters GP, Andres RJ, Boden TA, Houghton RA, House Jl, Keeling RF, Tans P, Arneth A, Bakker DCF, Barbero L, Bopp L, Chang J, Chevallier F, Chini LP, Ciais P, Fader M, Feely RA, Gkritzalis T, Harris I, Hauck J, Ilyina T, Jain AK, Kato E et al (2015) Global carbon budget 2015. Earth System Science Data 7:349-396. doi: 10.5194/essd-7-349-2015

Lebed L, Qi J, Heilman P (2012) An ecological assessment of pasturelands in the Balkhash area of Kazakhstan with remote sensing and models. Environ Res Lett 7(2):025203. doi: 10.1088/1748-9326/7/2/025203

LeGrande AN, Schmidt GA, Shindell DT, Field CV, Miller RL, Koch DM, Faluvegi G, Hoffmann $G$ (2006) Consistent simulations of multiple proxy responses to an abrupt climate change event. Proc Natl Acad Sci 103(4):837-842. doi: 10. 1073/pnas.0510095103

Lei G (2011) Impacts of natural disaster to agricultural development in Heilongjiang Province. J Agrotech Economics 2011(4):38-39

Lerman Z, Csaki C, Feder G (2004) Agriculture in transition: land policies and evolving farm structures in post-soviet countries. Lexington Books, Lanham, Boulder, New York, Toronto, Oxford

Li C, Qi J, Yang L, Wang S, Yang W, Zhu G, Zou S, Zhang F (2014) Regional vegetation dynamics and its response to climate change - a case study in the Tao River basin in Northwestern China. Environ Res Lett 9(12):125003

Li Q, Xu L, Pan X, Zhang L, Li C, Yang N, Qi J (2016) Modeling phenological responses of Inner Mongolia grassland species to regional climate change. Environ Res Lett 11(1):015002

Liefert WM, Liefert O, Vocke G, Allen EW (2010) Former soviet union region to play larger role in meeting world wheat needs. Amber waves. Retrieved from http://ideas.repec.org/a/ags/uersaw/121958.html

Lieskovský J, Bezák P, pulerova J, Lieskovský T, Koleda P, Dobrovodská M, Bürgi M, Gimmi U (2015) The abandonment of traditional agricultural landscape in Slovakia - analysis of extent and driving forces. J Rural Stud 37:75-84. doi: 10 1016/j.jrurstud.2014.12.007 
Linsbauer A, Paul F, Haeberli W (2012) Modeling glacier thickness distribution and bed topography over entire mountain ranges with glabtop: application of a fast and robust approach. J Geophys Res Earth Surf 117(3):1-17. doi: 10 1029/2011JF002313

Lioubimtseva E, Henebry GM (2009) Climate and environmental change in arid Central Asia: impacts, vulnerability, and adaptations. J Arid Environ 73(11): 963-977. doi: 10.1016/j.jaridenv.2009.04.022

Lioubimtseva E, Henebry GM (2012) Grain production trends in Russia, Ukraine and Kazakhstan: new opportunities in an increasingly unstable world? Frontiers of Earth Science 6(2):157-166. doi: 10.1007/s11707-012-0318-y

Liu Y, Liu Y, Chen Y, Long H (2010) The process and driving forces of rural hollowing in China under rapid urbanization. J Geograph Sci 20(6):876-888 doi: 10.1007/s11442-010-0817-2

Liu Y, Zhuang Q, Chen M, Pan Z, Tchebakova N, Sokolov A, Kicklighter D, Melillo J, Sirin A, Zhou G, He Y, Chen J, Bowling L, Miralles D, Parfenova E (2013) Response of evapotranspiration and water availability to changing climate and land cover on the Mongolian plateau during the 21st century. Glob Planet Chang 108:85-99. doi: 10.1016/j.gloplacha.2013.06.008

Liu Y, Zhuang Q, Miralles D, Pan Z, Kicklighter D, Zhu Q, He Y, Chen J, Tchebakova N, Sirin A, Niyogi D, Melillo J (2015) Evapotranspiration in northern Eurasia: impact of forcing uncertainties on terrestrial ecosystem model estimates. J Geophys Res Atmospheres 120(7):2647-2660. doi: 10. 1002/2014JD022531

Liu Y, Zhuang Q, Pan Z, Miralles D, Tchebakova N, Kicklighter D, Chen J, Sirin A, He Y, Zhou G, Melillo J (2014) Response of evapotranspiration and water availability to the changing climate in northern Eurasia. Clim Chang 126(3): 413-427. doi: 10.1007/s10584-014-1234-9

Loboda TV, Chen D (2016) Spatial distribution of young forests and carbon fluxes within recent disturbances in Russia. Glob Chang Biol. doi: 10.1111/gcb.13349

Loboda TV, Csiszar IA (2007) Assessing the risk of ignition in the Russian far east within a modeling framework of fire threat. Ecol Appl 17(3):791-805. doi: 10. 1890/05-1476

Loboda TV, Krankina ON, Kurbanov EA, Savin I, Hall JV (2016) Land management and impact of 2010 extreme drought event on agricultural and ecological systems of European Russia. In: Gutman G, Radeloff V (eds) Land-cover and land-use change in Eastern Europe 1990-2010: impacts of the breakup of the soviet union

Loboda TV, Zhang Z, O'Neal KJ, Sun G, Csiszar IA, Shugart HH, Sherman NJ (2012) Reconstructing disturbance history using satellite-based assessment of the distribution of land cover in the Russian far east. Remote Sens Environ 118: 241-248. doi: 10.1016/j.rse.2011.11.022

Loranty MM, Berner LT, Goetz SJ, Jin Y, Randerson JT (2014) Vegetation controls on northern high latitude snow-albedo feedback: observations and CMIP5 model simulations. Glob Chang Biol 20(2):594-606. doi: 10.1111/gcb.12391

Lu N, Wilske B, Ni J, John R, Chen J (2009) Climate change in Inner Mongolia from 1955 through 2005. Environ Res Lett 4:045006. doi: 10.1088/1748-9326/4/4/045006

Lu Y, Zhuang Q, Zhou G, Sirin A, Melillo J, Kicklighter D (2009) Possible decline of the carbon sink in the Mongolian plateau during the 21st century. Environ Res Lett 4(4):045023. doi: 10.1088/1748-9326/4/4/045023

Lu Z, Streets DG, Zhang Q, Wang S, Carmichael GR, Cheng YF, Wei C, Chin M, Diehl T, Tan Q (2010) Sulfur dioxide emissions in China and sulfur trends in East Asia since 2000. Atmos Chem Phys 10(13):6311-6331. doi: 10.5194/acp10-6311-2010

Lugina KM, Groisman PY, Vinnikov KY, Koknaeva W, Speranskaya NA (2006) Monthly surface air temperature time series area-averaged over the 30 degree latitudinal belts of the globe, 1881-2005. In: Trends online: a compendium of data on global change. Carbon Dioxide Information Analysis Center, Oak Ridge National Laboratory, U.S. Department of Energy, Oak Ridge. doi: 10.3334/CDIAC/cli.003 (on October 28, 2017 has been available at http://cdiac.ess-dive.lbl.gov/trends/temp/lugina/lugina.html)

Lupo AR, Mokhov II, Akperov MG, Chernokulsky AV, Hussain A (2012) A dynamic analysis of the role of the planetary and synoptic scale in the summer of 2010 blocking episodes over the European part of Russia. Adv Meteorol 2012:584257

Lupo AR, Oglesby RJ, Mokhov II (1997) Climatological features of blocking anticyclones: a study of northern hemisphere CCM1 model blocking events in present-day and double $\mathrm{CO}_{2}$ concentration atmospheres. Climate Dyn 13(3):181-195. doi: 10.1007/s003820050159

MacDougall AH, Knutti R (2016) Projecting the release of carbon from permafrost soils using a perturbed parameter ensemble modeling approach Biogeosciences 13:2123-2136. doi: 10.5194/bg-13-2123-2016
Macias-Fauria M, Forbes BC, Zetterberg P, Kumpula T (2012) Eurasian Arctic greening reveals teleconnections and the potential for structurally novel ecosystems. Nat Clim Chang 2:613-618. doi: 10.1038/nclimate1558

Magliocca NR, Brown DG, Ellis EC (2013) Exploring agricultural livelihood transitions with an agent-based virtual laboratory: global forces to local decision-making. PLoS One 8(9):e73241. doi: 10.1371/journal.pone.0073241

Maksyutov S, Takagi H, Valsala VK, Saito M, Oda T, Saeki T, Belikov DA, Saito R, Ito A, Yoshida Y, Morino I, Uchino O, Andres RJ, Yokota T (2013) Regional $\mathrm{CO}_{2}$ flux estimates for 2009-2010 based on GOSAT and ground-based $\mathrm{CO}_{2}$ observations. Atmos Chem Phys 13:9351-9373

Malevsky-Malevich SP, Molkentin EK, Nadyozhina ED, Shklyarevich OB (2008) An assessment of potential change in wildfire activity in the Russian boreal forest zone induced by climate warming during the twenty-first century. Clim Chang 86(3):463-474. doi: 10.1007/s10584-007-9295-7

Mannig B, Müller M, Starke E, Merkenschlager C, Mao W, Zhi X, Podzun R, Jacob D, Paeth H (2013) Dynamical downscaling of climate change in Central Asia. Glob Planet Chang 110:26-39

Marchenko SS, Gorbunov AP, Romanovsky VE (2007) Permafrost warming in the Tien Shan Mountains, Central Asia. Glob Planet Chang 56(3-4):311-327. doi: 10.1016/j.gloplacha.2006.07.023

Markov ML (1994) The role of cryogenic barrage in the formation of river discharge in permafrost areas. Meteorology and Hydrology 1994(2):98-104 (in Russian)

Markov ML (2003) Spatial-temporal dynamic of surface and ground water interaction. Proc State Hydrolog Inst Hydrometeoizdat 25:90-104 (in Russian)

Mathieson RS (1979) Japan's role in Soviet economic growth: transfer of technology since 1965. Praeger Publishers, New York

Mátyás C, Sun G (2014) Forests in a water limited world under climate change. Environ Res Lett 9:085001. doi: 10.1088/1748-9326/9/8/085001

McCarty JL, Ellicott EA, Romanenkov V, Rukhovitch D, Koroleva P (2012) Multi-year black carbon emissions from cropland burning in the Russian Federation. Atmos Environ 63:223-238. doi: 10.1016/j.atmosenv.2012.08.053

McCarty JL, Krylov A, Prishchepov AV, Banach DM, Tyukavina A, Potapov P, Turubanova S (2017) Agricultural fires in European Russia, Belarus, and Lithuania, and their impact on air quality, 2002-2012. In: Gutman G, Radeloff $\checkmark$ (eds) Land-cover and land-use change in Eastern Europe after the collapse of the Soviet Union in 1991. Springer, Switzerland doi: 10.1007/978-3-31942638-9-9

McClelland JW, Dery SJ, Peterson BJ, Holmes RM, Wood EF (2006) A pan-arctic evaluation of changes in river discharge during the latter half of the 20th century. Geophys Res Lett 33:L06715. doi: 10.1029/2006GL025753

McClelland JW, Holmes RM, Peterson BJ, Stieglitz M (2004) Increasing river discharge in the Eurasian Arctic: consideration of dams, permafrost thaw, and fires as potential agents of change. J Geophys Res 109(D18):D18102. doi: 10. 1029/2004JD004583

McGuire AD, Hayes DJ, Kicklighter DW, Manizza M, Zhuang Q, Chen M, Follows MJ, Gurney KR, McClelland JW, Melillo JM, Peterson BJ, Prinn RG (2010) An analysis of the carbon balance of the Arctic Basin from 1997 to 2006. Tellus B 62(5):455-474. doi: 10.1111/j.1600-0889.2010. 00497.x

Melillo JM, Lu X, Kicklighter DW, Reilly JM, Cai Y, Sokolov AP (2016) Protected areas' role in climate-change mitigation. Ambio 45(2):133-145. doi: 10.1007/ s13280-015-0693-1

Melillo JM, Reilly JM, Kicklighter DW, Gurgel AC, Cronin TW, Paltsev S, Felzer BS, Wang X, Sokolov AP, Schlosser CA (2009) Indirect emissions from biofuels: how important? Science 326(5958):1397-1399. doi: 10.1126/science.1180251

Meredith EP, Semenov VA, Maraun D, Park W, Chernokulsky AV (2015) Crucial role of Black Sea warming in amplifying the 2012 Krymsk precipitation extreme. Nat Geosci 8(8):615-619. doi: 10.1038/ngeo2483

Meyfroidt P, Schierhorn F, Prishchepov AV, Müller D, Kuemmerle T (2016) Drivers, constraints and trade-offs associated with recultivating abandoned cropland in Russia, Ukraine and Kazakhstan. Glob Environ Chang 37:1-15. doi: 10.1016/ j.gloenvcha.2016.01.003

Miao C, Duan Q, Sun Q, Huang Y, Kong D, Yang T, Ye A, Di Z, Gong W (2014) Assessment of CMIP5 climate models and projected temperature changes over northern Eurasia. Environ Res Lett 9(5):055007

Mišurec J, Kopačková V, Lhotáková Z, Campbell P, Albrechtová J (2016) Detection of spatio-temporal changes of Norway spruce forest stands in Ore Mountains using Landsat time series and airborne hyperspectral imagery. Remote Sens 8(2):92. doi: 10.3390/rs8020092

Mokhov II, Akperov MG, Prokofyeva MA, Timazhev AV, Lupo AR, Le Treut H (2013) Blockings in the northern hemisphere and euro-Atlantic region: estimates of 
changes from reanalysis data and model simulations. Doklady Earth Sci 449(2):430-433. doi: 10.1134/S1028334X13040144

Mokhov II, Semenov VA, Khon VC, Pogarsky FA (2013) Change of the sea ice extent in the Arctic and the associated climate effects: detection and simulation. Ice Snow 2013(2):53-62 (in Russian with English Summary and Figure captions). doi: 10.15356/2076-6734-2013-2-53-62

Monier E, Kicklighter D, Sokolov A, Zhuang Q, Sokolik I, Lawford R, Kappas M, Paltsev S, Groisman P (2017) A review of and perspectives on global change modeling for northern Eurasia. Environ Res Lett 12:083001

Monier E, Sokolov A, Schlosser A, Scott J, Gao X (2013) Probabilistic projections of 21st century climate change over northern Eurasia. Environ Res Lett 8(4): 045008. doi: 10.1088/1748-9326/8/4/045008

Motovilov Y, Gelfan A (2013) Assessing runoff sensitivity to climate change in the Arctic basin: empirical and modelling approaches. In: Gelfan A, Yang D, Gusev E, Kunstmann H (eds) Cold and mountain region hydrological systems under climate change: towards improved projections, vol 360. IAHS Publications, pp 105-112

Mukhortova L, Schepaschenko D, Shvidenko A, McCallum I, Kraxner F (2015) Soil contribution to carbon budget of Russian forests. Agric For Meteorol 200:97-108

Narama C, Kääb A, Duishonakunov M, Abdrakhmatov K (2010) Spatial variability of recent glacier area changes in the Tien Shan Mountains, Central Asia, using corona ( 1970), Landsat ( 2000), and ALOS ( 2007) satellite data. Glob Planet Chang 71:42-54. doi: 10.1016/j.gloplacha.2009.08.002

Narayan C, Fernandes PM, van Brusselen J, Schuck A (2007) Potential for $\mathrm{CO}_{2}$ emissions mitigation in Europe through prescribed burning in the context of the Kyoto protocol. For Ecol Manag 251(3):164-173. doi: 10.1016/j.foreco. 2007.06.042

Nelson GC, Valin H, Sands RD, Havlík P, Ahammad H, Deryng D, Elliott J, Fujimori S, Hasegawa T, Heyhoe E, Kyle P, Von Lampe M, Lotze-Campen H, Mason d'Croza D, van Meijl H, van der Mensbrugghem D, Müller C, Popp A Robertson R, Robinson S, Schmid E, Schmitz C, Tabeau A, Willenbockel D (2014) Climate change effects on agriculture: economic responses to biophysical shocks. PNAS 111(9):3274-3279. doi: 10.1073/pnas.1222465110

Nelson GC, von der Mensbrugghe D, Ahammad H, Blanc E, Calvin K, Hasegawa T, Havlik P, Heyhoe E, Kyle P, Lotze-Campen H, von Lampe M, Mason d'Croz D, van Meijl H, Müller C, Reilly J, Robertson R, Sands RD, Schmitz C, Tabeau A, Takahashi K, Valin H, Willenbockel D (2014) Agriculture and climate change in global scenarios: why don't the models agree. Agric Econ 45(1):85-101. doi: 10.1111/agec.12091

Newell JP, Simeone J (2014) Russia's forests in a global economy: how consumption drives environmental change. Eurasian Geography Econ 55(1): 37-70. doi: 10.1080/15387216.2014.926254

Newell JP, Wilson E (2004) The Russian far east. Friends of the Earth, Tokyo

Newson RL (1973) Response of a general circulation model of the atmosphere to removal of the Arctic ice-cap. Nature 241:39-40. doi: 10.1038/241039b0

Nghiem SV, Balk D, Rodriguez E, Neumann G, Sorichetta A, Small C, Elvidge CD (2009) Observations of urban and suburban environments with global satellite Scatterometer data. ISPRS J Photogr Remote Sens 64:367-380. doi: 10.1016/j.isprsjprs.2009.01.004

Nghiem SV, Hall DK, Rigor IG, Li P, Neumann G (2014) Effects of Mackenzie River discharge and bathymetry on sea ice in the Beaufort Sea. Geophys Res Lett 41:873-879. doi: 10.1002/2013GL058956

Nghiem SV, Small C (2016) Synergistic use of multi-satellite sensors for mapping and monitoring LCLUC across multi-scales in the time-space continuum, invited key-note presentation. 2nd EARSeL SIG LU/LC and NASA LCLUC joint Workshop, Prague

Nikodemus O, Bell S, Grine I, Liepins I (2005) The impact of economic, social and political factors on the landscape structure of the Vidzeme uplands in Latvia. Landsc Urban Plan 70(1-2):57-67. doi: 10.1016/j.landurbplan. 2003.10.005

Nosenko GA, Khromova TE, Rototaeva OV, Shahgedanova MV (2013) Glacier reaction to temperature and precipitation change in central Caucasus, 20012010. Ice Snow 2013(1):26-33 (in Russian with English Summary)

Novenko EY, Olchev AV (2015) Early Holocene vegetation and climate dynamics in the central part of the East European Plain (Russia). Quat Int 388:12-22. doi: 10.1016/j.quaint.2015.01.027

Novenko EY, Zyuganova IS, Olchev AV (2014) Application of the paleoanalog method for prediction of vegetation dynamics under climate changes. Dok Biol Sci 457(1):228-232. doi: 10.1134/S0012496614040024

Ojima D, Chuluun T (2008) Policy changes in Mongolia: implications for land use and landscapes. In: Galvin K, Reid R, Behnke R, Hobb N (eds) Fragmentation in semi-arid and arid landscape: consequences for human and natural systems. Springer, Dordrecht

Olchev A, Novenko E, Desherevskaya O, Krasnorutskaya K, Kurbatova J (2009) Effects of climatic changes on carbon dioxide and water vapor fluxes in boreal forest ecosystems of European part of Russia. Environ Res Lett 4(4): 045007. doi: 10.1088/1748-9326/4/4/045007

Olchev A, Radler K, Sogachev A, Panferov O, Gravenhorst G (2009) Application of a three-dimensional model for assessing effects of small clear-cuttings on radiation and soil temperature. Ecol Model 220(21):3046-3056. doi: 10.1016/j. ecolmodel.2009.02.004

Olchev A, Volkova E, Karataeva T, Novenko E (2013) Growing season variability of net ecosystem $\mathrm{CO}_{2}$ exchange and evapotranspiration of a sphagnum mire in the broad-leaved forest zone of European Russia. Environ Res Lett 8(3): 035051. doi: 10.1088/1748-9326/8/3/035051

Olchev AV, Deshcherevskaya OA, Kurbatova YA, Molchanov AG, Novenko EY, Pridacha VB, Sazonova TA (2013) $\mathrm{CO}_{2}$ and $\mathrm{H}_{2} \mathrm{O}$ exchange in the forest ecosystems of southern taiga under climate changes. Dokl Biol Sci 450:173176. doi: $10.1134 / \mathrm{S} 0012496613030216$

Oltchev A, Cermak J, Gurtz J, Tishenko A, Kiely G, Nadezhdina N, Zappa M, Lebedeva N, Vitvar T, Albertson JD, Tatarinov F, Tishenko D, Nadezhdin V, Kozlov B, Ibrom A, Vygodskaya N, Gravenhorst G (2002) The response of the water fluxes of the boreal forest region at the Volga's source area to climatic and land-use changes. Phys Chem Earth 27(9-10):675-690. doi: 10.1016/S1474-7065(02)00052-9

Oltchev A, Cermak J, Nadezhdina N, Tatarinov F, Tishenko A, Ibrom A, Gravenhorst G (2002) Transpiration of a mixed forest stand: field measurements and simulation using SVAT models. Boreal Env Res 7:389-397 http://www.borenv.net/

Onuchin A, Korets M, Shvidenko A, Burenina T, Musokhranova A (2014) Modeling air temperature changes in northern Asia. Glob Planet Chang 122:14-22. doi: 10.1016/j.gloplacha.2014.07.011

Osadchiev A (2015) A method for quantifying freshwater discharge rates from satellite observations and Lagrangian numerical modeling of river plumes. Environ Res Lett 10(8):085009

Oulehle F, Cosby BJ, Wright RF, Hruška J, Kopáček J, Krám P, Evans CD, Moldan F (2012) Modelling soil nitrogen: the MAGIC model with nitrogen retention linked to carbon turnover using decomposer dynamics. Environ Pollut 165: 158-166. doi: 10.1016/j.envpol.2012.02.021

Oulehle F, Evans CD, Hofmeister J, Krejci R, Tahovska K, Persson T, Cudlin P, Hruska J (2011) Major changes in forest carbon and nitrogen cycling caused by declining sulphur deposition. Glob Chang Biol 17(10):3115-3129. doi: 10. 1111/j.1365-2486.2011.02468.x

Oulehle F, McDowell WH, Aitkenhead-Peterson JA, Krám P, Hruška J, Navrátil T, Buzek F, Fottová D (2008) Long-term trends in stream nitrate concentrations and losses across watersheds undergoing recovery from acidification in the Czech Republic. Ecosystems 11(3):410-425 doi: 10/1007/s10021-008-9130-7

Overland JE, Hanna E, Hanssen-Bauer I, Kim B-M, Kim S-J, Walsh J, Wang M, Bhatt U (2014) Air temperature, in Arctic report card: update for 2014. http://www. arctic.noaa.gov/Report-Card

Pan Y, Birdsey RA, Fang J, Houghton R, Kauppi PE, Kurz WA, Phillips OL, Shvidenko A Lewis SL, Canadell JG, Ciais P, Jackson RB, Pacala SW, McGuire AD, Piao S, Rautiainen A, Sitch S, Hayes D (2011) A large and persistent carbon sink in the world's forests. Science 333:988-993. doi: 10.1126/science.1201609

Parfenova El, Tchebakova NM, Vlasenko VI (2013) Possible change of ecosystems, species ranges, and biodiversity in the Altai-Sayan ecoregion in a changing climate by 2050. Chapter 6.2:267-288. In: Mikhailov NN (ed) Climate change and biodiversity in the Russian portion of the Altai-Sayan ecoregion. UN Program on Development "Network extension of exclusive protected natural territories in the Altai-Sayan ecoregion", Krasnoyarsk (in Russian)

Parham LM, Prokushkin AS, Pokrovsky OS, Titov SV, Grekova E, Shirokova LS, McDowell WH (2014) Permafrost and fire as regulators of stream chemistry in basins of the central Siberian plateau. Biogeochemistry 116(1):55-68. doi: 10. 1007/s10533-013-9922-5

Park T, Ganguly S, Tømmervik H, Euskirchen ES, Høgda K-A, Karlsen SR, Brovkin V, Nemani RR, Myneni RB (2016) Changes in growing season duration and productivity of northern vegetation inferred from long-term remote sensing data. Environ Res Lett 11:084001. doi: 10.1088/1748-9326/11/8/084001

Park YH, Sokolik I (2016) Toward developing a climatology of fire emissions in Central Asia. Air Soil Water Res 9:87-96. doi: 10.4137/ASWR.S39940

Pelyasov A (2011) European regional science: the strength of gaps in our knowledge (review of the ERSA 2009 Lodz congress papers). ERSA conference papers, European regional science association 
Peng Y, Gitelson AA, Sakamoto T (2013) Remote estimation of gross primary productivity in crops using MODIS 250 m data. Remote Sens Environ 128 186-196. doi: 10.1016/j.rse.2012.10.005

Peterson BJ, Holmes RM, McClelland JW, Vörösmarty CJ, Lammers RB, Shiklomanov Al, Shiklomanov IA, Rahmstorf S (2002) Increasing river discharge to the Arctic Ocean. Science 298(5601):2171-2173. doi: 10.1126/ science. 1077445

Peterson LK, Bergen KM, Brown DG, Vashchuk L, Blam Y (2009) Forested land-cover patterns and trends over changing forest management eras in the Siberian Baikal region. For Ecol Manag 257:911-922. doi: 10.1016/j. foreco.2008.10.037

Pieczonka T, Bolch T (2015) Region-wide glacier mass budgets and area changes for the central Tien Shan between 1975 and 1999 using hexagon KH-9 imagery. Glob Planet Chang 128:1-13. doi: 10.1016/j.gloplacha.2014.11.014

Pokrovsky OS, Viers J, Dupré B, Chabaux F, Gaillardet J, Audry S, Prokushkin AS, Shirokova LS, Kirpotin SN, Lapitsky SA, Shevchenko VP (2012) Biogeochemistry of carbon, major and trace elements in watersheds of northern Eurasia drained to the Arctic Ocean: the change of fluxes, sources and mechanisms under the climate warming prospective. Compt Rendus Geosci 344(11-12):663-677. doi: 10.1016/j.crte.2012.08.003

Polishchuk WY, Polishchuk YM (2013) Geoimitational modeling of the thermokarst lakes pattern in the permafrost zones. Yugra State University Publ, KhantyMansijsk (in Russian). ISBN 978-5-9611-0079-2

Polishchuk VY, Polishchuk YM (2014) Modeling of thermokarst lake dynamics in west Siberian permafrost. In: Pokrovsky O (ed) Permafrost: distribution, composition and impacts on infrastructure and ecosystems, vol chap. 6. Nova Sci. Publ, New York, pp 205-234 doi: 10.978-94-007-4569-8

Polishchuk YM, Bryksina NA, Polishchuk WY (2015) Remote analysis of changes in the number and distribution of small Thermokarst Lakes by sizes in Cryolithozone of western Siberia, 2015. Stud Earth Space 2015(3):34-42. doi: $10.7868 /$ S0205961415030100

Porfiriev BN (2001) Instant and creeping environmental crises in Russia. In: Rosenthal U, Boin AR, Comfort LK (eds) Managing crises: threats, dilemmas and opportunities. Charles Thomas Publisher Ltd, Springfield, Illinois

Porfiriev BN (2012) Economic issues of disaster and disaster risk reduction policies: international versus Russian perspectives. Intern J Disaster Risk Reduction 1:55-61. doi: 10.1016/j.jijdrr.2012.05.005

Porfiriev BN (2013) Assessment and forecast of the technological risks of longterm economic growth in Russia. Stud Russian Econ Dev 24(4):316-332

Porfiriev BN (2014) Evaluation of human losses from disasters: the case of the 2010 heat waves and forest fires in Russia. Intern J Disaster Risk Reduction 7: 91-99. doi: 10.1016/j.ijdrr.2013.12.007

Porfiriev BN (2016) The economics of natural disasters. Herald Russ Acad Sci 86(1):1-11

Potapov P, Turubanova S, Zhuravleva I, Hansen M, Yaroshenko A, Manisha A (2012) Forest cover change within the Russian European north after the breakdown of Soviet Union (1990-2005). Int J Forestry Res 2012:729614. doi: 10.1155/2012/729614

Potapov P, Yaroshenko A, Turubanova S, Dubinin M, Laestadius L, Thies C, Aksenov D, Egorov A, Yesipova Y, Glushkov I, Karpachevskiy M, Kostikova A, Manisha A, Tsybikova E, Zhuravleva I (2008) Mapping the world's intact forest landscapes by remote sensing. Ecol Soc 13(2):51 https://www. ecologyandsociety.org/vol13/iss2/art51/

Potapov PV, Turubanova SA, Tyukavina A, Krylov AM, McCarty JL, Radeloff VC, Hansen MC (2015) Eastern Europe's forest cover dynamics from 1985 to 2012 quantified from the full Landsat archive. Remote Sens Environ 159:28-43. doi: 10.1016/j.rse.2014.11.027

Prinn RG (2013) Development and application of earth system models. Proc Nat Acad Sci USA 110(Suppl 1):3673-3680. doi: 10.1073/pnas.1107470109

Prinn RG, Jacoby H, Sokolov A, Wang C, Xiao X, Yang Z, Eckhaus R, Stone P, Ellerman D, Melillo J, Fitzmaurice J, Kicklighter D, Holian G, Liu Y (1999) Integrated global system model for climate policy assessment: feedbacks and sensitivity studies. Clim Chang 41(3-4):469-546. doi: 10.1023/A:1005326126726

Prishchepov AV, Müller D, Baumann M, Kuemmerle T, Alcantara C, Radeloff VS (2017) Underlying drivers and spatial determinants of post-soviet agricultural land abandonment in temperate Eastern Europe. In: Land-cover and land-use changes in Eastern Europe after the collapse of the soviet union in 1991 1-27. Springer International Publishing, Switzerland. doi: 10.1007/978-3-319-42638-9_5

Prishchepov AV, Müller D, Dubinin M, Baumann M, Radeloff VC (2013) Determinants of agricultural land abandonment in post-Soviet European Russia. Land Use Policy 30(1):873-884. doi: 10.1016/j.landusepol.2012.06.011
Prishchepov AV, Radeloff VC, Baumann M, Kuemmerle T, Müller D (2012) Effects of institutional changes on land use: agricultural land abandonment during the transition from state-command to marketdriven economies in post-Soviet Eastern Europe. Environ Res Lett 7(2): 024021. doi: 10.1088/1748-9326/7/2/024021

Qi J, Bobushev TS, Kulmatov R, Groisman P, Gutman G (2012) Addressing global change challenges for central Asian socio-ecosystems. Front Earth Sci 6(2): 115-121. doi: 10.1007/s11707-012-0320-4

Qi J, Chen J, Wan S, Ai L (2012) Understanding the coupled natural and human systems in the Dryland East Asia. Environ Res Lett 7(1):015202. doi: 10.1088/ 1748-9326/7/1/015202

Rahmstorf S (2002) Ocean circulation and climate during the past 120,000 years. Nature 419(6903):207-214. doi: 10.1038/nature01090

Rawlins MA, McDonald KC, Frolking S, Lammers RB, Fahnestock M, Kimball JS, C.J. Vörösmarty CJ (2005) Remote sensing of snow thaw at the pan-Arctic scale using the SeaWinds scatterometer. J Hydrol 312(1-4):294-311. doi: 10.1016/j. jhydrol.2004.12.018

Rawlins MA, McGuire AD, Kimball JS, Dass P, Lawrence D, Burke E, Chen X, Delire C, Koven C, Mac Dougall A, Peng S, Rinke A, Saito K, Zhang W, Alkama R, Bohn TJ, Ciais P, Decharme B, Gouttevin I, Hajima T, Ji D, Krinner G, Lettenmaier DP, Miller P, Moore JC, Smith B, Sueyoshi T (2015) Assessment of model estimates of land-atmosphere $\mathrm{CO}_{2}$ exchange across Northern Eurasia. Biogeosciences 12:4385-4405. doi: 10.5194/bg-4385-2015

Rawlins MA, Steele M, Holland M, Adam J, Cherry J, Francis J, Groisman P, Hinzman L, Huntington T, Kane D, Kimball J, Kwok R, Lammers R, Lee C, Lettenmaier D, McDonald K, Podest E, Pundsack J, Rudels B, Serreze M, Shiklomanov A, Skagseth $\varnothing$, Troy TJ, Vörösmarty CJ, Wensnahan M, Wood, EF Woodgate R, Yang D, Zhang K, T (2010) Analysis of the Arctic system for freshwater cycle intensification: observations and expectations. J Clim 23: 5715-5737. doi: 10.1175/2010JCLI3421.1

Rawlins MA, Steele M, Serreze MC, Vörösmarty CJ, Ermold W, Lammers RB, McDonald KC, Pavelsky TM, Shiklomanov A, Zhang J (2009) Tracing freshwater anomalies through the air-land-ocean system: a case study from the Mackenzie River basin and the Beaufort gyre. Atmos Ocean 47(1):79-97. doi: 10.3137/OC301.2009

Raynolds MK, Walker DA, Ambrosius KJ, Brown J, Everett KR, Kanevskiy M, Kofinas GP, Romanovsky VE, Shur Y, Webber PJ (2014) Cumulative geoecological effects of 62 years of infrastructure and climate change in ice-rich permafrost landscapes, Prudhoe Bay Oilfield, Alaska. Glob Chang Biol 20(4):1211-1224. doi: $10.1111 /$ gcb.12500

Reid PC., Hari RE, Beaugrand G, Livingstone DM, Marty C, Straile D, Barichivich J, Goberville E, Adrian R, Aono Y, Brown R, Foster J, Groisman P, Helaouet P, Hsu HH, Kirby R, Knight J, Kraberg A, Li J, Lo TT, Myneni RB, North RP, Pounds JA, Sparks T, Stubi R, Tian Y, Wiltshire KH,. Xiao D, Zhu Z (2016) Global impacts of the 1980s regime shift. Glob Chang Biol, 22: 682-703. doi: 10.1111/gcb.13106

Reilly J, Melillo J, Cai Y, Kicklighter D, Gurgel A, Paltsev S, Cronin T, Sokolov A Schlosser A (2012) Using land to mitigate climate change: hitting the target, recognizing the tradeoffs. Environ Sci Technoly 46(11):5672-5679. doi: 10. 1021/es2034729

Renner AHH, Gerland S, Haas C, Spreen G, Beckers JF, Hansen E, Nicolaus M, Goodwin H (2014) Evidence of Arctic sea ice thinning from direct observations. Geophys Res Lett 41(14):5029-5036. doi: 10.1002/2014GL060369

Riahi K, Grübler A, Nakicenovic N (2007) Scenarios of long-term socio-economic and environmental development under climate stabilization. Technol Forecast Soc Chang 74(7):887-935

Richter-Menge J, Walsh JE, Brigham LW, Francis AA, Holland M, Nghiem SV, Raye R, Woodgate R (2012) Seasonal-to-decadal predictions of Arctic Sea ice: challenges and strategies. Committee on the future of Arctic Sea ice research in support of seasonal to decadal prediction. Polar Res Board Div Earth Life Studies Nat Res Council ISBN-13: 978-0-309-26526-3, National Academy of Sciences

Rimkus E, Stonevicius E, Korneev VR, Kažys J, Valiuškevicius G, Pakhomau A (2013) Dynamics of meteorological and hydrological droughts in the Neman river basin. Environ Res Lett 8(4):045014. doi: 10.1088/1748-9326/8/4/045014

Robinson DT, Sun S, Hutchins M, Riolo RL, Brown DG, Parker DC, Filatova T, Currie WS, Kiger S (2013) Effects of land markets and land management on ecosystem function: a framework for modelling exurban land change. Environ Model Softw 45:129-140. doi: 10.1016/j.envsoft.2012.06.016

Rogers BM, Soja AJ, Goulden ML, Randerson JT (2015) Influence of tree species on continental differences in boreal fires and climate feedbacks. Nat Geosc 8:228-234. doi: 10.1038/ngeo2352 
Romanenkov V, Rukhovitch D, Koroleva P, McCarty JL (2014) Estimating black carbon emissions from agricultural burning. In: Mueller L, Lischeid G, Saparov A (eds) Novel measurement and assessment tools for monitoring and Management of Land and Water Resources in agricultural landscapes of Central Asia. Springer, New York

Romanovsky VE, Drozdov DS, Oberman NG, Malkova GV, Kholodov AL, Marchenko SS, Moskalenko NG, Sergeev DO, Ukraintseva NG, Abramov AA, Gilichinsky DA, Vasiliev AA (2010) Thermal state of permafrost in Russia. Permafrost Periglacial Process 21:136-155. doi: 10.1002/ppp.683

Romanovsky VE, SI S, Shiklomanov NI, Marchenko SS (2017) Terrestriasl Permafrost. Bull Amer Meteorol Soc 98(8):147-149

Romanovsky VE, Smith SL, Christiansen HH (2010) Permafrost thermal state in the polar northern hemisphere during the international polar year 2007-2009: a synthesis. Permafrost Periglacial Process 21(2):106-116. doi: 10.1002/ppp.689

Rosenzweig C, Elliott J, Deryng D, Ruane AC, Müller C, Arneth A, Boote KJ, Folberth C, Glotter M, Khabarov N, Neumann K, Piontek F, Pugh TAM, Schmid E, Stehfest E, Yang H, Jones JW (2014) Assessing agricultural risks of climate change in the 21 st century in a global gridded crop model intercomparison. Proc Nat Acad Sci USA 111(9):3268-3273. doi: 10.1073/pnas.1222463110

Rossini M, Migliavacca M, Galvagno M, Meroni M, Cogliati S, Cremonese E, Fava F, Gitelson A, Julitta T, Morra di Cella U, Siniscalco C, Colombo R (2014) Remote estimation of grassland gross primary production during extreme meteorological seasons. Intern J Appl Earth Observ Geoinform 29:1-10. doi: 10.1016/j.jag.2013.12.008

Rosstat (2016) Central statistical database. Rosstat. Federal service of state statistics of Russian Federation. Retrieved from http://www.gks.ru/dbscripts/ Cbsd/DBInet.cg

Rotmans J, de Boois H, Swart RJ (1990) An integrated model for the assessment of the greenhouse effect: the Dutch approach. Clim Chang 16(3):331-356. doi: $10.1007 / B F 00144508$

Ruppel CD, Kessler JD (2017) The interaction of climate change and methane hydrates. Rev Geophys 55:126-168. doi: 10.1002/2016RG000534

Sabrekov AF, Glagolev MV, Alekseychik PK, Smolentsev BA, Terentieva IE, Krivenok LA, Maksyutov SS (2016) A process-based model of methane consumption by upland soils. Environ Res Lett 11(7):075001

Sabrekov AF, Runkle BRK, Glagolev MV, Kleptsova IE, Maksyutov SS (2014) Seasonal variability as a source of uncertainty in the West Siberian regional $\mathrm{CH}_{4}$ flux upscaling. Environ Res Lett 9(4):045008

Saeki T, Maksyutov S, Sasakawa M, Machida T, Arshinov M, Tans P, Conway TJ, Saito M, Valsala V, Oda T, Andres RJ, Belikov D (2013) Carbon flux estimation for Siberia by inverse modeling constrained by aircraft and tower $\mathrm{CO}_{2}$ measurements. J Geophys Res 118(2):1100-1122. doi: 10.1002/jgrd.50127

Schaphoff S, Lucht W, Gerten D, Sitch S, Cramer W, Prentice IC (2006) Terrestrial biosphere carbon storage under alternative climate projections. Clim Chang 74(1-3):97-122. doi: 10.1007/s10584-005-9002-5

Schaphoff S, Reyer CPO, Schepaschenko D, Gerten D, Shvidenko A (2015) Tamm review: observed and projected climate change impacts on Russian forests and its carbon balance. For Ecol Manag 361:432-444. doi: 10.1016/j.foreco. 2015.11.043

Schepaschenko DG, Mukhortova LV, Shvidenko AZ, Vedrova EF (2013) The pool of organic carbon in the soils of Russia. Eurasian Soil Sci 46(2):107-116. doi: 10.1134/S1064229313020129

Schierhorn F, Faramarzi M, Prishchepov AV, Koch FJ, Müller D (2014) Quantifying yield gaps in wheat production in Russia. Environ Res Lett 9(8):084017. doi: 10.1088/1748-9326/9/8/084017

Schierhorn F, Müller D, Beringer T, Prishchepov AV, Kuemmerle T, Balmann A (2013) Post-soviet cropland abandonment and carbon sequestration in European Russia, Ukraine, and Belarus. Glob Biogeochem Cycles 27(4):11751185. doi: 10.1002/2013GB004654

Schierhorn F, Müller D, Prishchepov AV, Faramarzi M, Balmann A (2014) The potential of Russia to increase its wheat production through cropland expansion and intensification. Global Food Security 3(3-4):133-141. doi: 10. 1016/j.gfs.2014.10.007

Schöpp W, Posch M, Mylona S, Johansson M (2003) Long-term development of acid deposition (1880-2030) in sensitive freshwater regions in Europe. Hydro Earth Syst Sci 7(4):436-446. doi: 10.5194/hess-7-436-2003

Schubert SD, Wang H, Koster RD, Suarez MJ, Groisman PY (2014) Northern Eurasian heat waves and droughts. J Clim 27(9):3169-3207. doi: 10.1175/JCLID-13-00360.1

Schulze E-D, Wirth C, Mollicone D, von Lüpke N, Ziegler W, Achard F, Mund M, Prokushkin A, Scherbina S (2012) Factors promoting larch dominance in central Siberia: fire versus growth performance and implications for carbon dynamics at the boundary of evergreen and deciduous conifers. Biogeosciences 9:1405-1421. doi: 10.5194/bg-9-1405-2012

Sedykh VN (2014) Dynamics of plain Siberian pine forests of Siberia. Nauka, Novosibirsk (In Russian)

Semenov VA (2012) Meteorology: Arctic warming favours extremes. Nat Clim Chang 2:315-316. doi: 10.1038/nclimate1502

Serreze MC, Barrett AP, Slater AG, Woodgate RA, Aagaard K, Lammers RB, Steele M, Moritz R, Meredith M, Lee CM (2006) The large-scale freshwater cycle of the Arctic. J Geophys Res 111(C11):C11010. doi: 10.1029/2005JC003424

Severskiy I, Vilesov E, Armstrong R, Kokarev A, Kogutenko L, Usmanova Z (2016) Changes in glaciation of the Balkhash-Alakol Basin over the past decades. Ann Glaciol 57(71):382-394. doi: 10.3189/2016AoG71A575

Shahgedanova M, Afzal M, Usmanova Z, Kapitsa V, Mayr E, Hagg W, Severskiy I, Zhumabayev D (2016) Impacts of climate change on river discharge in the northern Tien Shan: results from long-term observations and modelling. In: Medeu A (ed) Water resources in Central Asia and their use. Almaty, Kazakhstan, pp 248-258

Shahgedanova M, Nosenko G, Bushueva I, Ivanov M (2012) Changes in area and geodetic mass balance of small glaciers, polar Urals, Russia, 1950-2008. J Glaciol 58(211):953-964. doi: 10.3189/2012JoG11J233

Shahgedanova M, Nosenko G, Khromova T, Muravyev A (2010) Glacier shrinkage and climatic change in the Russian Altai from the mid-20th century: an assessment using remote sensing and PRECIS regional climate model. J Geophys Res Atmos 115(D16):D16107. doi: 10.1029/2009JD012976

Shahgedanova M, Nosenko G, Kutuzov S, Rototaeva O, Khromova T (2014) Deglaciation of the Caucasus Mountains, Russia/Georgia in the 21st century observed with ASTER satellite imagery and aerial photography. Cryosphere 8: 2367-2379. doi: 10.5194/tc-8-2367-2014

Shahgedanova M, Popovnin V, Aleynikov A, Stokes CR (2011) Geodetic mass balance of the Azarova gGlacier, Kodar Mountains, eastern Siberia and its links to observed and projected climatic changes. Ann Glaciol 52(58):129-137

Shakhova N, Semiletov I, Leifer I, Sergienko V, Salyuk A, Kosmach D, Chernykh D, Stubbs C, Nicolsky D, Tumskoy V, Gustafsson Ö (2013) Ebullition and storminduced methane release from the East Siberian Arctic shelf. Nat Geosci 7: 64-70. doi: 10.1038/NGEO2007

Shakhova N, Semiletov I, Sergienko V, Lobkovsky L, Yusupov V, Salyuk A, Salomatin A, Chernykh D, Kosmach D, Panteleev G, Nicolsky D, Samarkin V, Joye S, Charkin A, Dudarev O, Meluzov A, Gustafsson Ö (2015) The East Siberian Arctic shelf: towards further assessment of permafrost-related methane fluxes and role of sea ice. Phil Trans Roy Soc A 373:20140451. doi: 10.1098/rsta.2014.0451

Shiklomanov Al, Lammers RB (2009) Record Russian river discharge in 2007 and the limits of analysis. Environ Res Lett 4(4):045015. doi: 10.1088/1748-9326/4/ 4/045015

Shiklomanov Al, Lammers RB (2011) River discharge in Arctic. State of the climate in 2010. Bull Amer Meteor Soc 92(6):S153-S154. doi: 10.1175/ 1520-0477-92.6.S1

Shiklomanov Al, Lammers RB (2013) Changing discharge patterns of high-latitude rivers. In: Pielke RA (ed) Climate vulnerability: understanding and addressing threats to essential resources. Volume 5: vulnerability of water resources to climate. Academic Press, Oxford. ISBN 9780123847041. doi: 10.1016/B978-012-384703-4.00526-8

Shiklomanov Al, Lammers RB (2014) River ice responses to a warming Arctic - recent evidence from Russian rivers. Environ Res Lett 9(3):035008. doi: 10.1088/1748-9326/9/3/035008

Shiklomanov Al, Lammers RB, Lettenmaier DP, Polischuk YM, Savichev OG, Smith LS, Chernokulsky AV (2013) Hydrological changes: historical analysis, contemporary status, and future projections. In: Groisman PY, Gutman G (eds) Regional environmental changes in Siberia and their global consequences. Springer, Dordrecht. doi: 10.1007/978-94-007-4569-8_4

Shiklomanov Al, Lammers RB, Rawlins MA, Smith LS, Pavelsky TM (2007) Temporal and spatial variations in maximum river discharge from a new Russian data set. J Geophys Res Biogeosci 112(G4):G04S53. doi: 10.1029/2006JG000352

Shiklomanov NI, Streletskiy DA (2013) Effect of climate change on Siberian infrastructure. In: Groisman PY, Gutman G (eds) Environmental changes in Siberia: regional changes and their global consequences. Springer, Dordrecht

Shiklomanov NI, Streletskiy DA, Swales TB, Kokorev VA (2017) Climate change and stability of urban infrastructure in Russian permafrost regions: prognostic assessment based on GCM climate projections. Geograph Rev 107(1):125142. doi: $10.1111 /$ gere. 12214 
Shkolnik I, Pavlova T, Efimov S, Zhuravlev S (2017) Future changes in peak river flows across northern Eurasia as inferred from an ensemble of regional climate projections under the IPCC RCP8.5 scenario. Clim Dyn 10.1007/ s00382-017-3600-6

Shkolnik IM, Efimov SV (2013) Cyclonic activity in high latitudes as simulated by a regional atmospheric climate model: added value and uncertainties. Environ Res Lett 8(4):045007. doi: 10.1088/1748-9326/8/4/045007

Shkolnik IM, Meleshko VP, Efimov SV, Stafeeva EN (2012) Changes in climate extremes on the territory of Siberia by the middle of the 21 st century: ensemble forecast based on the MGO regional climate model. Russ Meteorol Hydrol 37(2):71-84

Shkolnik IM, Nadyozhina ED, Pavlova TV, Khlebnikova El, Semioshina AA, Molkentin EK, Stafeeva EN (2012) Simulation of the regional features of the seasonal thawing layer in the Siberian permafrost zone. Earth Cryo 16:52-59 (in Russian). http://www.izdatgeo.ru/pdf/krio/2012-2/52.pdf

Shuman JK, Shugart HH (2009) Evaluating the sensitivity of Eurasian forest biomass to climate change using a dynamic vegetation model. Environ Res Lett 4(4):045024. doi: 10.1088/1748-9326/4/4/045024

Shuman JK, Shugart HH (2012) Resilience and stability associated with the conversion of boreal forest. In: Fatoyinbo TE (ed) Remote sensing of biomass: principles and application. Book 1. Intech Open Access Publishing ISBN: 978953-51-0313-4

Shuman JK, Shugart HH, Krankina ON (2013a) Assessment of carbon stores in tree biomass for two management scenarios in Russia. Environ Res Lett 8(4): 045019. doi: 10.1088/1748-9326/8/4/045019

Shuman JK, Shugart HH, Krankina ON (2013b) Testing individual-based models of forest dynamics: issues and an example from the boreal forests of Russia. Ecol Model 293:102-110. doi: 10.1016/j.ecolmodel.2013.10.028

Shuman JK, Tchebakova NM, Parfenova El, Soja AJ, Shugart HH, Ershov D, Holcomb K (2015) Forest forecasting with vegetation models across Russia. Can J For Res 45(2):175-184. doi: 10.1139/cjfr-2014-0138

Shur YL, Goering DJ (2009) Climate change and foundations of buildings in permafrost regions. In: Margesin R (ed) Permafrost soils. Springer, Berlin

Shvetsov EG, Kukavskaya EA, Buryak LV (2016) Satellite monitoring of the state of forest vegetation after fire impacts in the Zabaykal region. Contemp Probl Ecol 9(6):763-771

Shvidenko AZ, Gustafson E, McGuire D, Kharuk VI, Schepaschenko D, Shugart HH, Tchebakova NM, Vygodskaya NN, Onuchin AA, Hayes DJ, McCallum I, Maksyutov S, Mukhortova LV, Soja AJ, Belelli-Marchesini L, Kurbatova JA, Oltchev AV, Parfenova El, Shuman JK (2013) Terrestrial ecosystems and their change. In: Groisman PY, Gutman G (eds) Regional environment change in Siberia and their global consequences. Springer, Dordecht

Shvidenko AZ, Nilsson S (1994) What do we know about the Siberian forests? Ambio 23(7):396-404

Shvidenko AZ, Schepaschenko DG (2013) Climate change and wildfires in Russia. Contemp Probl Ecol 6(7):683-692. doi: 10.1134/S199542551307010X

Shvidenko AZ, Schepaschenko DG (2014) Carbon budget of forests in Russia. Siberian J Forest Sci 2014(1):69-92 (in Russian)

Shvidenko AZ, Schepaschenko DG, Vaganov EA, Sukhinin Al, Maksyutov SS, McCallum I, Lakyda PI (2011) Impacts of wildfire in Russia between 1998-2010 on ecosystems and the global carbon budget. Dokl Earth Sci 441(2):1678-1682

Siljamo P, Sofiev M, Filatova E, Grewling L, Jäger S, Khoreva E, Linkosalo T, Ortega Jimenez S, Ranta H, Rantio-Lehtimäki A, Svetlov A, Veriankaite L, Yakovleva E, Kukkonen J (2013) A numerical model of birch pollen emission and dispersion in the atmosphere. Model evaluation and sensitivity analysis. Int J Biometeorol 57(1):125-136. doi: 10.1007/ s00484-012-0539-5

Smaliychuk A, Müller D, Prishchepov AV, Levers C, Kruhlov I, Kuemmerle T (2016) Recultivation of abandoned agricultural lands in Ukraine: patterns and drivers. Glob Environ Chang 38:70-81. doi: 10.1016/j.gloenvcha.2016.02.009

Smith LC, Pavelsky TM, MacDonald GM, Shiklomanov Al, Lammers RB (2007) Rising minimum daily flows in northern Eurasian rivers: a growing influence of groundwater in the high-latitude hydrologic cycle. J Geophys Res Biogeosci 112(G4):G04S47. doi: 10.1029/2006JG000327

Smith LC, Sheng Y, MacDonald GM, Hinzman LD (2005) Disappearing Arctic Lakes Sc 308(5727):1429. doi: 10.1126/science.1108142

Sofiev M, Siljamo P, Ranta H, Linkosalo T, Jaeger S, Rasmussen A, RantioLehtimaki A, Severova E, Kukkonen J (2013) A numerical model of birch pollen emission and dispersion in the atmosphere. Description of the emission module. Int J Biometeorol 57(1):45-58. doi: 10.1007/ s00484-012-0532-z
Soja AJ, Cofer WR, Shugart HH, Sukhinin Al, Stackhouse PW Jr, McRae DJ, Conard SG (2004) Estimating fire emissions and disparities in boreal Siberia (19982002). J Geophys Res 109(D14):D14S06. doi: 10.1029/2004JD004570

Soja AJ, Tchebakova NM, French NHF, Flannigan MD, Shugart HH, Stocks BJ, Sukhinin Al, Parfenova El, Chapin FS 3rd, Stackhouse PW Jr (2007) Climateinduced boreal forest change: predictions versus current observations. Glob and Planet Change 56(3-4):274-296. doi: 10.1016/j.gloplacha.2006.07.028

Sokolik IN (2013) Dust. In: Encyclopedia of atmospheric sciences, 2nd edn. Academic Press, London

Sokolik IN, Darmenova K, Huang J, Kalashnikova O, Kurosaki Y, Xi X (2013) Examining changes in land cover and land use, regional climate and dust in dryland East Asia and their linkages within the earth. In: Chen J, Wan S, Henebry G, Qi J, Gutman G, Ge S, Kappas M (eds) Dryland East Asia: land dynamics amid social and climate change. De Gryter Publ. House Amsterdam, Higher Education Press, Beijing. doi: 10.1515/9783110287912.183

Sokolov AP, Schlosser CA, Dutkiewicz S, Paltsev S, Kicklighter DW, Jacoby HD, Prinn RG, Forest CE, Reilly J, Wang C, Felzer B, Sarofim MC, Scott J, Stone PH, Melillo JM, Cohen J (2005) The MIT integrated global system model (IGSM) version 2: model description and baseline evaluation. MIT joint program on the science and policy of global change. Report 124.

Sokolov AP, Stonw PH, Forest CE, Prinn R, Sarofim MC, Webster M, Paltsev S, Schlosser CA, Kicklighter D, Dulkiewicz S, Reilly J, Wang C, Feltzer B, Melillo JM, Jakoby HD (2009) Probabilistic forecast for twenty-first-century climate based on uncertainties in emissions (without policy) and climate parameters. J Clim 22:5175-5204. doi: 10.1175/2009JCLI2863.1

Sokratov VS, Shmakin AB (2013) Numerical modeling of snow cover on Hooker Island (Franz Josef land archipelago). Ice Snow 2013(3):55-62 (in Russian with English Summary)

Sorg A, Bolch T, Stoffel M, Solomina O, Beniston M (2012) Climate change impacts on glaciers and runoff in Tien Shan (Central Asia). Nat Clim Chang 2: 725-731. doi: 10.1038/nclimate1592

Speranskaya NA (2011) Changes in some elements of the water cycle in the easternmost part of the Baltic Sea Drainage Basin between 1945 and 2010. Oceanologia 53(Suppl 1):279-292. doi: 10.5697/oc.53-1-TI.279

Speranskaya NA (2016) Actual evaporation from natural green land over European Russia: available observations and restored data. Izvestiya RAS. Seria Geografichescaya 2016(2):49-60 (in Russian)

Stammler F (2005) Reindeer nomads meet the market: culture, property and globalization at the end of the land. Litverlag, Halle Studies in the Anthropology of Eurasia, Muenster

Stephens BB, Gurney KR, Tans PP, Sweeney C, Peters W, Bruhwiler L, Ciais P, Ramonet M, Bousquet P, Nakazawa T, Aoki S, Machida T, Inoue G, Vinnichenko N, Lloyd J, Jordan A, Heimann M, Shibistova O, Langenfelds RL, Steele LP, Francey RJ, Denning AS (2007) Weak northern and strong tropical land carbon uptake from vertical profiles of atmospheric $\mathrm{CO}_{2}$. Science 316(5832):1732-1735. doi: 10.1126/science.1137004

Stephenson SR, Smith LC, Agnew JA (2011) Divergent long-term trajectories of human access to the Arctic. Nat Clim Chang 1(3):256-160. doi: 10.1038/ nclimate 1120

Stokes CR, Shahgedanova M, Evans IS, Popovnin W (2013) Accelerated loss of alpine glaciers in the Kodar Mountains, south-eastern Siberia. Glob Planet Chang 101:82-96

Strategic Assessment of Development of the Arctic (2014) Changes in Arctic maritime transport. URL: https://www.arcticinfo.eu

Streletskiy DA, Anisimov O, Vasiliev A (2015) Permafrost degradation. In: Haeberli W, Whiteman C, Shroder JF Jr (eds) Snow and ice related risks, hazards and disasters. Elsevier, Oxford. doi: 10.1016/B978-0-12-394849-6.00010-X

Streletskiy DA, Shiklomanov NI, Nelson FE (2012) Permafrost, infrastructure and climate change: a GIS-based landscape approach to geotechnical modeling. Arctic Antarctic Alpine Res 44(3):368-380. doi: 10.1657/19384246-44.3.368

Streletskiy DA, Tananaev NI, Opel T, Shiklomanov NI, Nyland KE, Streletskaya ID, Tokarev I, Shiklomanov Al (2015) Permafrost hydrology in changing climatic conditions: seasonal variability of stable isotope composition in rivers in discontinuous permafrost. Environ Res Lett 10(9):095003. doi: 10.1088/17489326/10/9/095003

Sue Wing I, Monier E, Stern A, Mundra A (2015) US major crops' uncertain climate change risks and greenhouse gas mitigation benefits. Environ Res Lett 10(11):115002. doi: 10.1088/1748-9326/10/11/115002

Sukhinin Al (ed) (2010) Catastrophic fires in Siberia. Sukachov Inst. of Forest SibRAS, Krasnoyarsk (in Russian) 
Swinnen J, Burkitbayeva S, Schierhorn F, Prishchepov AV, Müller D (2017) Production potential in the 'bread baskets' of Eastern Europe and Central Asia. Global Food Security 10.1016/j.gfs.2017.03.005

Syromyatina MV, Kurochkin YN, Bliakharskii DP, Chistyakov KV (2015) Current dynamics of glaciers in the Tavan Bogd Mountains (Northwest Mongolia). Environ Earth Sci 74(3):1905-1914. doi: 10.1007/s12665-015-4606-1

Syromyatina MV, Kurochkin YN, Chistyakov K, Ayurzana C (2014) Current state and changes of glaciers in the Tavan Bogd Mountains (Mongolia). Ice Snow 2014(3):31-38 (in Russian). doi: 10.15356/2076-6734-2014-3-31-38

Tchebakova NM, Parfenova El (2012) The 21st century climate change effects on the forests and primary conifers in central Siberia. Bosque 33(3):253-259. doi: 10.4067/S0717-92002012000300004

Tchebakova NM, Parfenova El (2013) Potential land cover change in Siberia predicted by Siberian bioclimatic model. Section 5.6.2. In: Groisman PY, Gutman G (eds) Regional environmental changes in Siberia and their global consequences. Springer, Heidelberg-New York- Dordrecht -London

Tchebakova NM, Parfenova El, Blyakharchuk TA (2012) Predicted and observed climate-induced fire in the Altai-Sayan Mts, Central Asia, during the Holocene. In: Spano D, Bacciu V, Salis M, Sirca C (eds) Modelling fire behavior and risk. A forecast and prevention system for climate change impacts on risk variability for wildlands and urban areas. Nuova StampaColor Industria Grafica Zona Industriale Muros 07030, Muros Sassari

Tchebakova NM, Parfenova El, Korets MA, Conard SG (2016) Potential change in forest types and stand heights in central Siberia in a warming climate. Environ Res Lett 11(3):035016. doi: 10.1088/1748-9326/11/3/035016

Tchebakova NM, Parfenova El, Lysanova Gl, Soja AJ (2011) Agroclimatic potential across central Siberia in an altered twenty-first century. Environ Res Lett 6(4): 045207. doi: 10.1088/1748-9326/6/4/045207

Tchebakova NM, Parfenova El, Soja AJ (2009) The effects of climate, permafrost and fire on vegetation change in Siberia in a changing climate. Environ Res Lett 4(4):045013. doi: 10.1088/1748-9326/4/4/045013

Tchebakova NM, Parfenova El, Soja AJ (2016) Significant Siberian vegetation change is inevitably brought on by the changing climate. In: Mueller L, Sheudshen AK, Eulenstein $F$ (eds) Novel methods for monitoring and managing land and water resources in Siberia. Springer, Dordrecht ISBN: 978-3-319-24407-5

Tchebakova NM, Rehfeldt GE, Parfenova El (2010) From vegetation zones to climatypes: effects of climate warming on Siberian ecosystems. In: Osawa A, Zyryanova OA, Matsuura Y, Kajimoto T, Wein RW (eds) Permafrost ecosystems: Siberian Larch Forest. Ecological studies 209. Springer, Heidelberg-New York-Dordrecht-London. doi: 10.1007/978-1-4020-9692-8

Thompson DWJ, Wallace JM (1998) The Arctic oscillation signature in the wintertime geopotential height and temperature fields. Geophys Res Lett 25(9):1297-1300

Tilinina N, Gulev SK, Rudeva I, Koltermann P (2013) Comparing cyclone life cycle characteristics and their interannual variability in different reanalyses. J Clim 26:6419-6438

Tinner W, Lotter AF (2001) Central European vegetation response to abrupt climate change at $8.2 \mathrm{ka}$. Geology 29(6):551-554. doi: 10.1130/ 00917613(2001)029<0551:CEVRTA>2.0.CO;2

Troy TJ, Sheffield J, Wood EF (2012) The role of winter precipitation and temperature on northern Eurasian streamflow trends. J Geophys Res Atmos 117(D5):D05131. doi: 10.1029/2011 JD016208

Trueblood MA, Arnade C (2001) Crop yield convergence: how Russia's yield performance has compared to global yield leaders. Comparat Econom Studies 43(2):59-81. doi: 10.1057/ces.2001.8

Udra IF (1988) Setting and migration of woody plants in temperate belt of Eurasia. Naukova Dumka, Kiev (in Russian)

Ukrstat (2014) Agriculture of Ukraine in 1990-2014. (Silske Gospodarstvo Ukrainy u 1990-2016 roci). A set of statistical yearbooks. State Committee of Statistics of Ukraine, Kyiv

Unger-Shayesteh K, Vorogushyn S, Farinotti D, Merz B (2013) What do we know about past changes in the water cycle of central Asian headwaters? A review. Glob Planet Chang 110:4-25

Valendik EN, Kisilyakhov EK, Kosov IV, Lobanov Al, Ponomarev El (2015) Catastrophic steppe fires: problems and ways of their solutions. Monitoring, modelling and forecast of dangerous natural phenomena and urgent situations 2015:34-36 (In Russian)

Valendik EN, Kisilyakhov EK, Ryzhkova VA, Ponomarev El, Goldammer JG (2014) Forest fires under anomaly weather conditions in Central Siberia. Siberian Forest J 3:43-52 http://сибирскийлеснойжурнал.pф/upload/iblock/50c/ 50cdf195672d6700b7cbba67f3054032.pdf (In Russian) van den Werf GR, Randerson JT, Giglio L, Collatz GJ, Mu M, Kasibhatla PS, Morton DC, DeFries RS, Jin Y, van Leeuwen TT (2010) Global fire emissions and the contribution of deforestation, savanna, forest, agricultural, and peat fires (1997-2009). Atmos Chem Phys 10(23):11707-11735. doi: 10.5194/acp-1011707-2010

van Vuuren DP, den Elzen MGJ, Lucas PL, Eickhout B, Strengers BJ, van Ruijven B, Wonink S, van Houdt R (2007) Stabilizing greenhouse gas concentrations at low levels: an assessment of reduction strategies and costs. Clim Chang 81(2):119-159. doi: 10.1007/s10584-006-9172-9

van Vuuren DP, Edmonds J, Kainuma M, Riahi K, Thomson A, Hibbard K, Hurtt GC, Kram T, Krey V, Lamarque J-F, Masui T, Meinshausen M, Nakicenovic N (2011) The representative concentration pathways: an overview. Clim Chang 109(12):5-31. doi: 10.1007/s10584-011-0148-z

van Vuuren DP, Eickhout B, Lucas PL, den Elzen MGJ (2006) Long-term multi-gas scenarios to stabilize radiative forcing - exploring costs and benefits within an integrated assessment framework. Energy J.I(27):201-233 http://www.jstor. org/stable/23297082

Vandergert P, Newell J (2003) Illegal logging in the Russian far east and Siberia. Int Forestry Rev 5(3):303-306

Vasileva A, Moiseenko K (2013) Methane emissions from 2000 to 2011 wildfires in northeast Eurasia estimated with MODIS burned area data. Atm Env 71:115121. doi: 10.1016/j.atmosenv.2013.02.001

Velichko AA (ed) (2002) Dynamic of terrestrial landscape components and inner marine basins of northern Eurasia during the last 130000 years (atlasmonograph). GEOS, Moscow

Velichko AA, Borisova OK, Zelikson EM, Morozova TD (2004) Changes in vegetation and soils of the east European plain to be expected in the 21st century due to anthropogenic changes in climate. Geogr Pol 77(2):37-45 http://rcin.org.pl/igipz/Content/80/77_2_calosc.pdf

Velicogna I, Wahr J (2013) Time-variable gravity observations of ice sheet mass balance: precision and limitations of the GRACE satellite data. Geophys Res Lett 40(12):3055-3063. doi: 10.1002/grl.50527

Vestreng V, Myhre G, Fagerli H, Reis S, Tarrasó L (2007) Twenty-five years of continuous sulphur dioxide emission reduction in Europe. Atmos Chem Phys 7(13):3663-3681. doi: 10.5194/acp-7-3663-2007

Vinnikov KY, Groisman PY, Lugina KM (1990) Empirical data on contemporary global climate changes (temperature and precipitation). J Clim 3(6):662-677

Voinova VD, Zakharova OD, Rybakovsky LL (1993) Contemporary Russian north and its population. In: Rybakovsky LL (ed) Social and demographic development of Russian north. Institute of Social and Economic Problems of population. RAS, Moscow (in Russian)

Volodin EM (2013) The mechanism of multidecadal variability in the Arctic and North Atlantic in climate model INMCM4. Environ Res Lett 8(3):035038. doi: 10.1088/1748-9326/8/3/035038

Volodin EM, Diansky NA, Gusev AV (2013) Simulation and prediction of climate changes in the 19th to 21 st centuries with the Institute of Numerical Mathematics, Russian Academy of Sciences, model of the Earth's climate system. Izvestia Atmospheric Oceanic Physics 49(4):347-366. doi: 10.1134/ s0001433813040105

Voronin Vl, Shubkin RG (2007) Analysis of the long-term chronologies of forest fires and forecast of fire activity in the Baikal region. Fire Safety 3:64-70 (in Russian)

Walker DA, Pierce JL (eds) (2015) Rapid Arctic transitions due to infrastructure and climate (RATIC): a contribution to ICARPIII. Alaska Geobotany Center Publ AGC 15-02. Univ Alaska-Fairbanks, Fairbanks

Warneke C, Bahreini R, Brioude J, Brock CA, de Gouw JA, Fahey DW, Froyd KD, Holloway JS, Middlebrook A, Miller L, Montzka S, Murphy DM, Peischl J, Ryerson TB, Schwarz JP, Spackman JR, Veres P (2009) Biomass burning in Siberia and Kazakhstan as an important source for haze over the Alaskan Arctic in April 2008. Geophys Res Lett 36(2):L02813. doi: 10.1029/ 2008GL036194

Weyant J, Davidson O, Dowlabathi H, Edmonds J, Grubb M, Parson EA, Richels R, Rotmans J, Shukla PR, Tol RSH, Cline W (1996) Integrated assessment of climate change: an overview and comparison of approaches and results. Cambridge University Press, Cambridge, UK; New York

White D, Hinzman L, Alessa L, Cassano J, Chambers M, Falkner K, Francis J, Gutowski WJ Jr, Holland M, Holmes RM, Huntington H, Kane D, Kliskey A, Lee C, Mc Clelland J, Peterson B, Rupp TS, Straneo F, Steele M, Woodgate R, Yang D, Yoshikawa K, Zhang T (2007) The arctic freshwater system: changes and impacts. J Geophys Res Biogeosci 112(G4):G04S54. doi: 10.1029/ 2006JG000353 
Williams J (2013) Exploring the onset of high-impact mega-fires through a forest land management prism. For Ecol Manag 294:4-10

Wise M, Calvin K, Thomson A, Clarke L, Bond-Lamberty B, Sands R, Smith SJ, Janetos A, Edmonds J (2009) Implications of limiting $\mathrm{CO}_{2}$ concentrations for land use and energy. Science 324(5931):1183-1186. doi: 10.1126/science. 1168475

Woo M-K (2012) Permafrost hydrology. Springer-Verlag, Berlin

World Glacier Monitoring Service (WGMS) (2015) In: Zemp M, Gärtner-Roer I, Nussbaumer SU, Hüsler F, Machguth H, Mölg N, Paul F, Hoelzle M (eds) Global glacier change bull. 1 (2012-2013). ICSU(WDS)/IUGG(IACS)/UNEP/ UNESCO/WMO, Zurich. doi: 10.5904/wgms-fog-2015-11

Wright CK, de Beurs KM, Henebry GM (2012) Combined analysis of land cover change and NDVI trends in the northern Eurasian grain belt. Front Earth Sci 6(2):177-187. doi: 10.1007/s11707-012-0327-x

Wright CK, de Beurs KM, Henebry GM (2014) Land surface anomalies preceding the 2010 Russian heat wave and a link to the North Atlantic oscillation. Environ Res Lett 9(12):124015. doi: 10.1088/1748-9326/9/12/124015

Wu T, Zhao L, Li R, Wang Q, Xie C, Pang Q (2013) Recent ground surface warming and its effects on permafrost on the central Qinghai-Tibet plateau. Int J Climatol 33(4):920-930. doi: 10.1002/joc.3479

Xi X, Sokolik IN (2015a) Dust interannual variability and trend in Central Asia from 2000 to 2014 and their climatic linkages. J Geophys Res Atmos 120(23): 12175-12197. doi: 10.1002/2015JD024092

Xi X, Sokolik IN (2015b) Seasonal dynamics of threshold friction velocity and dust emission in Central Asia. J Geophys Res Atmos 120(4):1536-1564. doi: 10. 1002/2014JD022471

Xuan J, Liu GL, Du K (2000) Dust emission inventory in Northern China. Atmos Environ 34(26):4565-4570

Yang D, Ye B, Shiklomanov A (2004) Discharge characteristics and changes over the Ob River watershed in Siberia. J Hydrometeorol 5(4):595-610. doi: 10. 1175/1525-7541(2004)005<0595:DCACOT>2.0.CO;2

Yue C, Ciais P, Zhu D, Wang T, Peng SS, Piao SL (2016) How have past fire disturbances contributed to the current carbon balance of boreal ecosystems? Biogeosciences 13:675-690. doi: 10.5194/bg-13-675-2016

Zaehle S, Jones CD, Houlton B, Lamarque J-F, Robertson E (2015) Nitrogen availability reduces CMIP5 projections of twenty-first-century land carbon uptake. J Clim 28:2494-2511. doi: 10.1175/JCLI-D-13-00776.1

Zhai PM, Chao Q, Zou X (2004) Progress in China's climate change study in the 20th century. J Geograph Sci (English version of Acta Geographica Sinica) 14(suppl 2004):3-11 Available at: http://www.geog.cn

Zhang N, Yasunari T, Ohta T (2011) Dynamics of the larch taiga-permafrost coupled system in Siberia under climate change. Environ Res Lett 6(2): 024003. doi: 10.1088/1748-9326/6/2/024003

Zhang X, Ermolieva T, Balkovic J, Mosnier A, Kraxner F, Liu J (2015) Recursive cross-entropy downscaling model for spatially explicit future land uses: a case study of the Heihe River basin. Phys Chem Earth Parts A/B/C 89:56-64. doi: 10.1016/j.pce.2015.05.007

Zhang X, He J, Zhang J, Polyakov I, Gerdes R, Inoue J, Wu P (2012a) Enhanced poleward moisture transport and amplified northern high-latitude wetting trend. Nat Clim Chang 3:47-51. doi: 10.1038/NCLIMATE1631

Zhang Y, Sachs T, Li C, Boike J (2012b) Upscaling methane fluxes from closed chambers to eddy covariance based on a permafrost biogeochemistry integrated model. Glob Change Biol 18(4):1428-1440. doi: 10.1111/j.13652486.2011.02587.x

Zhao TT, Bergen KM, Brown DG, Shugart HH (2009) Scale dependence in quantification of land-cover and biomass change over Siberian boreal forest landscapes. Landsc Ecol 24:1299-1313

Zhu Q, Zhuang Q (2013) Modeling the effects of organic nitrogen uptake by plants on the carbon cycling of boreal ecosystems. Biogeosciences 10:79437955. doi: 10.5194/bg-10-7943-2013

Zhu Q, Zhuang Q, Gao X, Sokolov A, Schlosser CA (2013) Pan-Arctic landatmospheric fluxes of methane and carbon dioxide in response to climate change over the 21st century. Environ Res Lett 8(4):045003. doi: 10.1088/ 1748-9326/8/4/045003

Zhu Q, Zhuang Q, Lu X, Song L (2014) Spatial scale-dependent land-atmospheric methane exchanges in the northern high latitudes from 1993 to 2004. Biogeosciences 11:1693-1704. doi: 10.5194/bg-11-1693-2014

Zhuang Q, Chen M, Xu K, Tang J, Saikawa E, Lu Y, Melillo JM, Prinn RG, McGuire AD (2013) Response of global soil consumption of atmospheric methane to changes in atmospheric climate and nitrogen deposition. Glob Biogeochem Cycles 27(3):650-663. doi: 10.1002/gbc.20057
Zickfeld KM, Eby M, Weaver AJ, Alexander K, Crespin E, Edwards NR, Eliseev AV, Feulner G, Fichefet T, Forest CE, Friedlingstein P, Goosse H, Holden PB, Joos F, Kawamiya M, Kicklighter D, Kienert H, Matsumoto K, Mokhov II, Monier E, Olsen SM, Pedersen JOP, Perrette M, Philippon-Berthier G, Ridgwell A, Schlosser A, Schneider Von Deimling T, Shaffer G, Sokolov A, Spahni R, Steinacher M, Tachiiri K, Tokos KS, Yoshimori M, Zeng N, Zhao F (2013) Longterm climate change commitment and reversibility: an EMIC intercomparison. J Clim 26:5782-5809. doi: 10.1175/JCLI-D-12-00584.1

Ziółkowska E, Ostopowicz K, Radeloff VC, Kuemmerle T (2014) Effects of different matrix representations and connectivity measures on habitat network assessments. Landsc Ecol 29(9):1551-1570. doi: 10.1007/s10980-014-0075-2

Zuev W, Semenov VA, Shelekhova EA, Gulev SK, Koltermann P (2012) Evaluation of the impact of oceanic heat transport in the North Atlantic and Barents Sea on the northern hemispheric climate. Dokl Earth Sci 445(2):1006-1010. doi: 10.1134/S1028334X12080181

\section{Submit your manuscript to a SpringerOpen ${ }^{\mathcal{O}}$ journal and benefit from:}

- Convenient online submission

- Rigorous peer review

- Open access: articles freely available online

- High visibility within the field

- Retaining the copyright to your article

Submit your next manuscript at $>$ springeropen.com 